UCRL-ID- 123238

NORBO

\title{
Containment Data Report
}

T. Stubbs

RECEIVED

MAR 28 铂6

R. Heinle

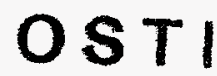

November 1995

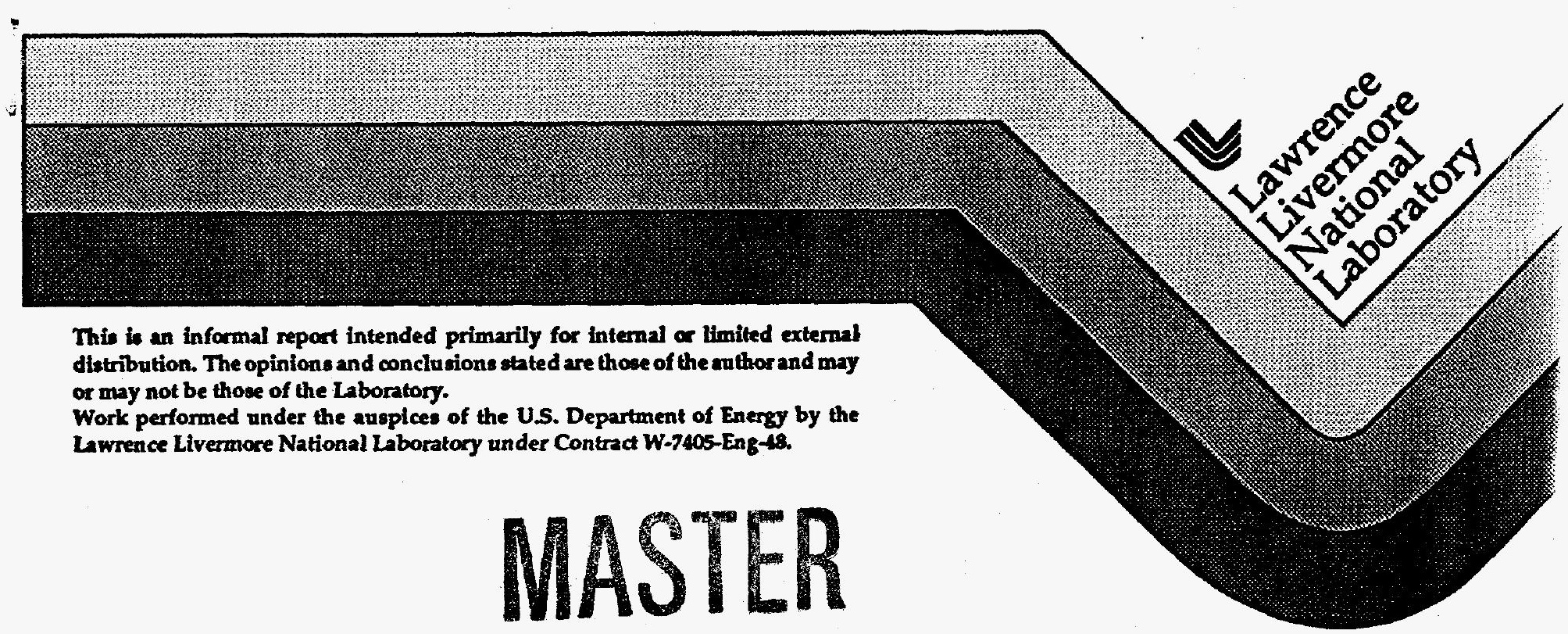




\section{DISCLAIMER}

This document was prepared as an account of work sponsored by an agency of the United States Government. Neither the United States Government nor the University of California nor any of their employees, makes any warranty, express or implied, or assumes any legal liability or responsibility for the accuracy, completeness, or usefulness of any information, apparatus, product, or process disclosed, or represents that its use would not infringe privately owned rights. Reference herein to any specific commercial products, process, or service by trade name, trademark, manufacturer, or otherwise, does not necessarily constitute or imply its endorsement, recommendation, or favoring by the United States Government or the University of California. The views and opinions of authors expressed herein do not necessarily state or reflect those of the United States Government or the University of California, and shall not be used for advertising or product endorsement purposes.

This report has been reproduced directly from the best available copy.

Available to DOE and DOE contractors from the Office of Scientific and Technical Information

P.O. Box 62, Oak Ridge, TN 37831

Prices available from (615) 576-8401, FTS 626-8401

Available to the public from the National Technical Information Service

U.S. Department of Commerce 5285 Port Royal Road Springfield, VA 22161 


\section{DISClaIMER}

Portions of this document may be illegible in electronic image products. Images are produced from the best available original document. 
NOBBO Instrumentation Summaxy

\begin{tabular}{|c|c|c|c|}
\hline Instrumentation & $\begin{array}{l}\text { Fielded on } \\
\text { this Event }\end{array}$ & $\begin{array}{c}\text { Data } \\
\text { Return }\end{array}$ & $\begin{array}{l}\text { Present in } \\
\text { this Report }\end{array}$ \\
\hline Pluo Emplacement & yes & yes & no \\
\hline Badiation & yes & yes & yes \\
\hline Pressure & & & \\
\hline Stemming & yes & yes & yes \\
\hline Challenge & no & - & - \\
\hline Cavity & no & - & $\cdot$ \\
\hline Atmospheric & no & - & - \\
\hline Motion & & & \\
\hline Free Field & yes & yes & yes \\
\hline Surface & yes & yes & yes \\
\hline Plug & yes & yes & yes \\
\hline Stemming & no & - & - \\
\hline Surface Casing & no & - & - \\
\hline Emplacement Pipe & no & - & - \\
\hline Hydroyield (a) & yes & yes & no \\
\hline Collapse (b) & yes & yes & yes \\
\hline Stress & yes & yes & yes \\
\hline Strain $(c)$ & yes & no & - \\
\hline Other Measurements $(d)$ & yes & yes & yes \\
\hline
\end{tabular}

(a) CORTEX or SLIFER in emplacement hole.

(b) EXCOR or CLIPER in emplacement hole.

(c) Emplacement pipe load.

(d) Stress gauge development.

\section{Event Personnel}

\section{Contaiment Phusics}
B. Hudson
E. Woodward
J. Kalinowski
T. Stubbs
LLNL
LLNL
EG\&G/AVO
EG\&G/AVO

instrumentation

$\begin{array}{ll}\text { L. Starm } & \text { LLNL } \\ \text { F. Sierra } & \text { EG\&G/AVO } \\ \text { W. G. Webb } & \text { EG\&GNNO } \\ \text { A. E. Moeller } & \text { EG\&GNVO }\end{array}$


Contents

1. Event Description

1.1 Site

1.2

1.3 Emplacement.

2. Stemming Performance

2.1 Radiation and Pressure

2.2 Motion .

3. Free-field (Satellite Hole) Measurements

4. Collapse phenomena

5. Stress measurements

References

APPENDIX Computation of strain from motion in a spherical field.
1
1
3

10
17

27

44

61

65

66

ii 


\section{Event Description}

\subsection{Site}

The NORBO event was detonated in hole U8c of the Nevada Test Site as indicated in figure 1.1. The device had a depth-of-burial (DOB) of $271 \mathrm{~m}$ in the bedded tuffs of area 8 , about $130 \mathrm{~m}$ above the Paleozoic formation and $280 \mathrm{~m}$ above the standing water level, as shown in figures 1.2 and 1.3(1). Stemming of the $2.44 \mathrm{~m}$ diameter emplacement hole followed the plan shown in figure 1.4. A log of the stemming operations was maintained by Holmes \& Narver(2).

Detonation time was 07:37 PST on March 7, 1980 and 53.5 minutes later a subsurface collapse or stemming fall to a depth between 75 and 24 m occurred.

A low level radiation arrival was detected in the emplacement hole below the top stemming plug after the subsurface collapse. This was attributed to activity contained within the prompt gas sample hose. No radiation arrival was detected above the top plug and the NORBO containment was considered successful.

\subsection{Instrumentation}

Figure 1.5 is a schematic layout of the instrumentation designed to monitor the emplacement procedures and stemming performance of the NORBO event.

The two stemming plugs were composed of coal-tar epoxy (LAE 59, denoted CTE). A soft layer of coal-tar and aggregate (LAE 59MY, denoted CTA) was poured on the top of the top plug to act as a gas seal.

Pressure and radiation were monitored in the coarse stemming at three locations in the coarse stemming between the device canister and the bottom plug and at three additional locations between the two plugs. 
Vertical motion was monitored in both of the plugs in the emplacement hole, at two locations in the coarse stemming, and in the ground surface, $15.24 \mathrm{~m}$ from SGZ. An array of ten vertical motion stations was fielded in the satellite hole which was $22.52 \mathrm{~m}$ east of the emplacement hole. Vertical motion of the recording trailer was also obtained.

As part of a continuing effort to develop an in-situ dynamic stress transducer, three elevations of the satellite hole were instrumented with carbon foil stress transducers.

Data from each of the above instruments were transmitted to the recording trailer by an analog system and recorded on magnetic tape.

D-cable information was used both for quality assurance during the stemming operations and as an adjunct to the CLIPER collapse measurements.

Two CLIPER/CORRTEX sensors were fielded in the emplacement hole and one in the satellite hole to measure the hydrodynamic yield of the device and to monitor cavity collapse and chimney formation. In the emplacement hole, one CLIPER was fielded on the emplacement pipe and device canister and the second on the instrumentation pendant. Results of the yield measurements are reported elsewhere (3).

A history of the fielding operations of the instrumentation is outlined in reference 4. Details of the instrumentation are given in reference 5 . 


\subsection{Emplacement}

A single strain station (83) was fielded near the top of the emplacement pipe to monitor the load during installation and stemming. This station was monitored randomly during these procedures and was recorded by hand during the device installation only. Emplacement was detailed by Holmes \& Narver(2).

The stemming plugs consisted of two "LAE 59" coal-tar epoxy (CTE) layers. The bottom was about $4.6 \mathrm{~m}$ thick while the top was about $4.9 \mathrm{~m}$ thick. The top plug was capped with about $2.9 \mathrm{~m}$ of soft coal-tar-aggregate "LAE 59MY" epoxy (CTA) to act as a gas sealant. Stemming between the plugs consisted of layers of fines and coarse gravel. The top of the hole (above the top plug) was filled with coarse stemming. See figure 1.4. 


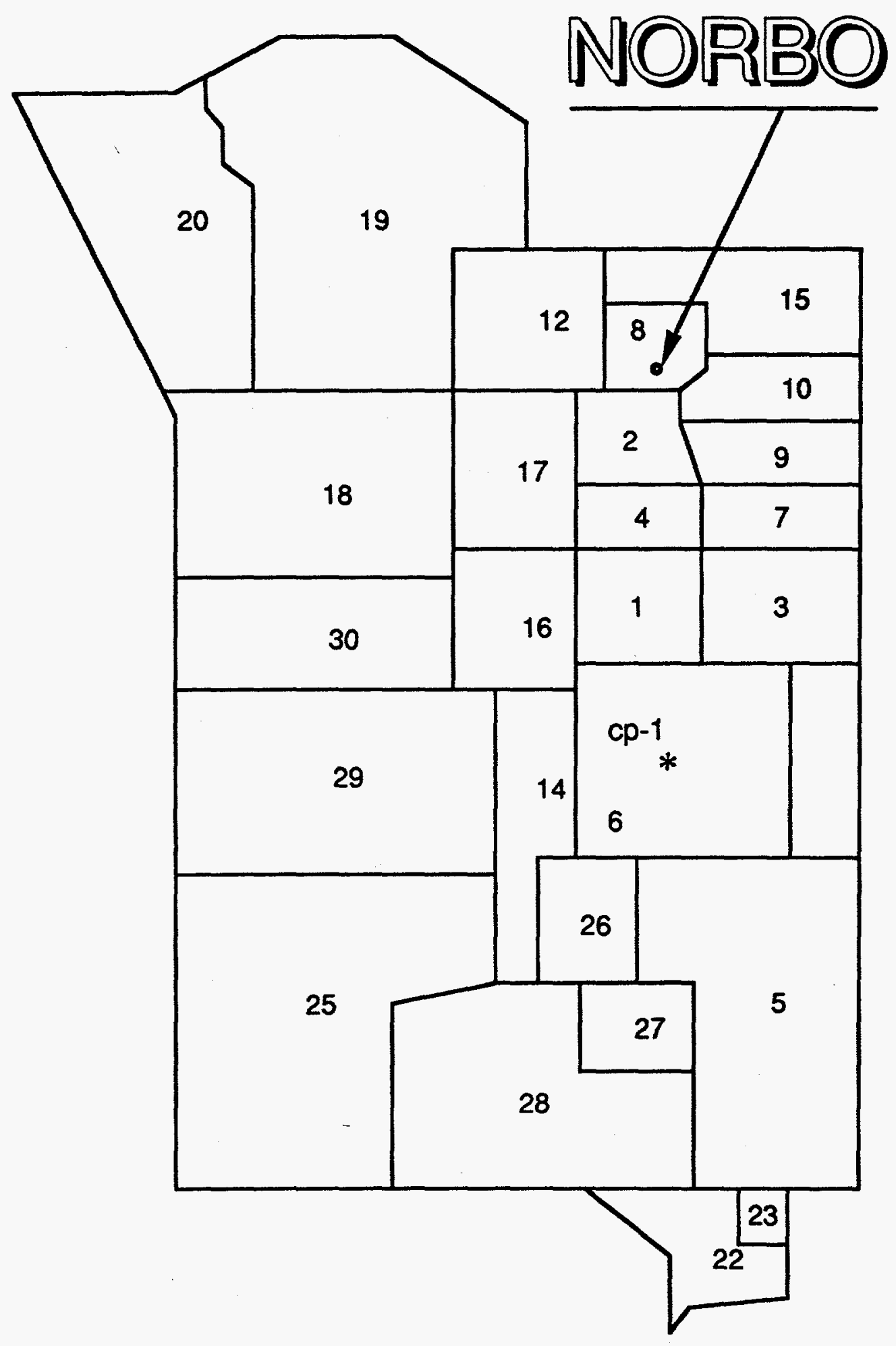

Figure 1.1 Map of the Nevada Test Site indicating the location of hole U8c. 


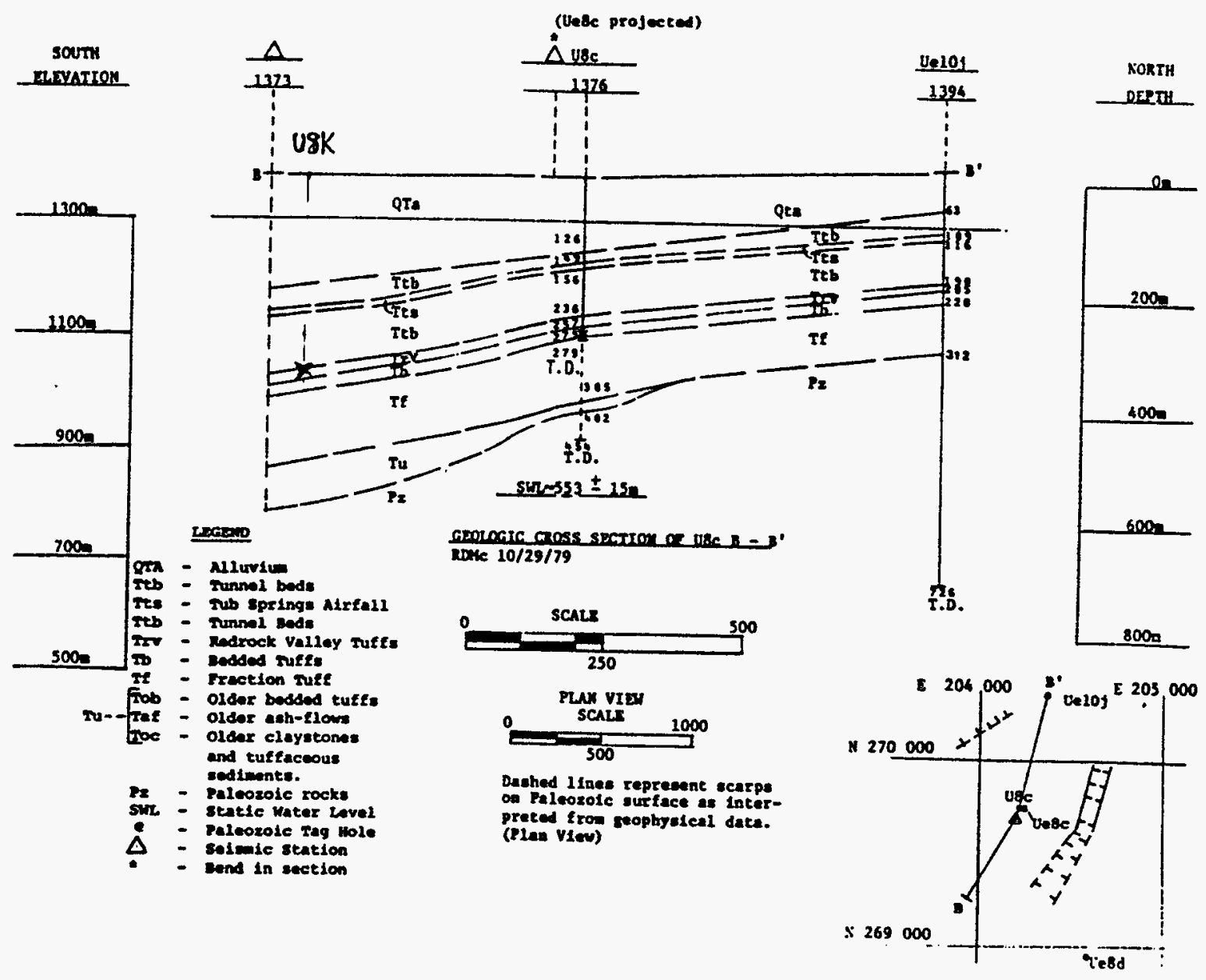

Figure 1.2 North-South geologic cross sections through hole U8c. 


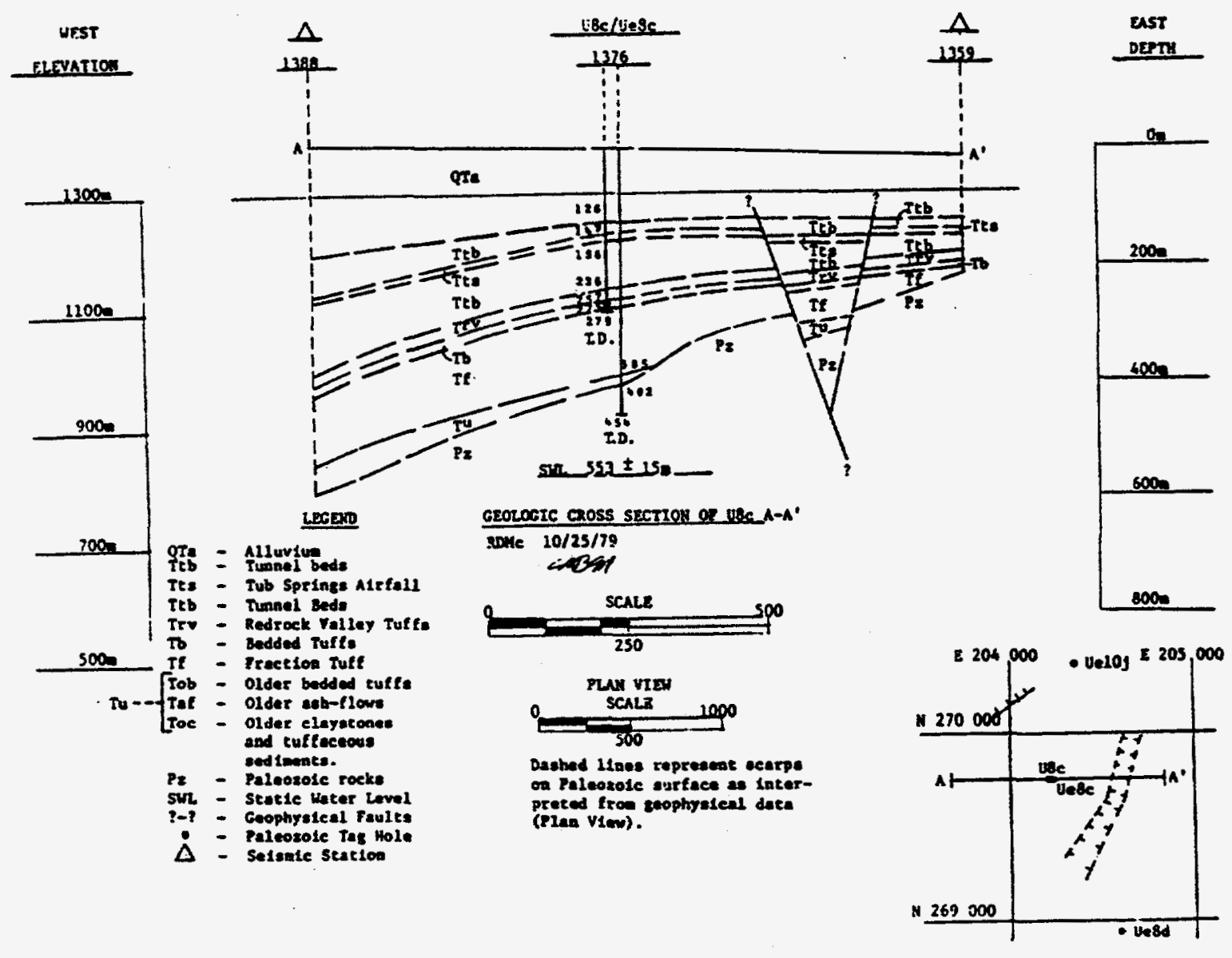

Figure 1.3 East-West geologic cross sections through hole U8c. 


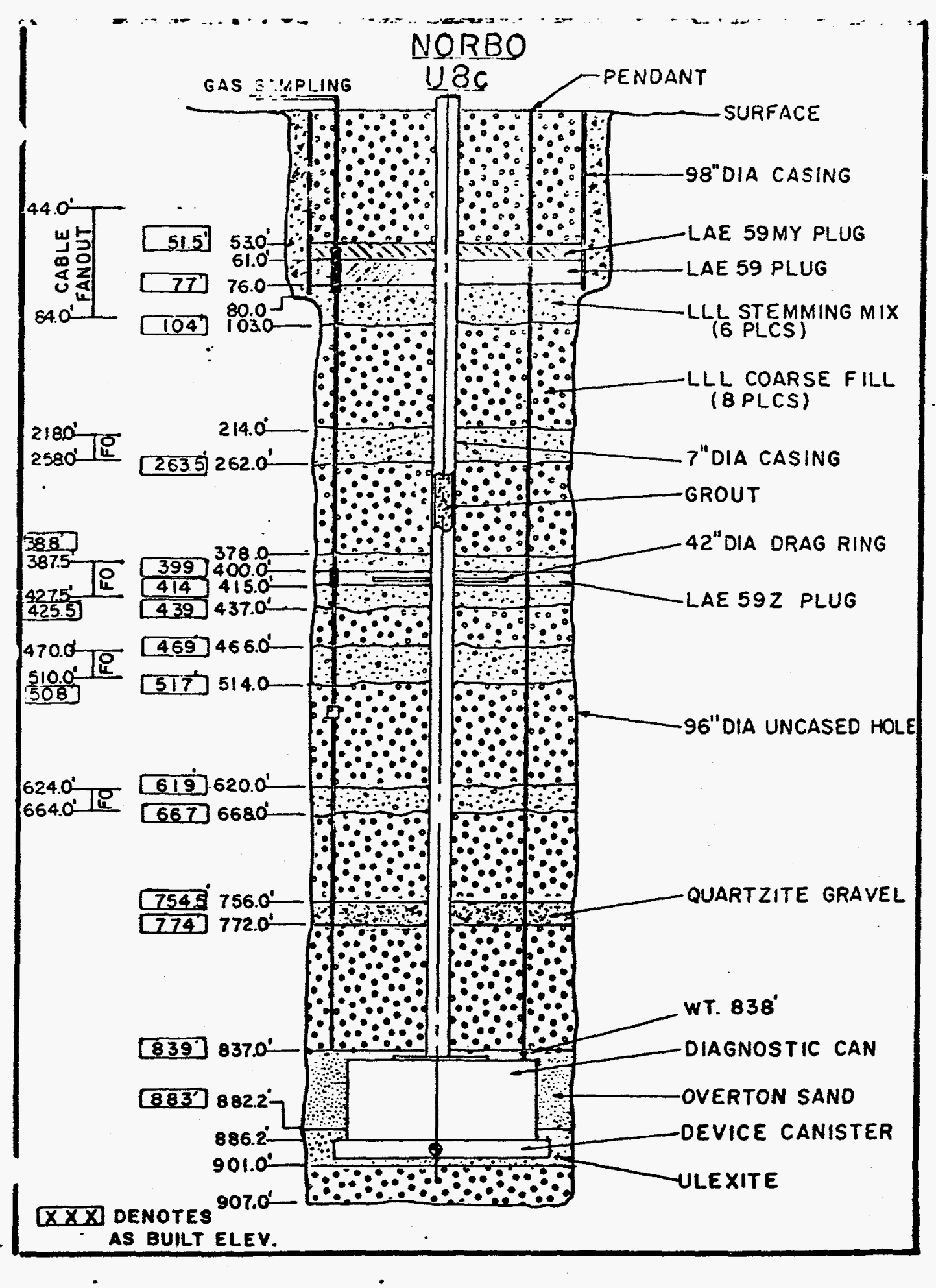

Figure 1.4 As-built stemming plan for the event NORBO in Hole U8c. 


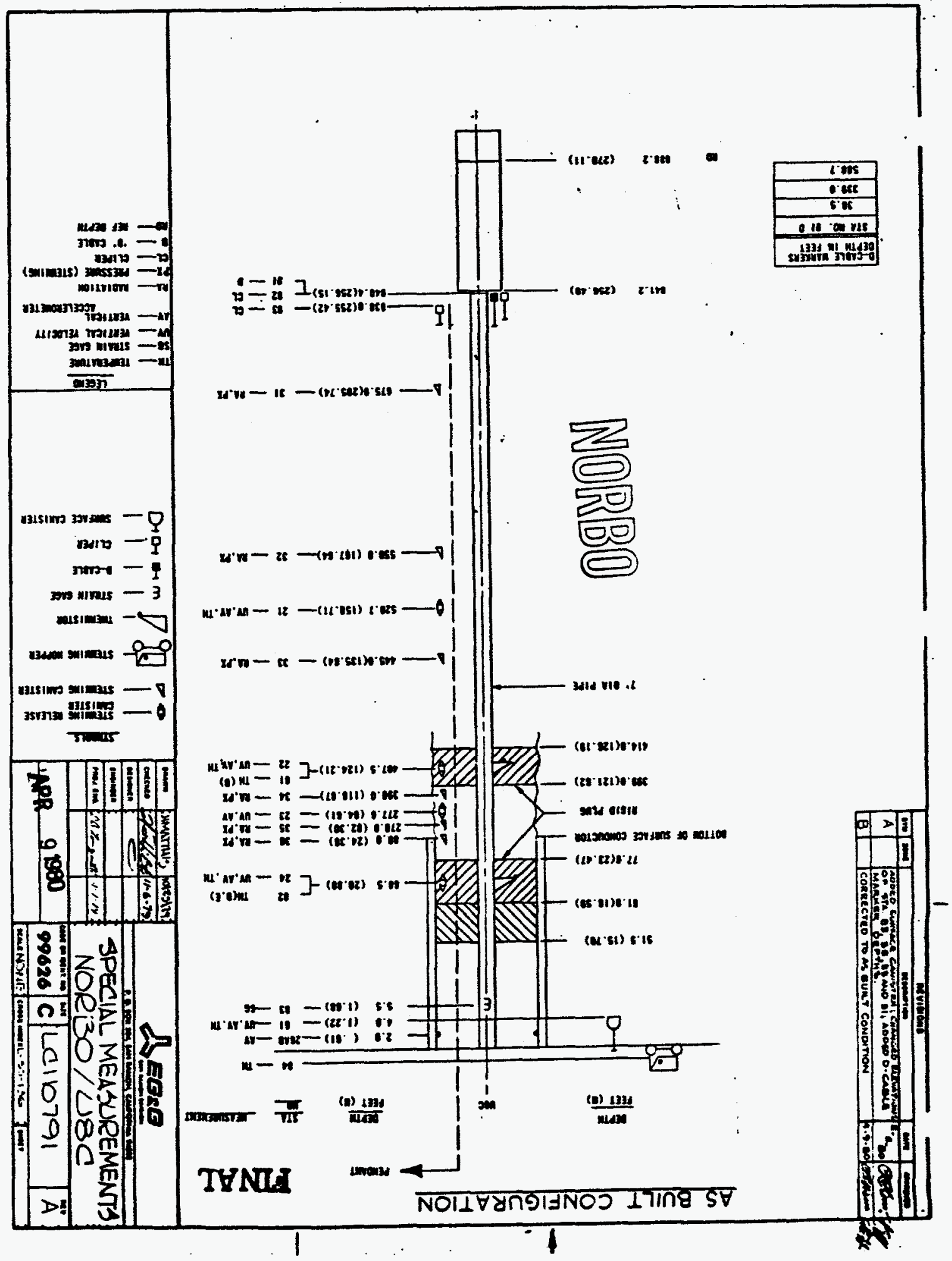




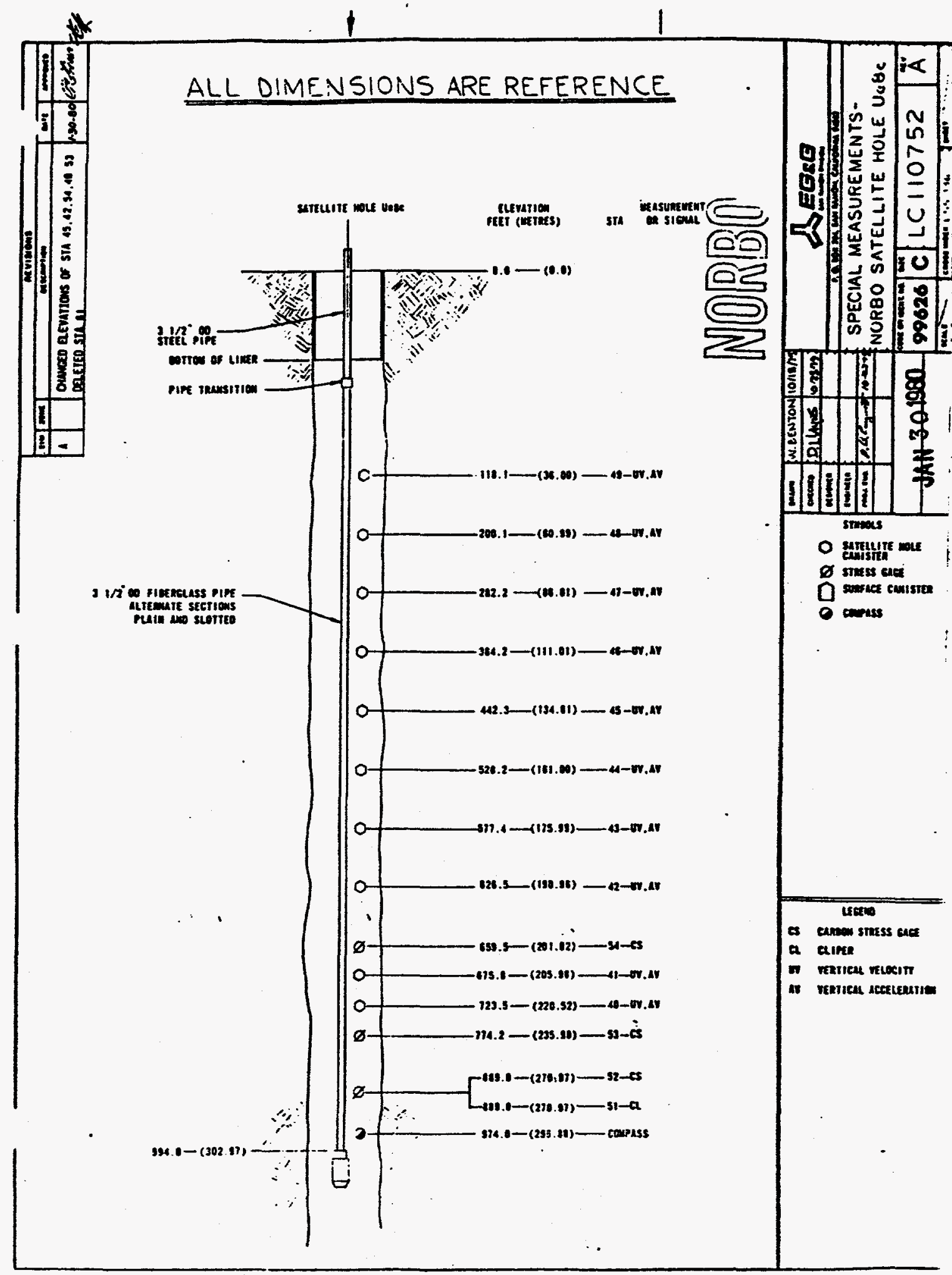

Figure 1.6 As-built containment instrumentation plan for the satellite hole (Ue8c) on the NORBO event. 


\section{Stemming Performance}

\subsection{Radiation and Pressure}

As seen in figure 1.5, pressure and radiation was monitored in the coarse stemming at a total of six stations. Three stations were placed in the loose stemming between the device canister and the bottom plug. An additional three stations were fielded in the loose stemming between the bottom and top plugs.

All stations above the bottom plug transmitted data until recording was terminated at about 6 hours after the detonation, signals from those below the bottom plug were lost prior to $4170 \mathrm{~s}$, presumably due to subsurface collapse. Recorded pressure and radiation histories are shown in figures 2.1-2.6.

The pressure records from stations 34,35 , and 36 (above the bottom plug) suggest a stemming fall, initiated by the subsurface collapse, progressing to near the bottom of the top plug.

There is clear indication from station 31 (figure 2.1) that radiation penetrated the stemming column to a depth of $206 \mathrm{~m}$, however, there is no evidence that it migrated another $70 \mathrm{~m}$ up the hole to station 33 at a depth of $136 \mathrm{~m}$ (figure 2.3). (The station 32 radiation channel is absent because of its loss during stemming.) Station 34 suffered a negative dose rate offset at both zero and subsurface collapse times, but indicated no radiation arrivals. The source chip in station 35 was dangerously high (about $0.5 \mathrm{R} / \mathrm{Hr}$ ) and all but swamped any low-level radiation signals, however, it may be inferred that an increase of about $0.1 \mathrm{R} / \mathrm{Hr}$ occurred at collapse time. Station 36 (figure 2.6) clearly shows radiation arrivals occurring at and after subsurface collapse. It is strongly suspected that the source of radiation seen at station 36 (and probably station 35) after subsurface collapse was "shine" from the prompt gas sample hose and was not migrating gas from the explosion. This seems to be a collapse-related phenomenon and will be discussed in section 4, "Collapse Phenomena".

Standard Heath \& Safety monitors detected no radiation arrivals above the ground surface and we conclude that pressure and radiation data are consistent with satisfactory containment. 

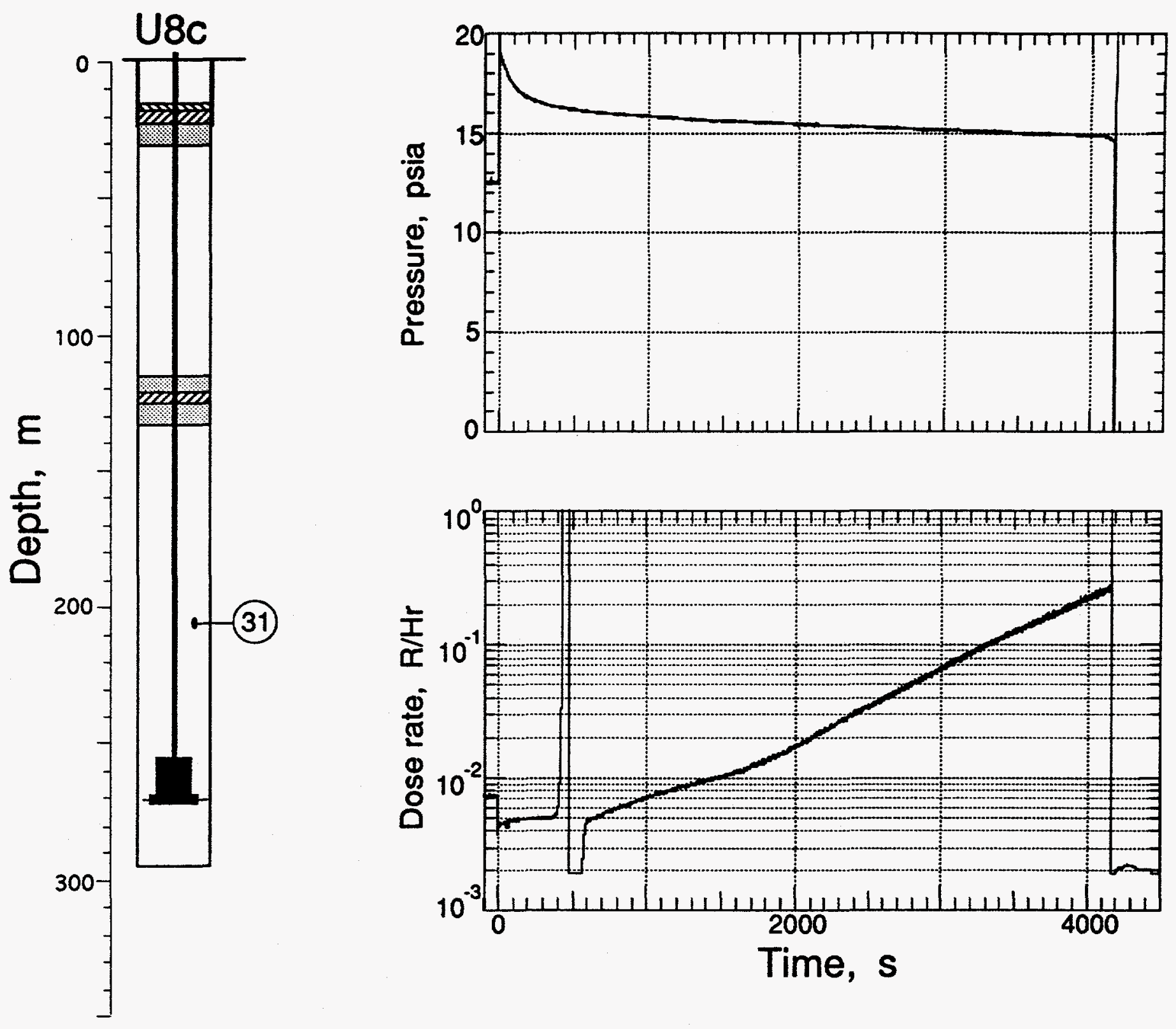

Figure 2.1 Pressure and radiation measured in the coarse stemming at $206 \mathrm{~m}$ depth (Station 31 ). Signals from this station were lost at about $4167 \mathrm{~s}$. 

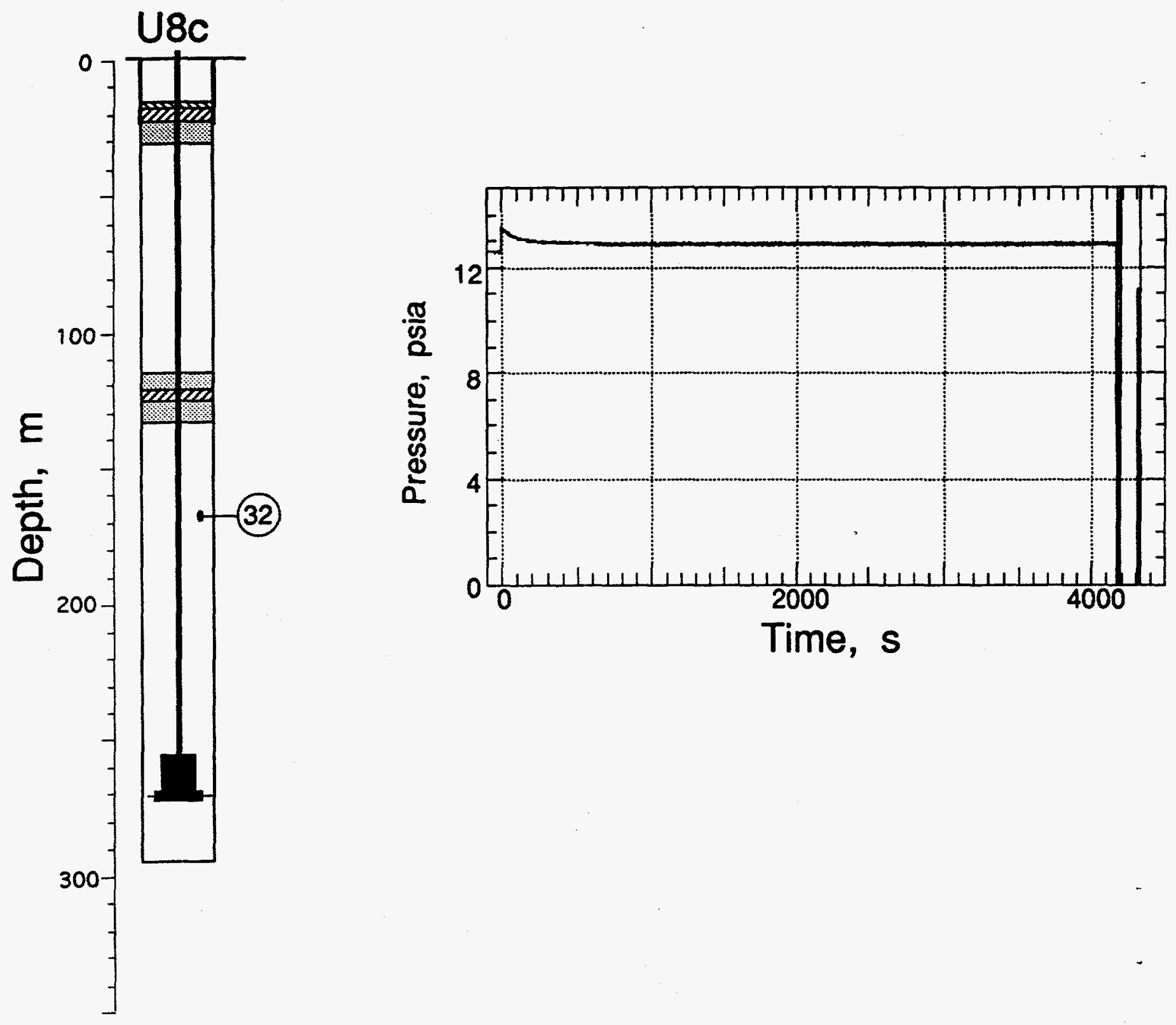

Figure 2.2 Pressure and radiation measured in the coarse stemming at 168m depth (Station 32 ). Signals from this station were lost at about $4167 \mathrm{~s}$. The radiation channel was dead pre-shot and not recorded. 

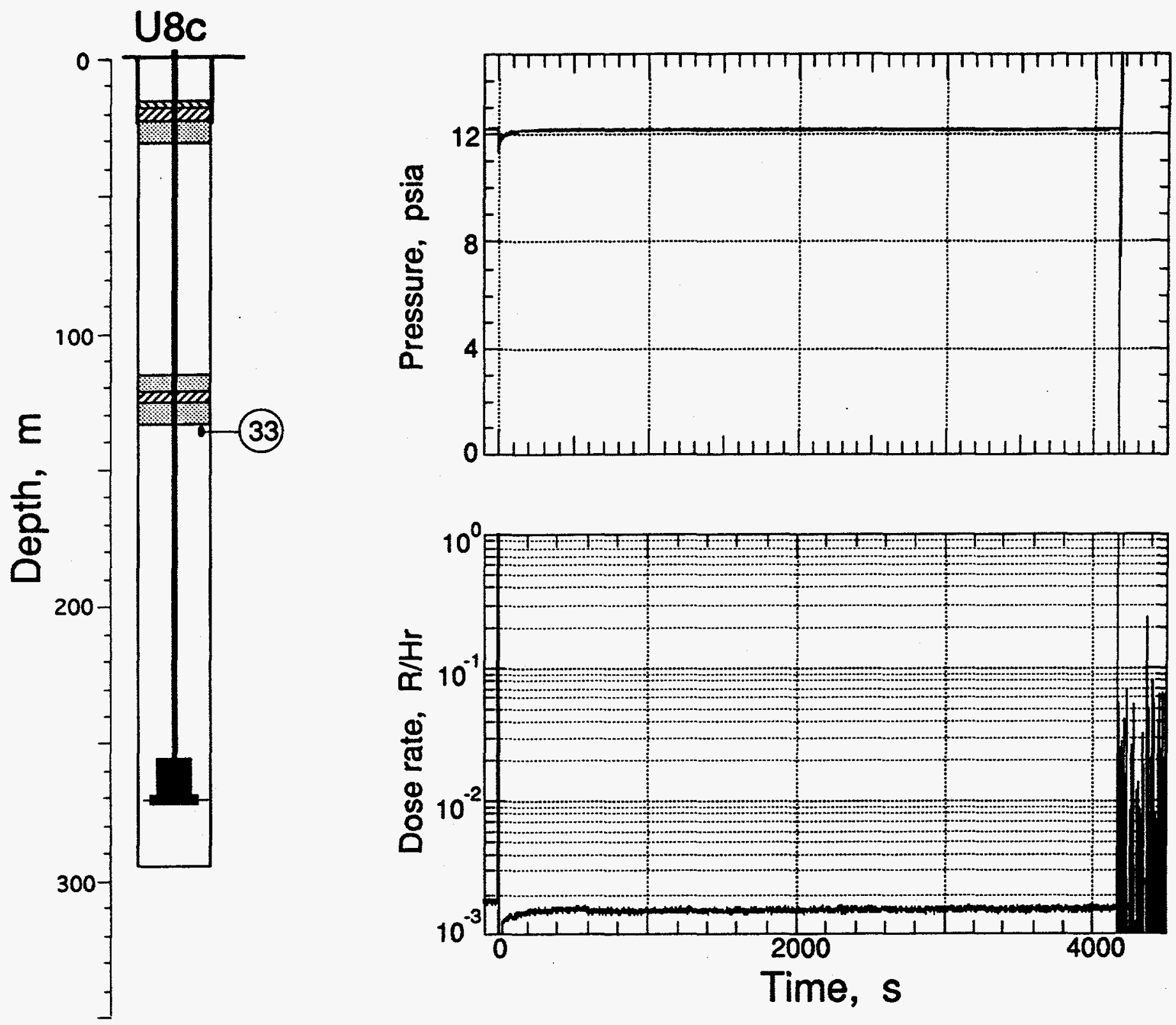

Figure 2.3 Pressure and radiation measured in the coarse stemming below the bottom plug at $136 \mathrm{~m}$ depth (Station 33). Signals from this station were lost at about $4167 \mathrm{~s}$. 

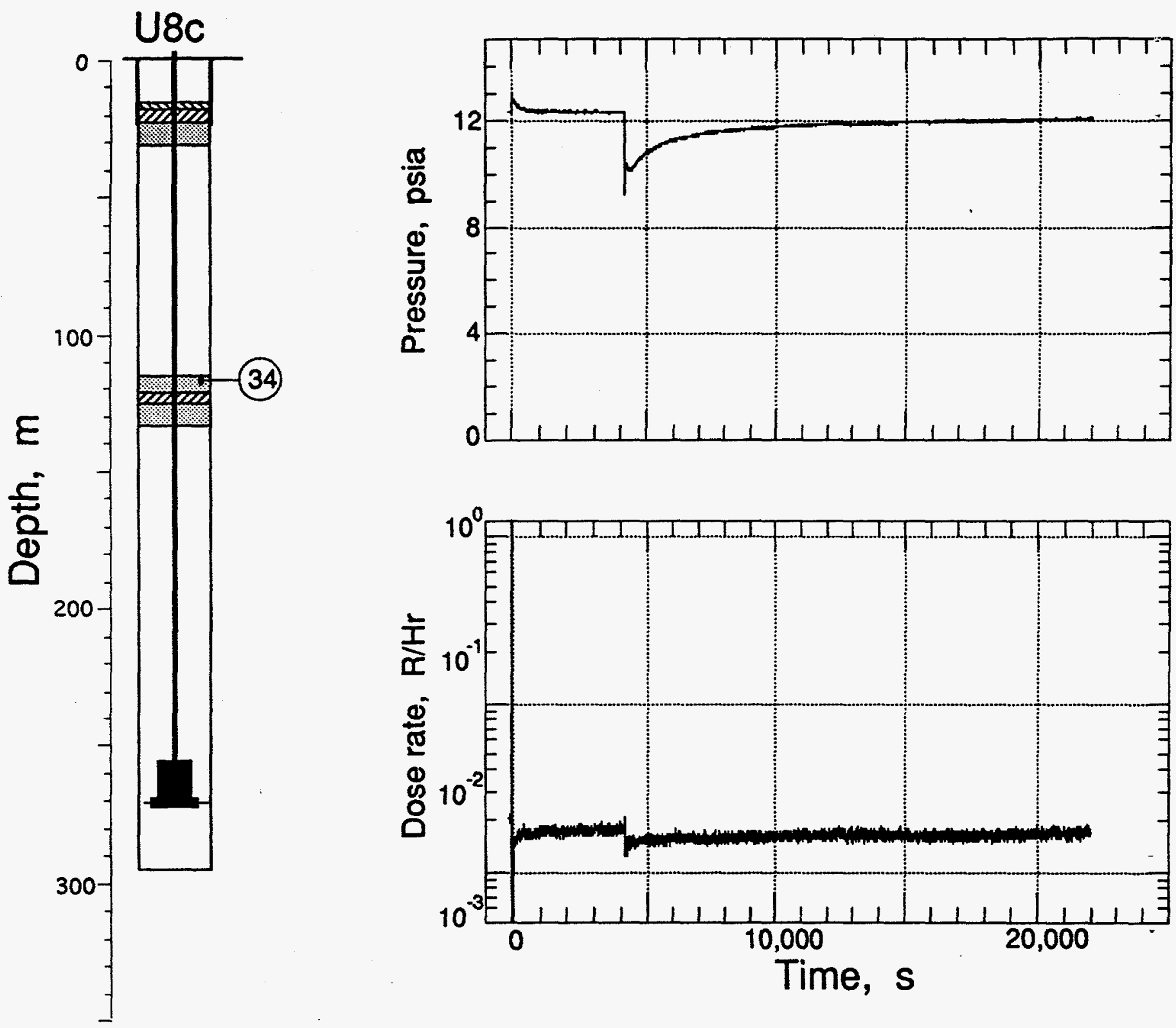

Figure 2.4 Pressure and radiation measured in the coarse stemming above the bottom plug at $119 \mathrm{~m}$ depth (Station 34). 

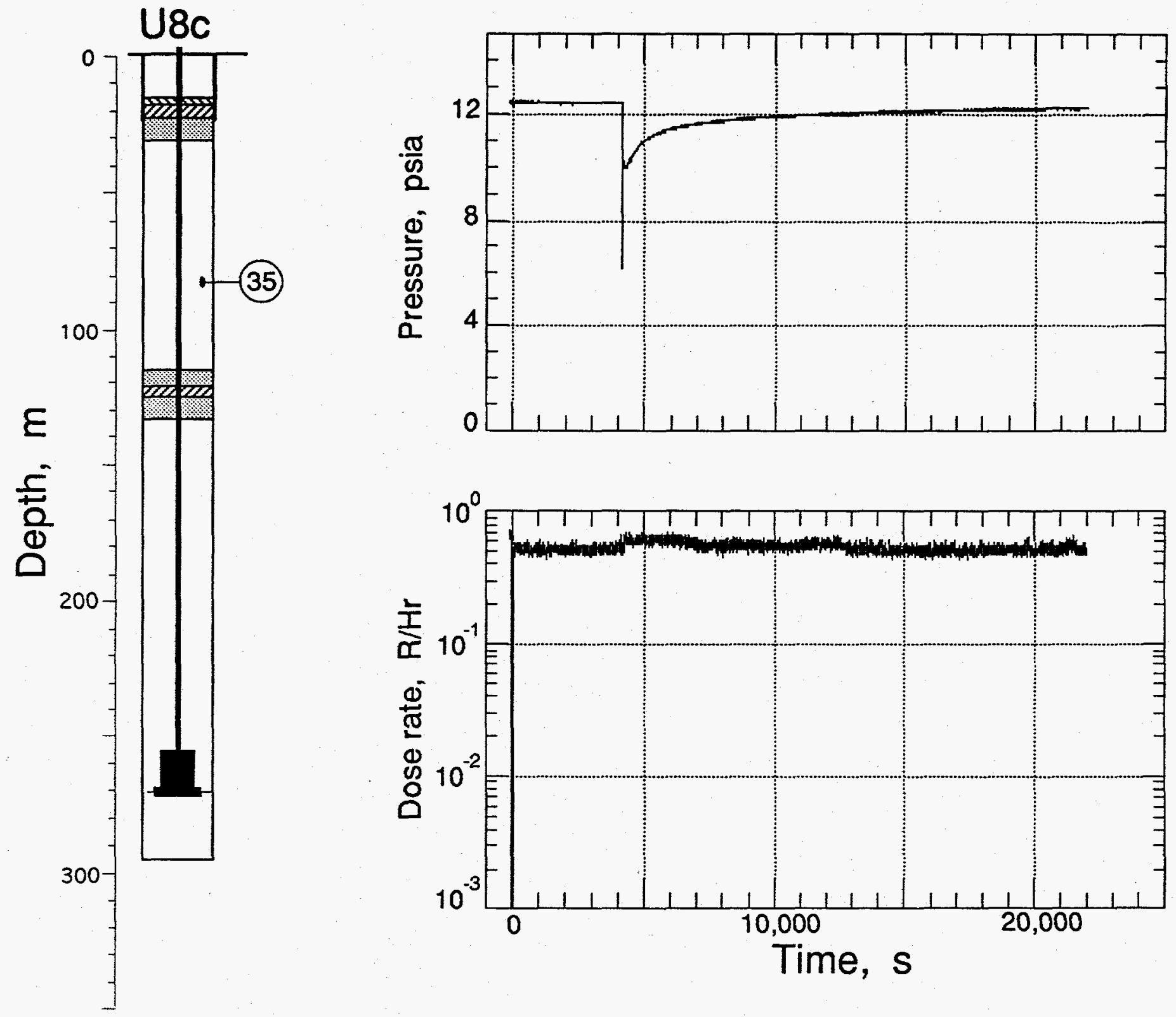

Figure 2.5 Pressure and radiation measured in the coarse stemming at $85 \mathrm{~m}$ depth (Station 35 ). 

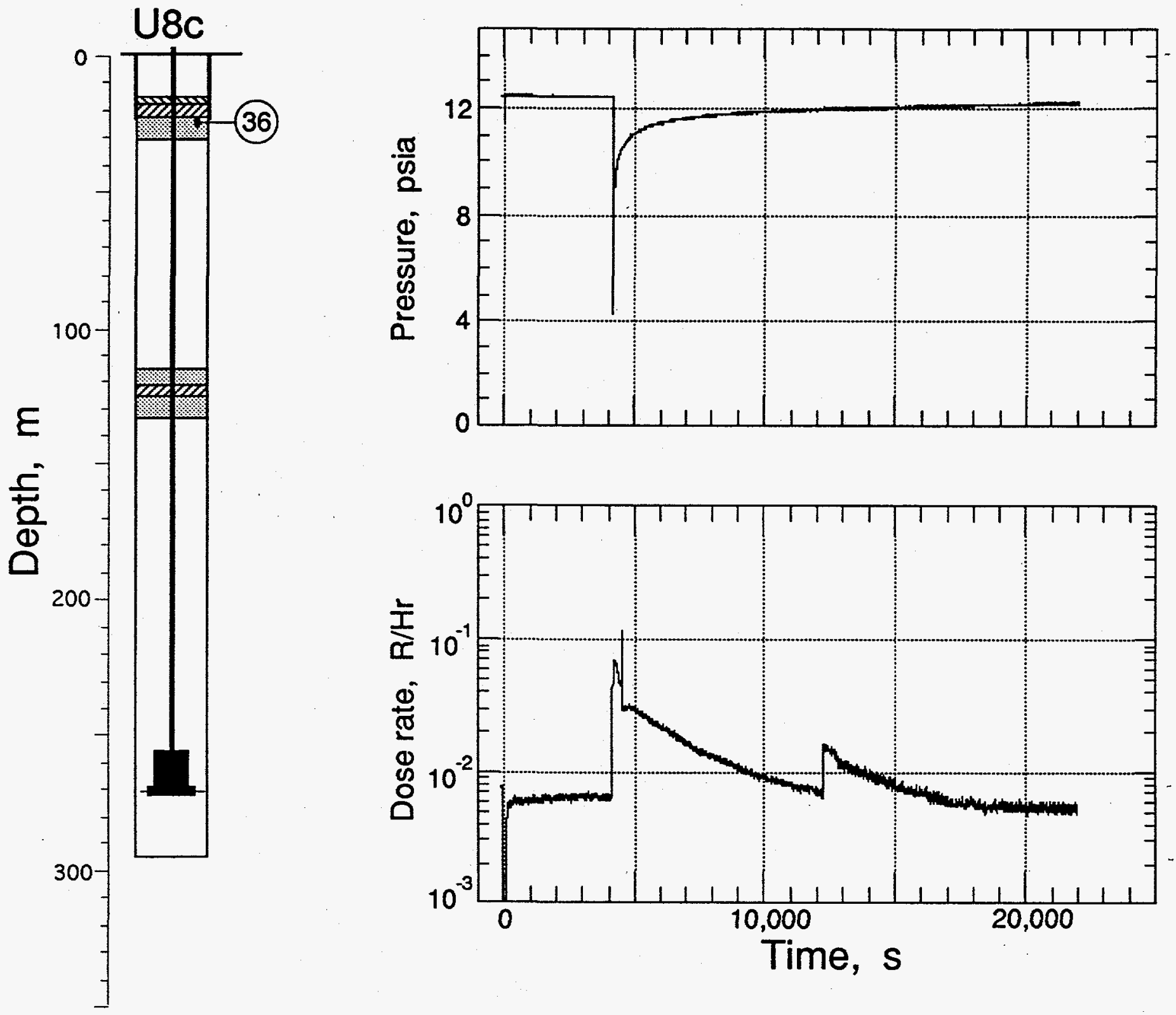

Figure 2.6 Pressure and radiation measured in the coarse stemming below the top plug at $24 \mathrm{~m}$ depth (Station 36). 


\subsection{Motion}

Explosion-induced histories of the containment related motion measured on the NORBO event are shown in figures 2.7-2.13. At station 22 (in the bottom plug, figure 2.8) only the velocimeter survived the initial shock wave, and that for less than $100 \mathrm{~ms}$.

Station 23 accelerometer was driven to high band edge at the time that the associated velocimeter lost coherent signal (about $0.6 \mathrm{~s}$, figure 2.9). Action of the calibration logic, applied at about $+60 \mathrm{~s}$, drove the acceleration signal back in band for the remaining time that it was recorded. However, the data from this channel are suspect after $0.6 \mathrm{~s}$ and should be used only for timing.

All other stations survived until subsurface collapse (at about $4170 \mathrm{~s}$ ) or until recording was terminated. Characteristics of the associated motion and transducers are given in tables 2.1-2.3.

Stations 26A and 26B were mounted on the top of the surface casing for a study by the Mechanical Engineering department. 


\section{Table 2.1 Summary of Containment-Related Motion}

\begin{tabular}{|c|c|c|c|c|c|c|}
\hline Gauge & $\begin{array}{l}\text { Slant Range } \\
(\mathrm{m})\end{array}$ & $\begin{array}{l}\text { Arrival Time } \\
\text { (ms) }\end{array}$ & $\begin{array}{l}\text { Acceleration } \\
\text { Peak (g) }\end{array}$ & $\begin{array}{l}\text { Velocity Peak } \\
(\mathrm{m} / \mathrm{s})\end{array}$ & $\begin{array}{c}\text { Displacement } \\
\text { Peak (cm) }\end{array}$ & $\begin{array}{l}\text { Displacement } \\
\text { Residual }(\mathrm{cm})\end{array}$ \\
\hline $21 \mathrm{av}$ & 112 & $30(a)$ & $7.2^{-}$ & 0.95 & 18.6 & -1 \\
\hline $21 u v$ & & $29(a)$ & . & 0.93 & 17.9 & 4 \\
\hline $22 a v^{(b)}$ & 147 & - & - & - & - & - \\
\hline $22 u v$ & & $36(c), 67$ & - & (d) & (d) & (d) \\
\hline $23 a v$ & 186 & $48(a)$ & $2.65(a)$ & 0.36 & 9.1 & (d) \\
\hline 23uv & & 53 (c), 97 & - & 0.38 & 9.5 & (d) \\
\hline $24 a v$ & 250 & $62(c), 146$ & 1.4 & 0.58 & 11.1 & -4 \\
\hline $24 u v$ & & $64(c), 150$ & - & 0.59 & 10.6 & (d) \\
\hline 26avA & 271 & $68(c), 140$ & $2.08(a)$ & 0.53 & 9.9 & -6 \\
\hline $26 \mathrm{avB}$ & & 68 (c) 140 & $1.8(a)$ & 0.53 & 10.3 & 3 \\
\hline $61 a v$ & 271 & 168 & $2.7,13.3(\theta)$ & 0.68 & 9.8 & -6 \\
\hline 61uv & & $165(a)$ & - & 0.53 & 8.8 & -2 \\
\hline $71 \mathrm{av}$ & $303(f)$ & 215 & $1.4,3.1(\theta)$ & 0.59 & 6.0 & -3 \\
\hline $71 u v$ & & 213 & - & 0.51 & 4.7 & -3 \\
\hline \multicolumn{7}{|c|}{$\begin{array}{l}\text { (a) Poorly defined. } \\
\text { (b) Dead pre-shot. } \\
\text { (c) Pipe arrival. } \\
\text { (d) Signal lost before this value attained. } \\
\text { (e) Slap-down. } \\
\text { (f) Approximate: station in recording trailer. }\end{array}$} \\
\hline
\end{tabular}


Table 2.2 Containment-Related Accelerometer Characteristics

\begin{tabular}{|c|c|c|c|}
\hline Gauge & $\begin{array}{c}\text { Natural Frequency } \\
(\mathrm{Hz})\end{array}$ & Damping Ratio & $\begin{array}{c}\text { System Range } \\
\text { (g's) }\end{array}$ \\
\hline $21 a v$ & 1000 & 0.65 & 150 \\
\hline $22 a v$ & 730 & 0.55 & 75 \\
\hline $23 a v$ & 330 & 0.75 & 12 \\
\hline $24 a v$ & 340 & 0.55 & 20 \\
\hline 26ava & 410 & 0.75 & 20 \\
\hline $26 a v b$ & 510 & 0.65 & 50 \\
\hline $61 a v$ & 330 & 0.65 & 20 \\
\hline 71 av & 230 & 0.75 & 10 \\
\hline
\end{tabular}

Table 2.3 Containment-Related Velocimeter Characteristics

\begin{tabular}{|c|c|c|c|c|c|}
\hline Gauge & $\begin{array}{c}\text { Natural } \\
\text { Frequency } \\
(\mathrm{Hz})\end{array}$ & $\begin{array}{l}\text { Time to } 0.5 \\
\text { Amplitude } \\
\text { (s) }\end{array}$ & $\begin{array}{c}\text { Calibration } \\
\text { Temperature } \\
\text { (OF) }\end{array}$ & $\begin{array}{c}\text { Operate } \\
\text { Temperature } \\
\left({ }^{\circ} \mathrm{F}\right)\end{array}$ & $\begin{array}{c}\text { System } \\
\text { Range } \\
(\mathrm{m} / \mathrm{s})\end{array}$ \\
\hline $21 u v$ & 3.60 & 7.2 & 73.1 & 63.9 & 7 \\
\hline $22 u v$ & 3.91 & 9.8 & 72.5 & (a) & 6 \\
\hline $23 u v$ & 3.44 & 8.15 & 72.7 & 59.4 & 2.4 \\
\hline $24 u v$ & 3.64 & 8.0 & 73.4 & 88.5 & 4 \\
\hline 61uv & 3.50 & 11.8 & 73.0 & 56.0 & 10 \\
\hline 71 uv & 3.75 & 13.09 & 74.75 & 64.7 & 1.2 \\
\hline
\end{tabular}

(a) This item not recorded. 

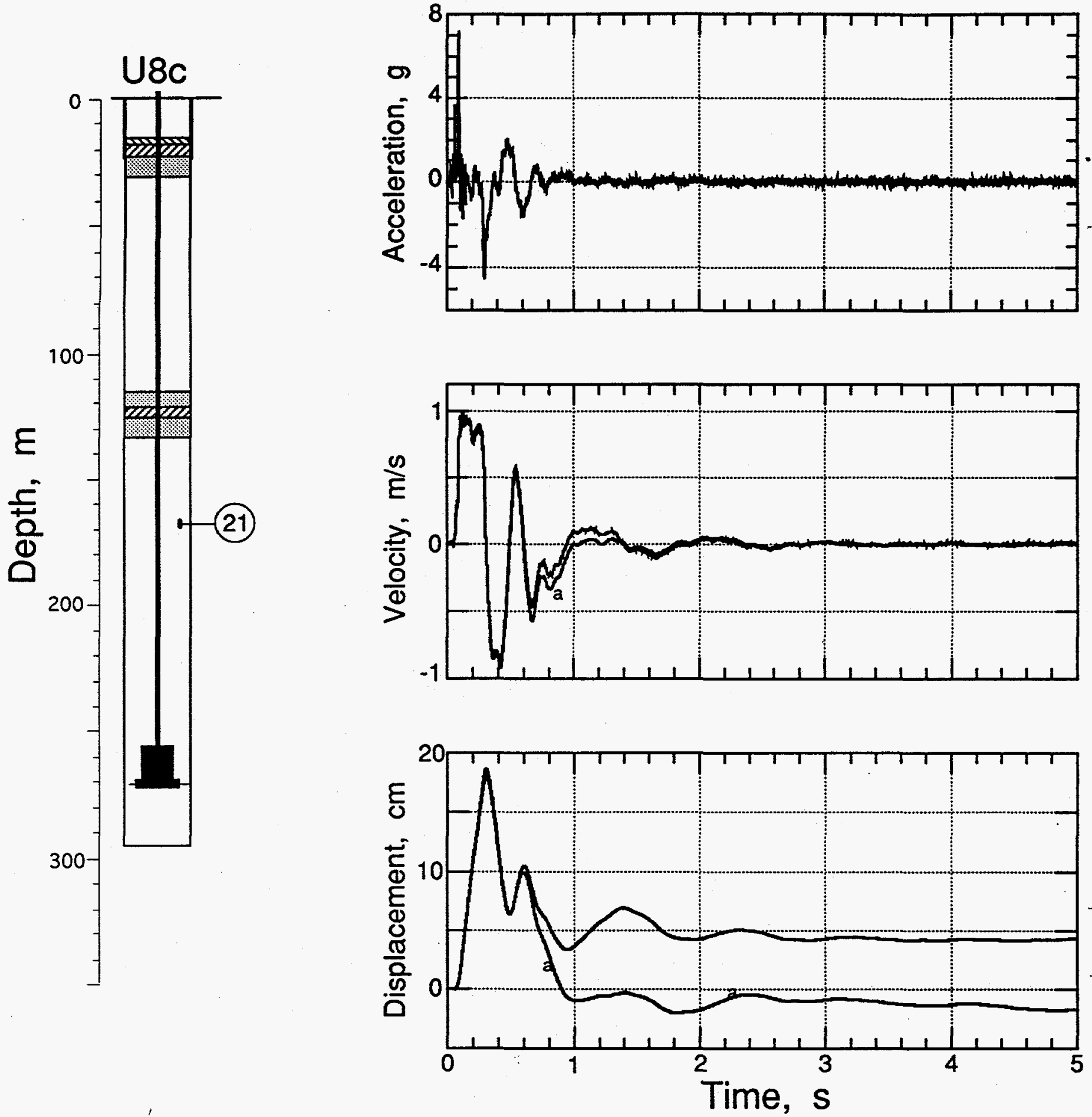

Figure 2.7 Explosion-induced vertical motion of the coarse stemming below the bottom plug at a depth of $159 \mathrm{~m}$ (station 21). Traces annotated with "a" are derived from the accelerometer. 

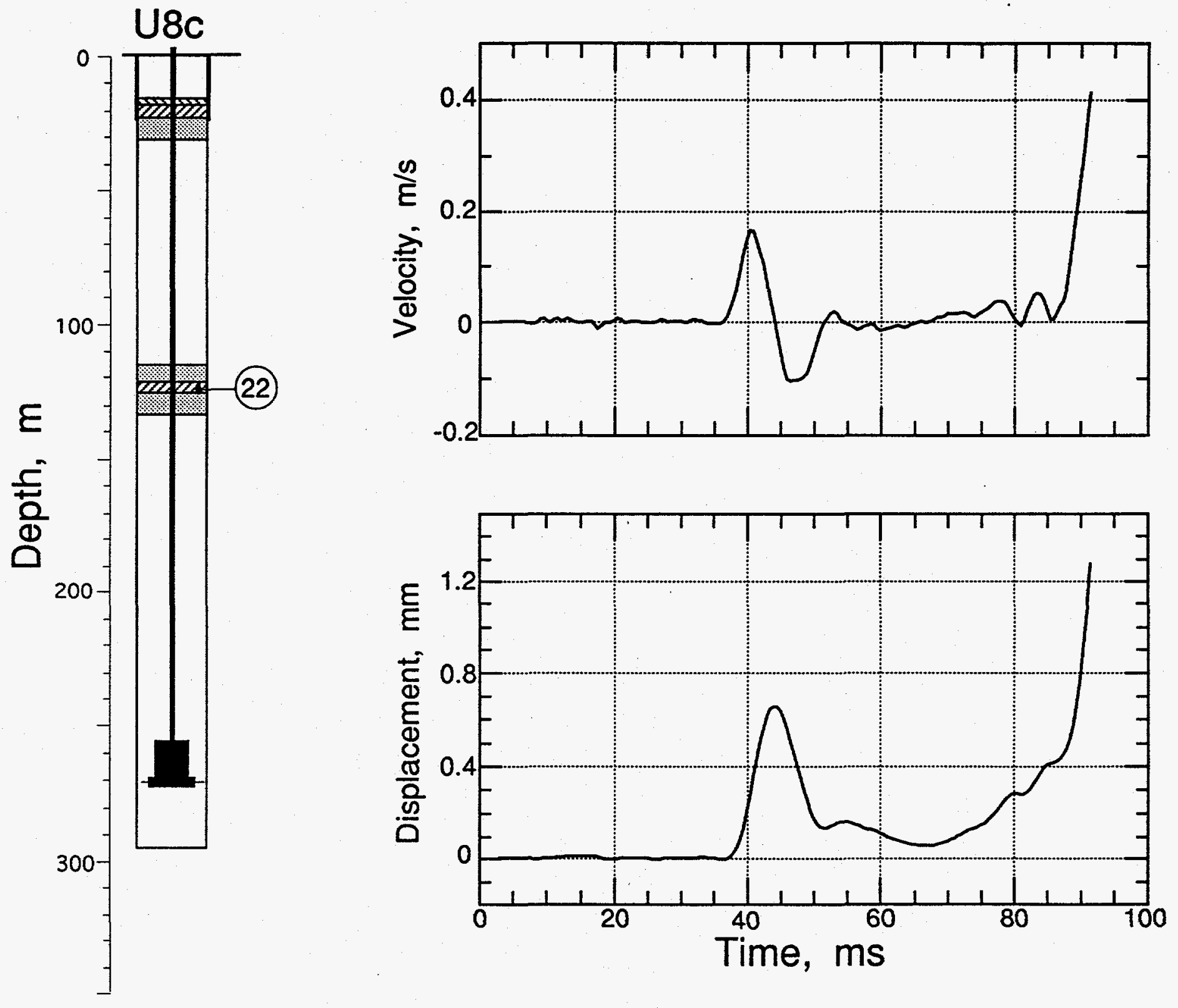

Figure 2.8 Explosion-induced vertical motion of the bottom plug at a depth of $124 \mathrm{~m}$ (station 22). The acceleration channel was dead pre-shot and is not represented. The velocity channel was lost at about $90 \mathrm{~ms}$. 

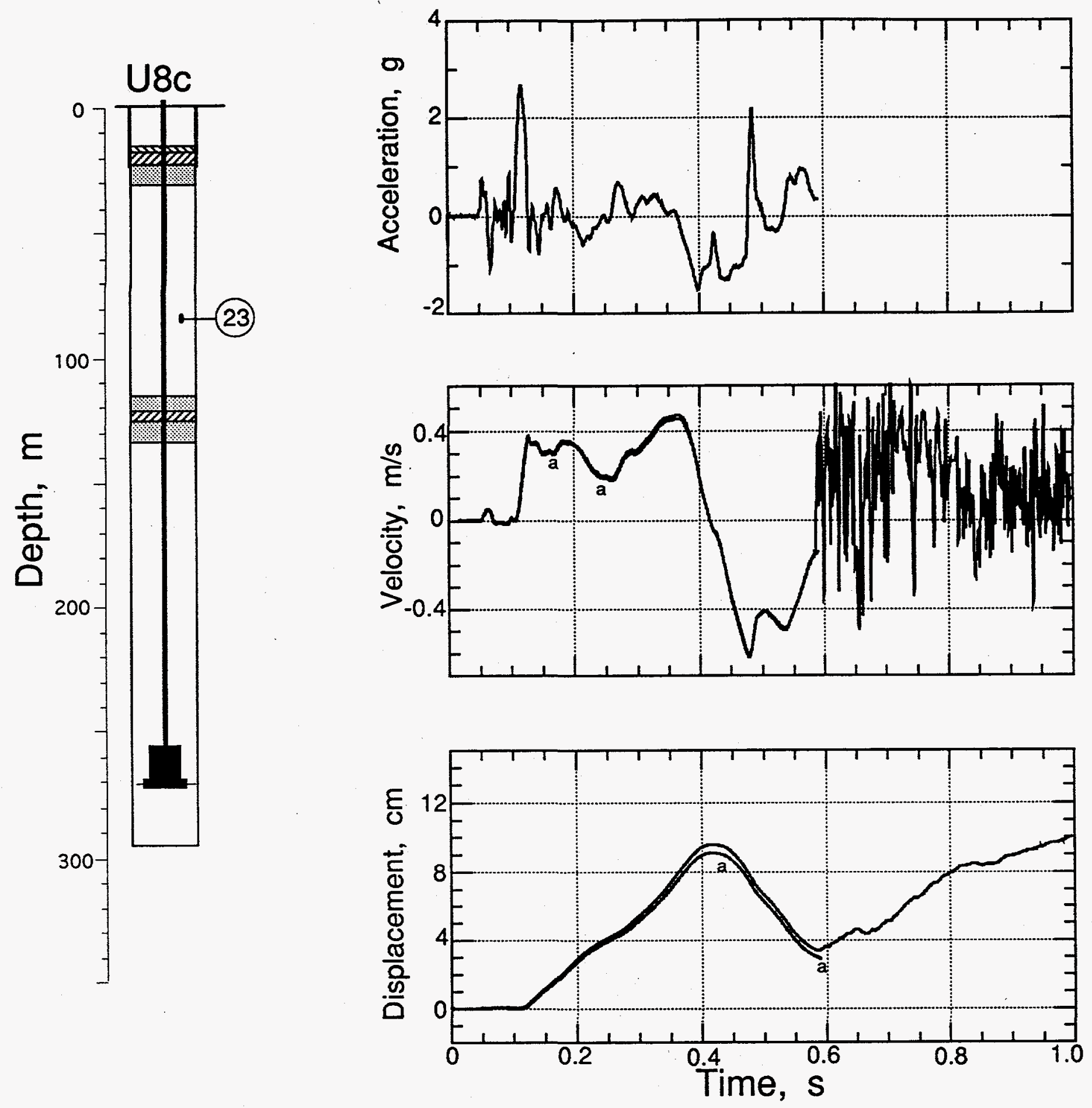

Figure 2.9 Explosion-induced vertical motion of the coarse stemming between the bottom and top plugs at a depth of $85 \mathrm{~m}$ (station 23). Both channels seem to have been lost at about $0.6 \mathrm{~s}$. Traces annotated with "a" are derived from the accelerometer. 

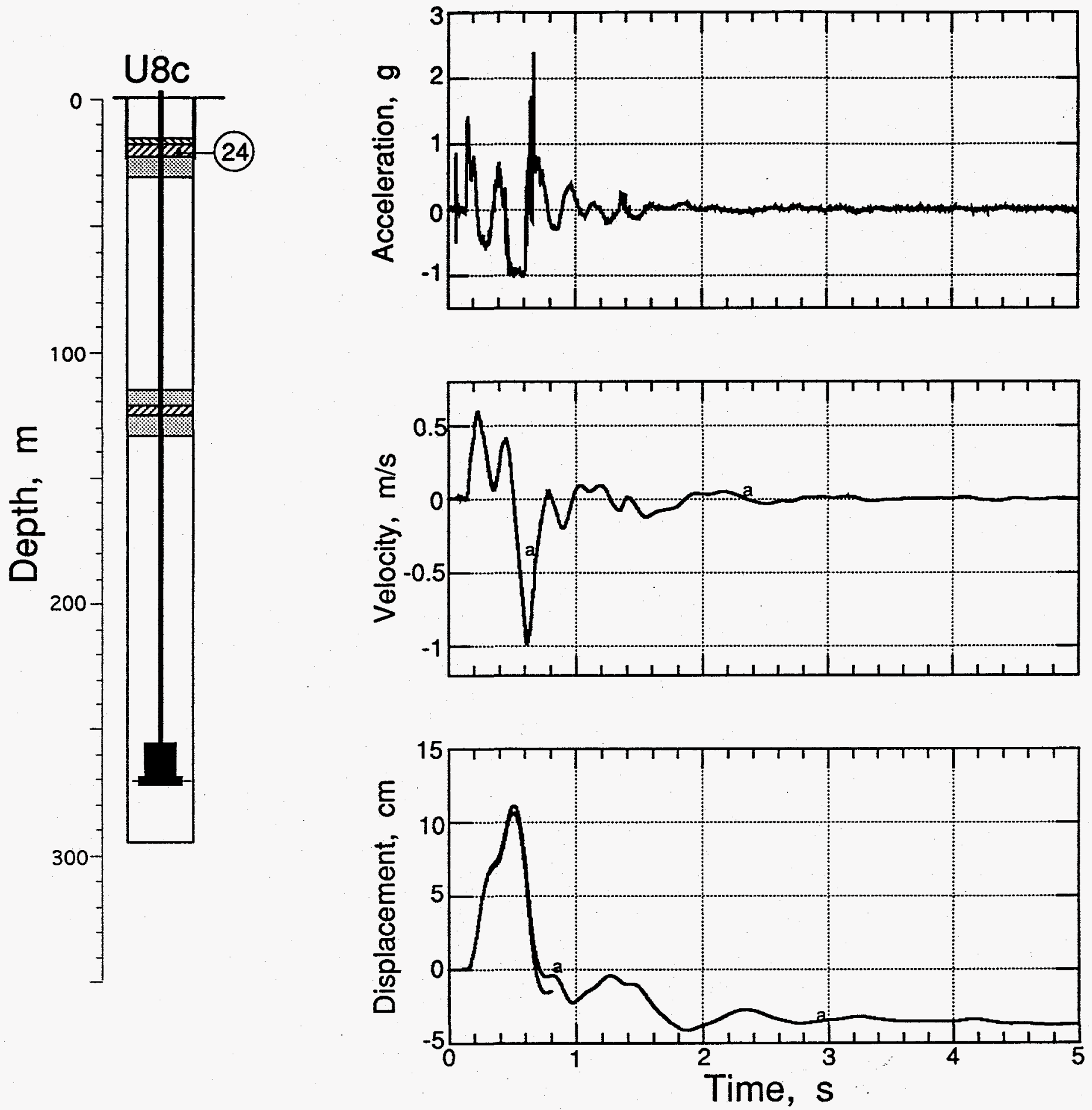

Figure 2.10 Explosion-induced vertical motion of top plug at a depth of $35 \mathrm{~m}$ (station 24). Traces annotated with "a" are derived from the accelerometer. 


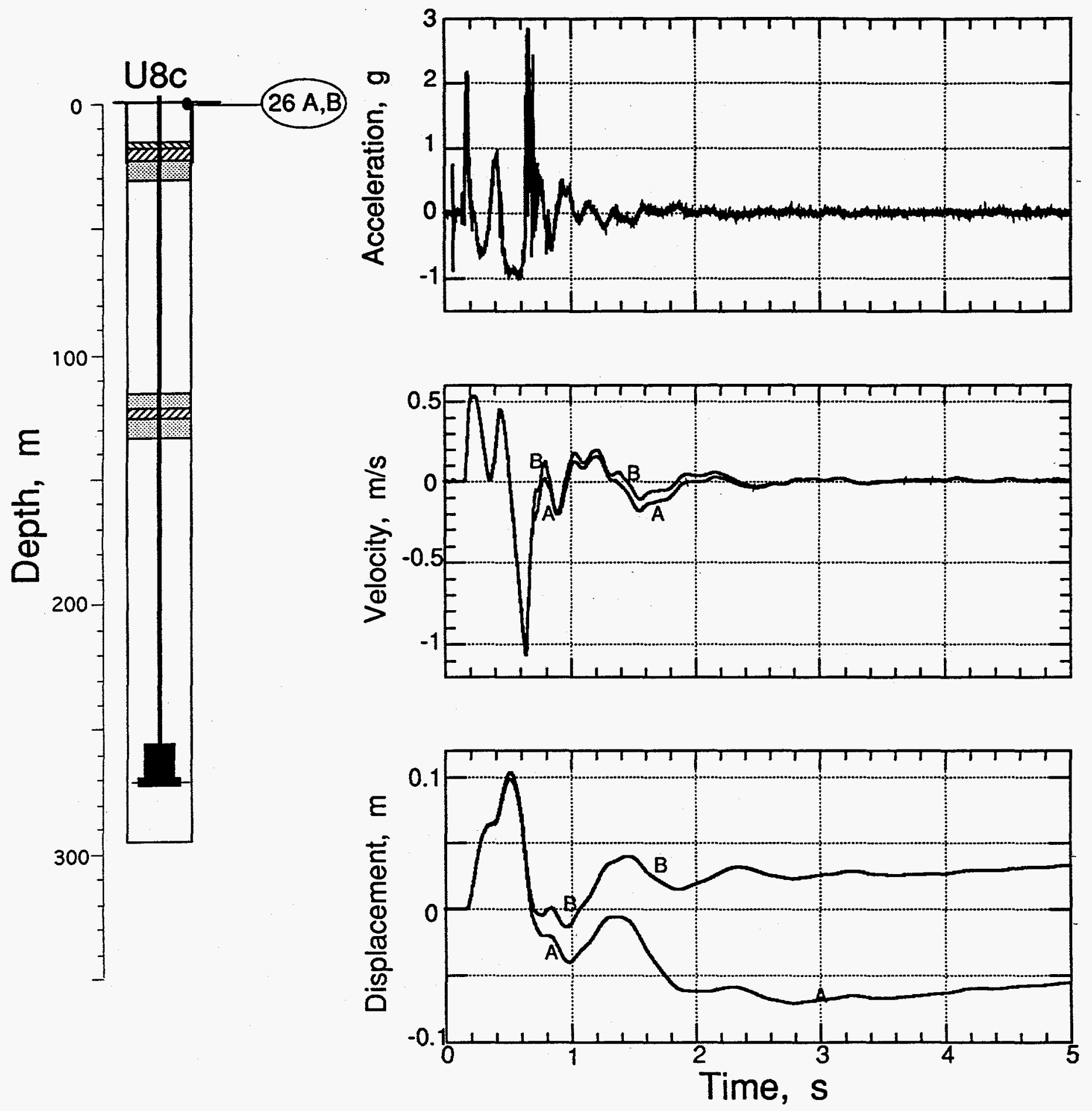

Figure 2.11 Explosion-induced vertical motion of the surface casing (stations 26A and 26B). Where possible, the two gauge records are annotated by their suffix. 

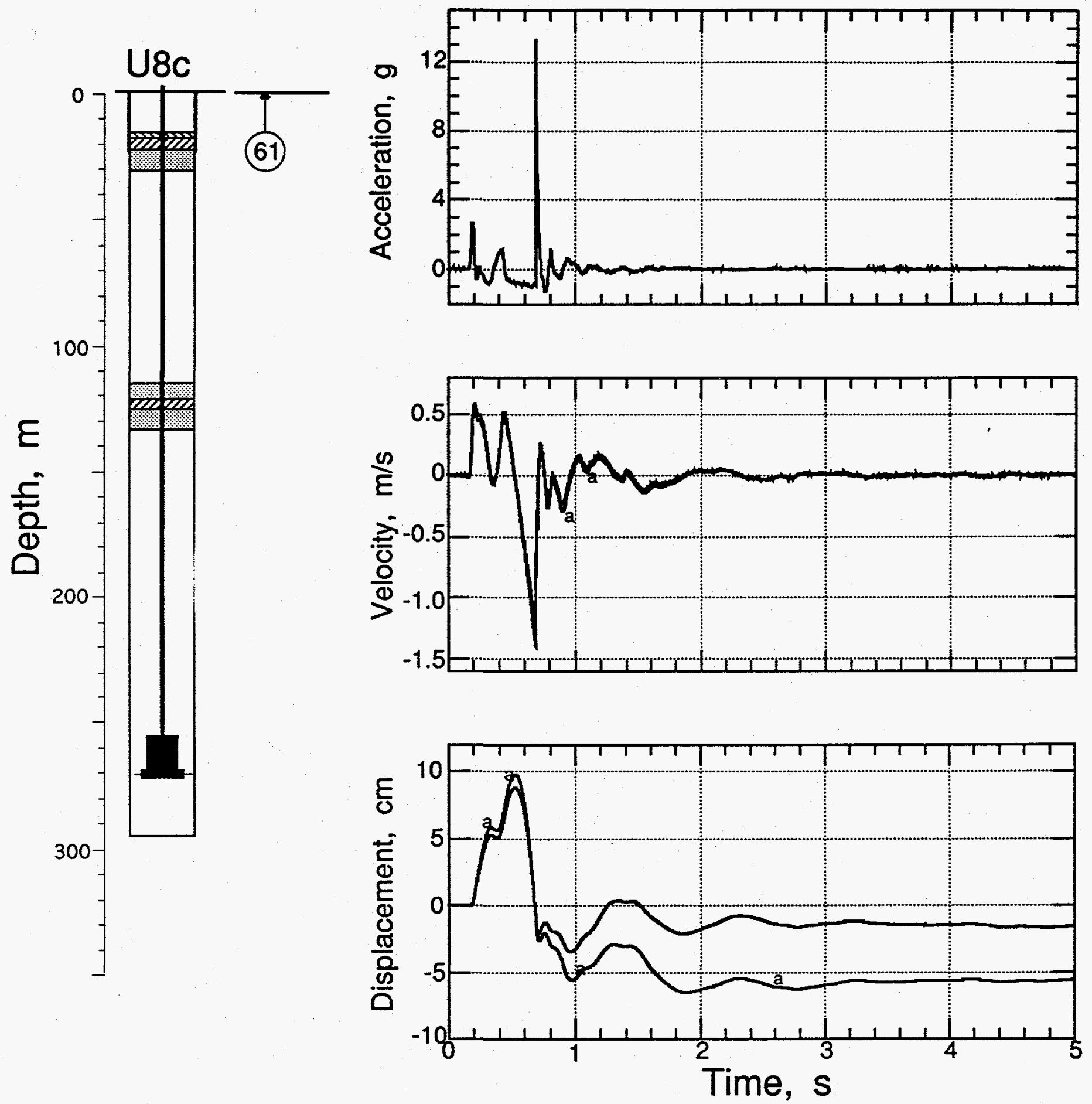

Figure 2.12 Explosion-induced vertical motion of the ground surface at a horizontal range of $15.24 \mathrm{~m}$ and a depth of $0.9 \mathrm{~m}$ (station 61). 


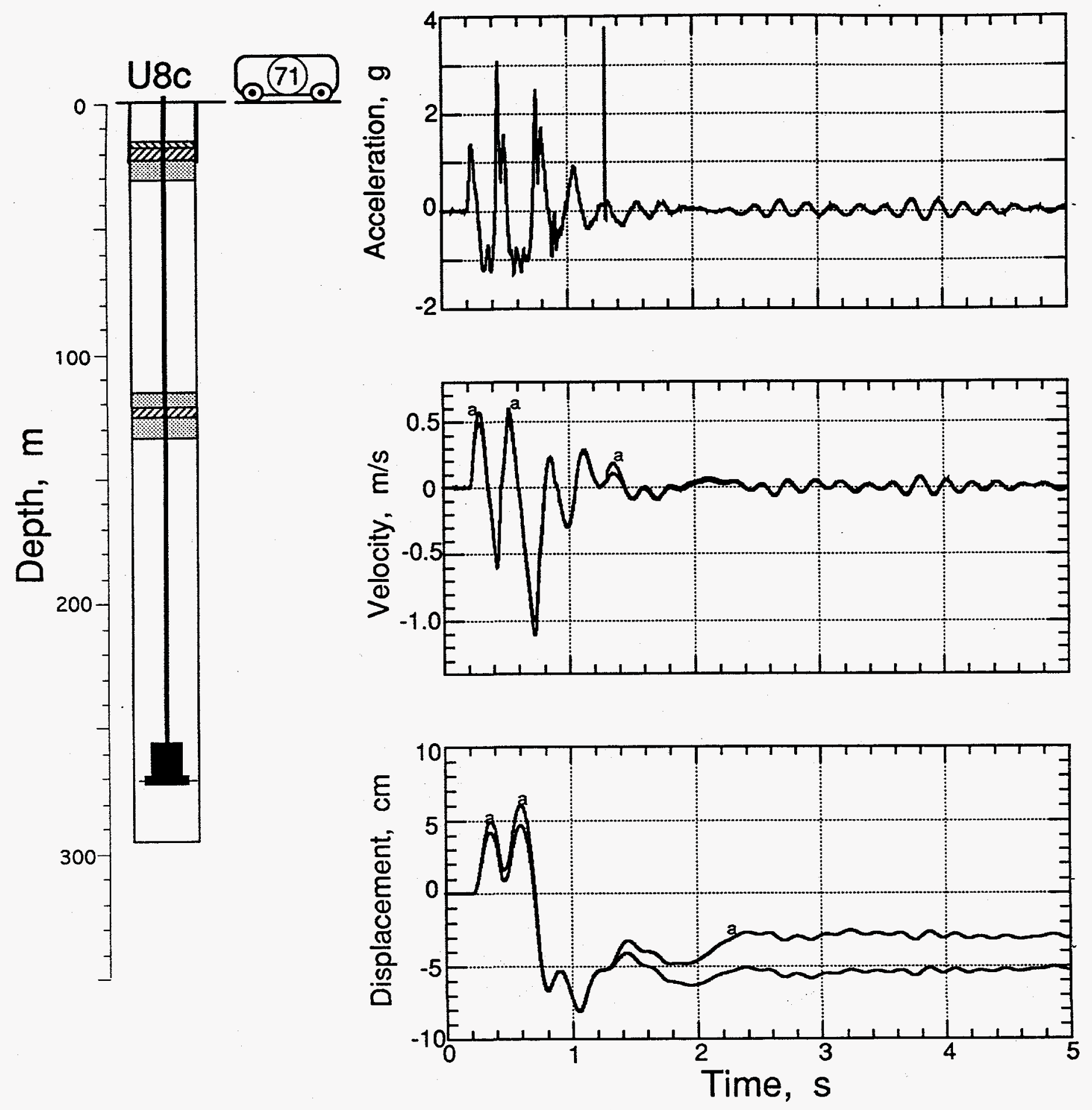

Figure 2.13 Explosion-induced vertical motion of the recording trailer (station 23). Traces annotated with "a" are derived from the accelerometer. 


\section{Free field (satellite hole) measurements}

Ten stations fielded in the satellite hole Ue8c $22.52 \mathrm{~m}$ east of the emplacement hole were instrumented to measure vertical acceleration and velocity as shown in figure 1.6. Alf stations were hung on a fiber glass pipe with a compass for orientation and a weight to keep the pipe straight. The hole was then grouted to the surface. Motion wave forms received from these stations are shown in figures 3.1-3.10.

Two of these stations (stations 44 and 47) were emplaced at the same slant ranges from the working point as were stations 21 and 23 in the loose stemming of the emplacement hole. Comparisons of the motion data at these two ranges are shown for the first $0.6 \mathrm{~s}$ in figures 3.11 and 3.12. Differences between the two wave forms in each figure can be attributed to the differences between mounting in loose stemming and grout.

A composite plot of the first $0.6 \mathrm{~s}$ of the acceleration histories from the top five stations is shown in figure 3.13. Of interest are the acceleration "noise" spikes seen at about $0.5 \mathrm{~s}$ in all of the records in the satellite hole but not in the emplacement hole. Furthermore, these spikes integrate to negligible interference in the velocity records as seen in figures $3.5-3.10$.

As an explanation, the volumetric strain history has been estimated from the motion at each of the five stations and is displayed in figure 3.14. Assuming spherical symmetry, the volumetric strain, $\varepsilon_{v}$, is given by (See the appendix, equation 3 );

$$
\varepsilon_{v}=\frac{D}{r}-\frac{U}{C}
$$

where $U$ is particle velocity, $C$ is local sonic velocity $(1696 \mathrm{~m} / \mathrm{s}$ as given in reference 1 and supported by this work), $D$ is particle displacement and $r$ is position. It is postulated that when the medium goes into dilatation, the fiber glass pipe support is allowed to relieve its previously grouted-in weight-induced strain, sending local acceleration signals to the motion stations with little resulting displacement. From figure 3.14 it is seen that the signals in question occur near the time of maximum dilatation. 
Table 3.1 Summary of Satellite Hole Motion

\begin{tabular}{|c|c|c|c|c|c|}
\hline Gauge & $\begin{array}{c}\text { Slant Range } \\
\text { (m) }\end{array}$ & $\begin{array}{c}\text { Arrival Time } \\
\text { (ms) }\end{array}$ & $\begin{array}{c}\text { Acceleration } \\
\text { Peak (g) }\end{array}$ & $\begin{array}{c}\text { Velocity Peak } \\
(\mathrm{m} / \mathrm{s})\end{array}$ & $\begin{array}{c}\text { Displacement } \\
\text { Peak (cm) }\end{array}$ \\
\hline 40av & 54 & (a) & - & - & - \\
\hline 40uv & & 30 & - & 14.7 & 163 \\
\hline 41 av & 69 & (a) & - & - & - \\
\hline 41uv & & 37 & - & 6.4 & 84 \\
\hline 42ar & 83 & 45 & 12.5 & 3.2 & 46 \\
\hline 42at & & 46 & - & 3.0 & 40 \\
\hline 43av & 98 & 53 & 13.1 & 2.46 & 37 \\
\hline 43uv & & 55 & - & 2.05 & 30 \\
\hline 44av & 112 & 61 & 10.0 & 0.89 & 16.7 \\
\hline 44uv & & 63 & - & 0.85 & 15.1 \\
\hline 45av & 138 & 77 & 6.2 & 0.54 & 9.9 \\
\hline 45uv & & 78 & - & 0.60 & 11.8 \\
\hline $46 a v$ & 162 & 91 & 4.0 & 0.42 & 11.2 \\
\hline 46uv & & 91 & - & 0.41 & 9.3 \\
\hline $47 a v$ & 186 & 106 & 3.3 & 0.38 & 9.7 \\
\hline 47uv & & 107 & - & 0.35 & 9.0 \\
\hline $48 a v$ & 211 & 120 & 2.3 & 0.31 & 8.9 \\
\hline 48 uv & & 121 & - & 0.28 & 8.3 \\
\hline 49av & 236 & 135 & 1.9 & 0.34 & 9.9 \\
\hline $49 u v$ & & 137 & - & 0.33 & 9.8 \\
\hline
\end{tabular}

(a) Dead pre-shot. 
Iable 3.2 Satellite Hole Accelerometer Characteristics

\begin{tabular}{|c|c|c|c|}
\hline Gauge & $\begin{array}{c}\text { Natural Frequency } \\
(\mathrm{Hz})\end{array}$ & Damping Ratio & $\begin{array}{c}\text { System Range } \\
\text { (g's) }\end{array}$ \\
\hline $40 a v$ & 1600 & 0.65 & 2000 \\
\hline $41 \mathrm{av}$ & 1500 & 0.65 & 1200 \\
\hline $42 a v$ & 1400 & 0.65 & 500 \\
\hline $43 a v$ & 1200 & 0.75 & 200 \\
\hline $44 a v$ & 920 & 0.65 & 150 \\
\hline $45 a v$ & 720 & $0.55^{\circ}$ & 50 \\
\hline $46 a v$ & 680 & 0.65 & 25 \\
\hline $47 a v$ & 340 & 0.60 & 12 \\
\hline $48 a v$ & 350 & 0.60 & 10 \\
\hline $49 a v$ & 300 & 0.65 & 10 \\
\hline
\end{tabular}

Table 3.3 Satellite Hole Velocimeter Characteristics

\begin{tabular}{|c|c|c|c|c|c|}
\hline Gauge & $\begin{array}{c}\text { Natural } \\
\text { Frequency } \\
(\mathrm{Hz})\end{array}$ & $\begin{array}{c}\text { Time to } 0.5 \\
\text { Amplitude } \\
\text { (s) }\end{array}$ & $\begin{array}{c}\text { Calibration } \\
\text { Temperature } \\
\text { (ㅇ) }\end{array}$ & $\begin{array}{c}\text { Operate } \\
\text { Temperature } \\
\left.\text { ( }{ }^{\circ} \mathrm{F}\right)\end{array}$ & $\begin{array}{c}\text { System } \\
\text { Range } \\
(\mathrm{m} / \mathrm{s})\end{array}$ \\
\hline 40uv & 3.75 & 35.5 & 72.4 & 74.1 & 65 \\
\hline 41uv & 3.81 & 19.2 & 73.3 & 73.8 & 30 \\
\hline $42 u v$ & 4.28 & 23.45 & 73.2 & 72.3 & 15 \\
\hline 43uv & 3.50 & 12.95 & 73.0 & 71.3 & 10 \\
\hline 44uv & 3.58 & 10.55 & 73.3 & 70.6 & 7 \\
\hline 45uv & 3.59 & 9.2 & 73.5 & 69.0 & 5 \\
\hline 46uv & 3.64 & 8.1 & 73.6 & 66.5 & 3 \\
\hline 47uv & 3.67 & 7.0 & 73.3 & 65.9 & 2.5 \\
\hline $48 u v$ & 3.52 & 9.1 & 73.3 & 64.9 & 2 \\
\hline 49uv & 3.52 & 9.7 & 72.5 & 64.1 & 2 \\
\hline
\end{tabular}



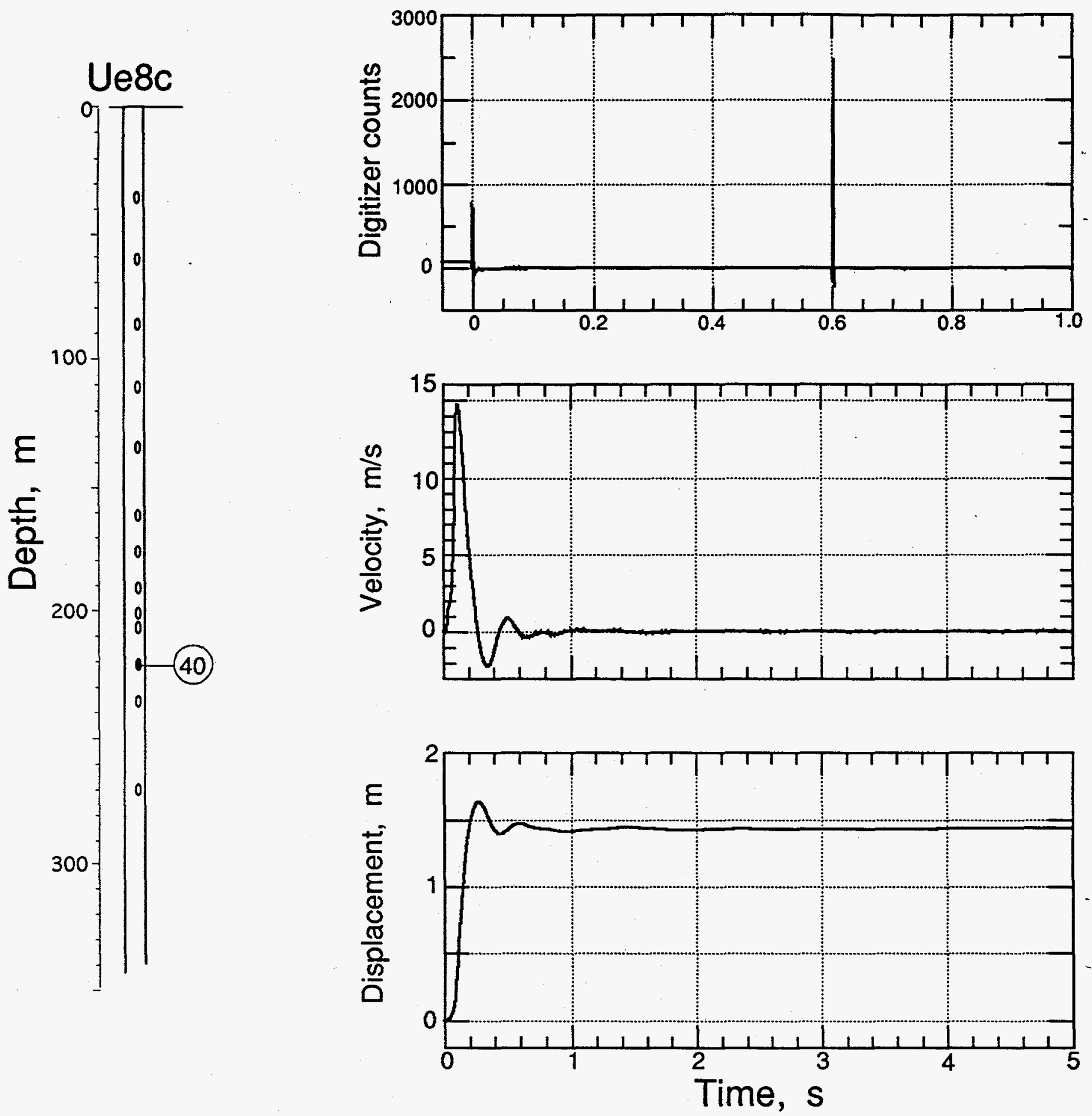

Figure 3.1 Vertical motion in the satellite hole at a slant range of $52.7 \mathrm{~m}$ (station 40 at a depth of $220.5 \mathrm{~m}$ ). The accelerometer at this location gave an unreliable record and was not reduced to engineering units. 

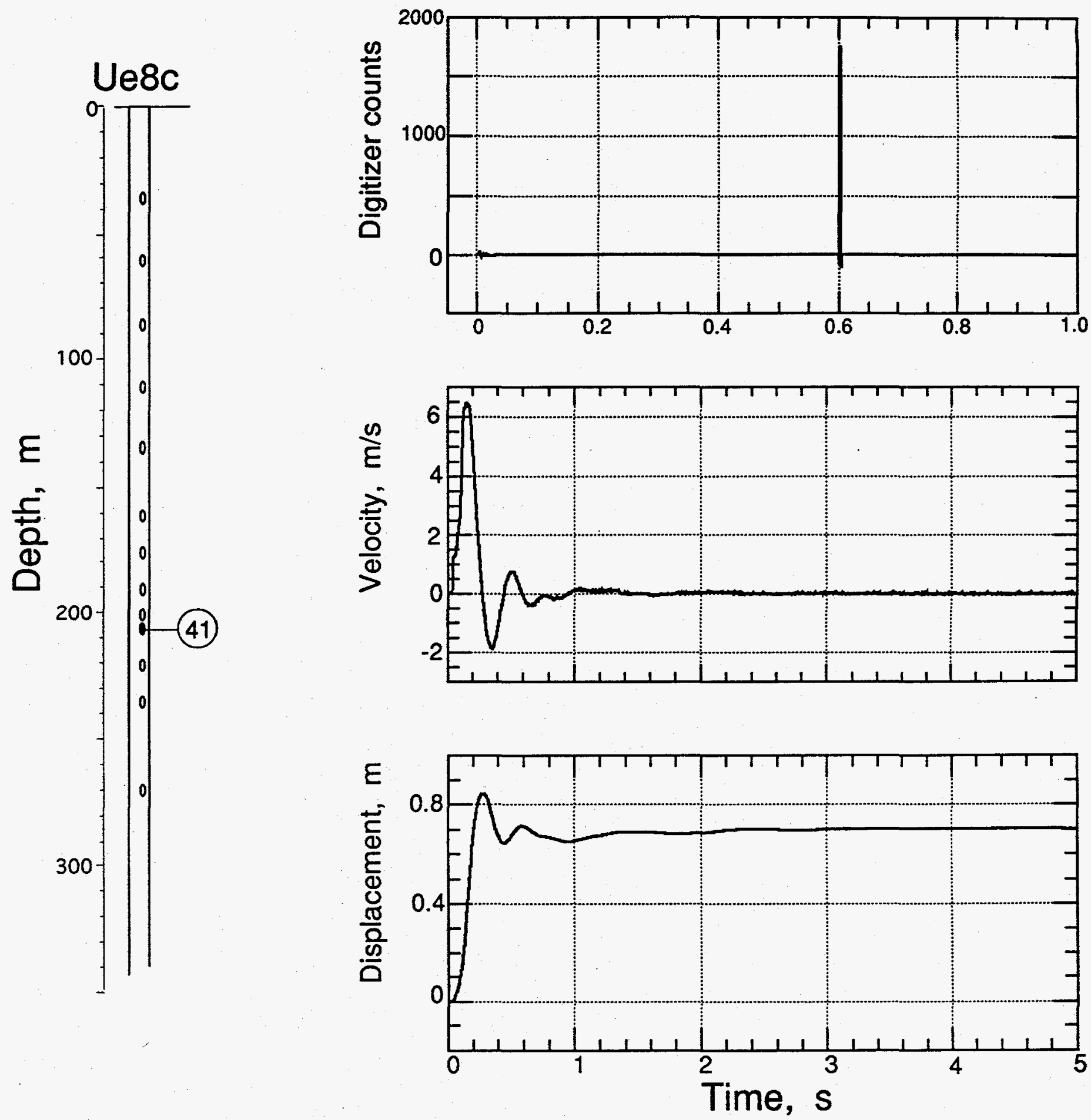

Figure 3.2 Vertical motion in the satellite hole at a slant range of $66.2 \mathrm{~m}$ (station 41 at a depth of $206.6 \mathrm{~m}$ ). The accelerometer at this location gave an unreliable record and was not reduced to engineering units. 

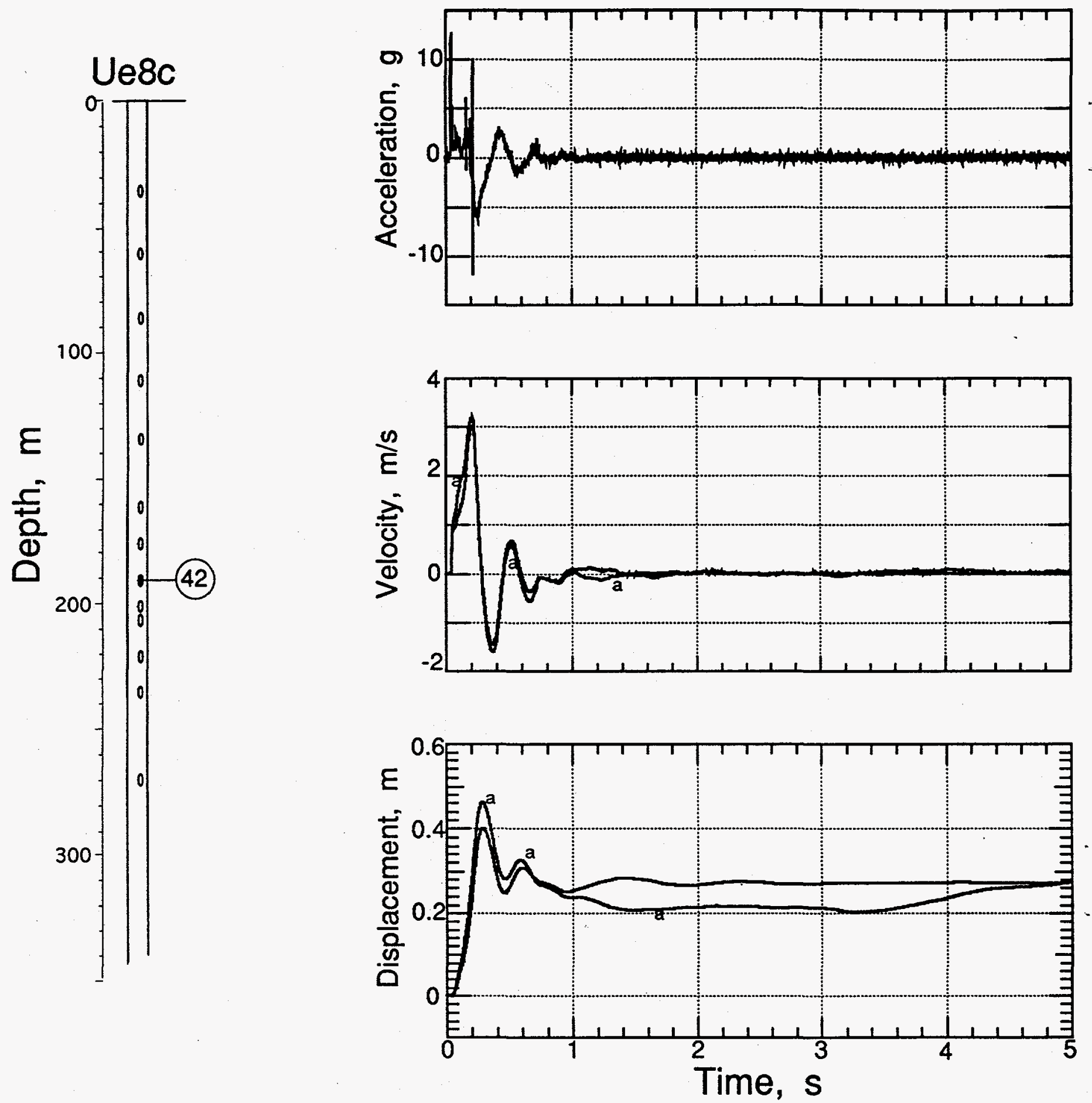

Figure 3.3 Vertical motion in the satelite hole at a slant range of $81.4 \mathrm{~m}$ (station 42 at a depth of $191.0 \mathrm{~m})$. 

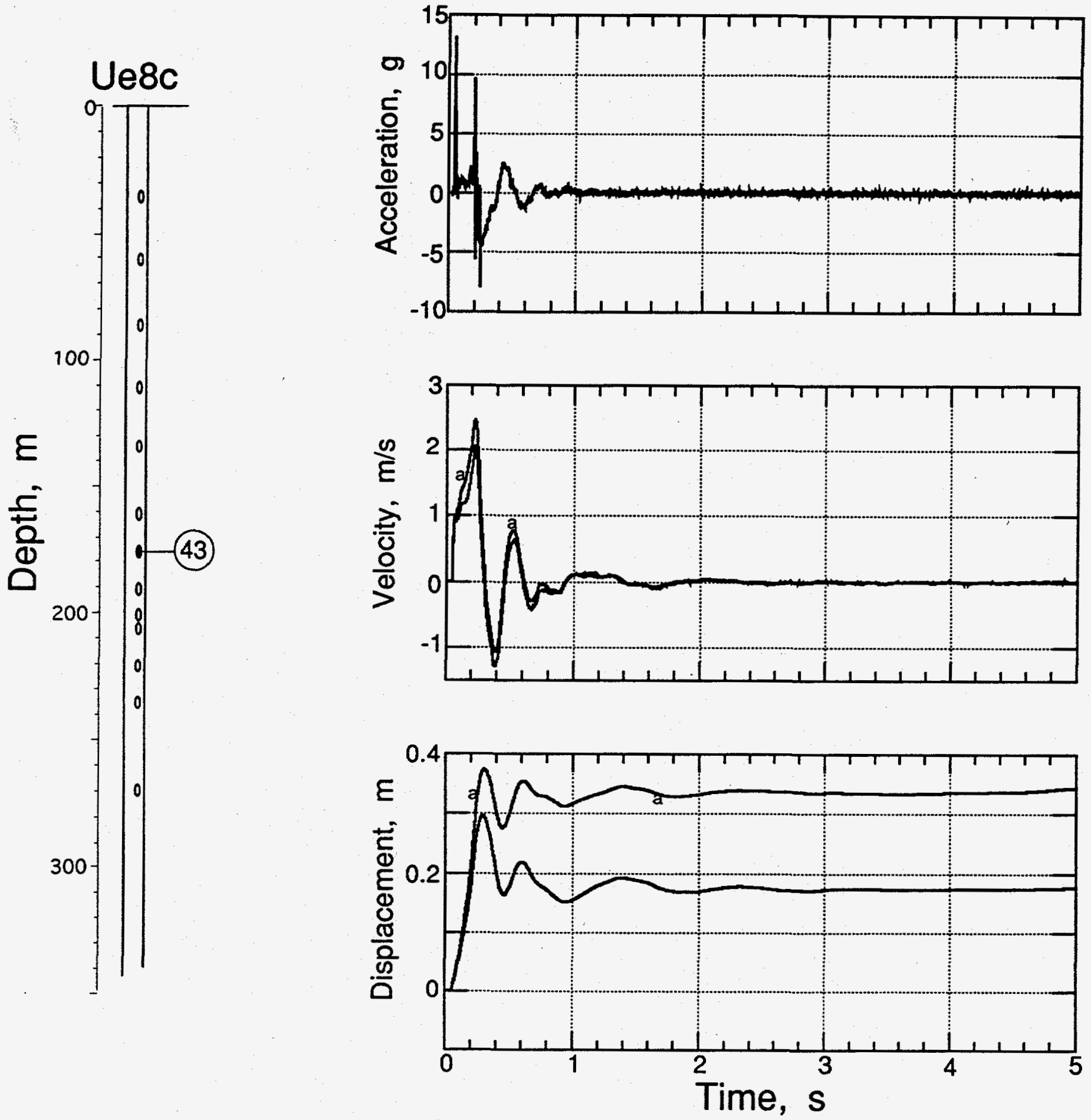

Figure 3.4 Vertical motion in the satellite hole at a slant range of $96.2 \mathrm{~m}$ (station 43 at a depth of $176.0 \mathrm{~m}$ ). 

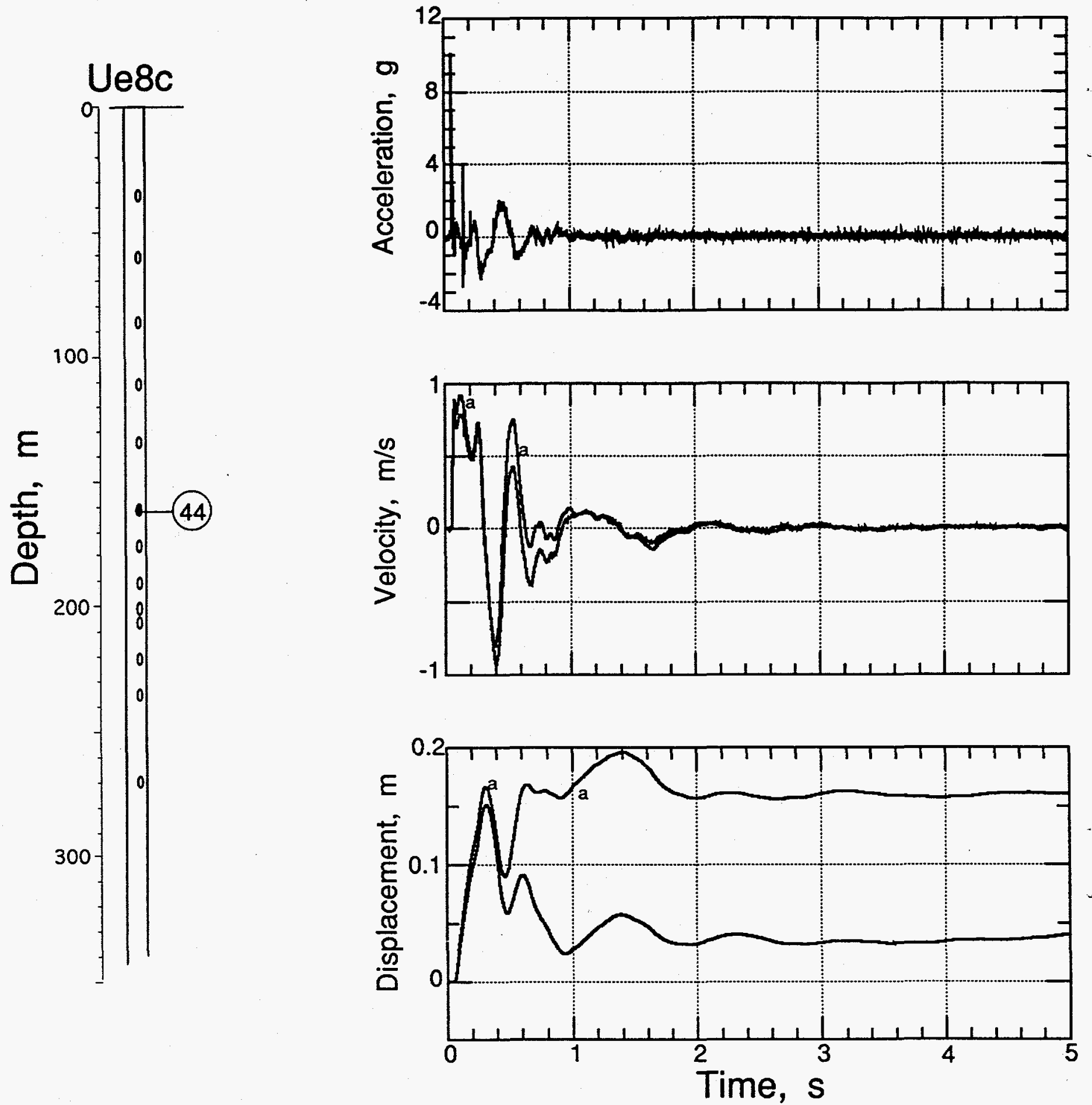

Figure 3.5 Vertical motion in the satellite hole at a slant range of $111.1 \mathrm{~m}$ (station 44 at a depth of $161.0 \mathrm{~m})$. 

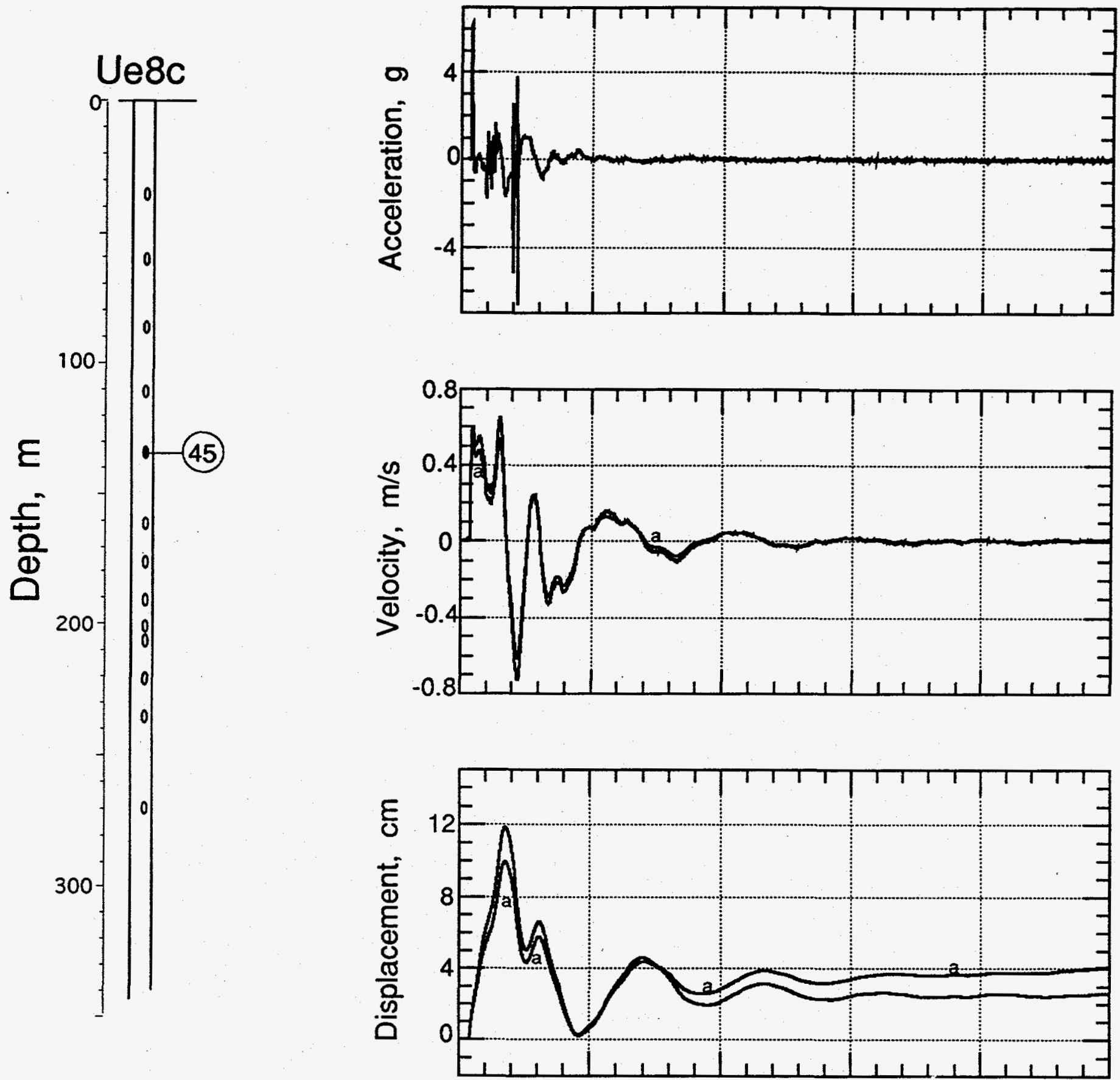

Figure 3.6 Vertical motion in the satellite hole at a slant range of $137.0 \mathrm{~m}$ (station 45 at a depth of $134.8 \mathrm{~m})$. 

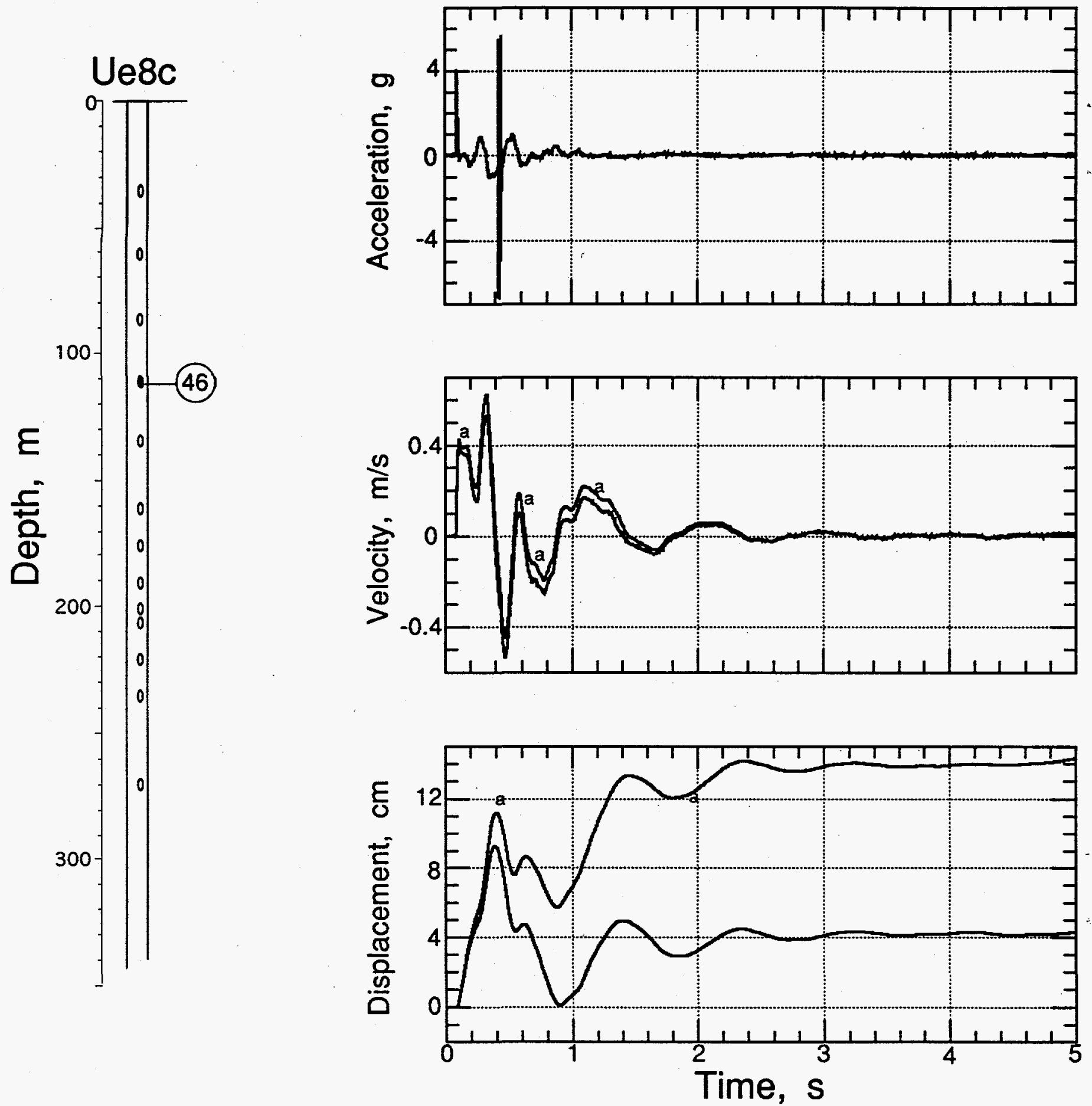

Figure $3.7 \quad$ Vertical motion in the satellite hole at a slant range of $160.7 \mathrm{~m}$ (station 46 at a depth of $111.0 \mathrm{~m}$ ). 

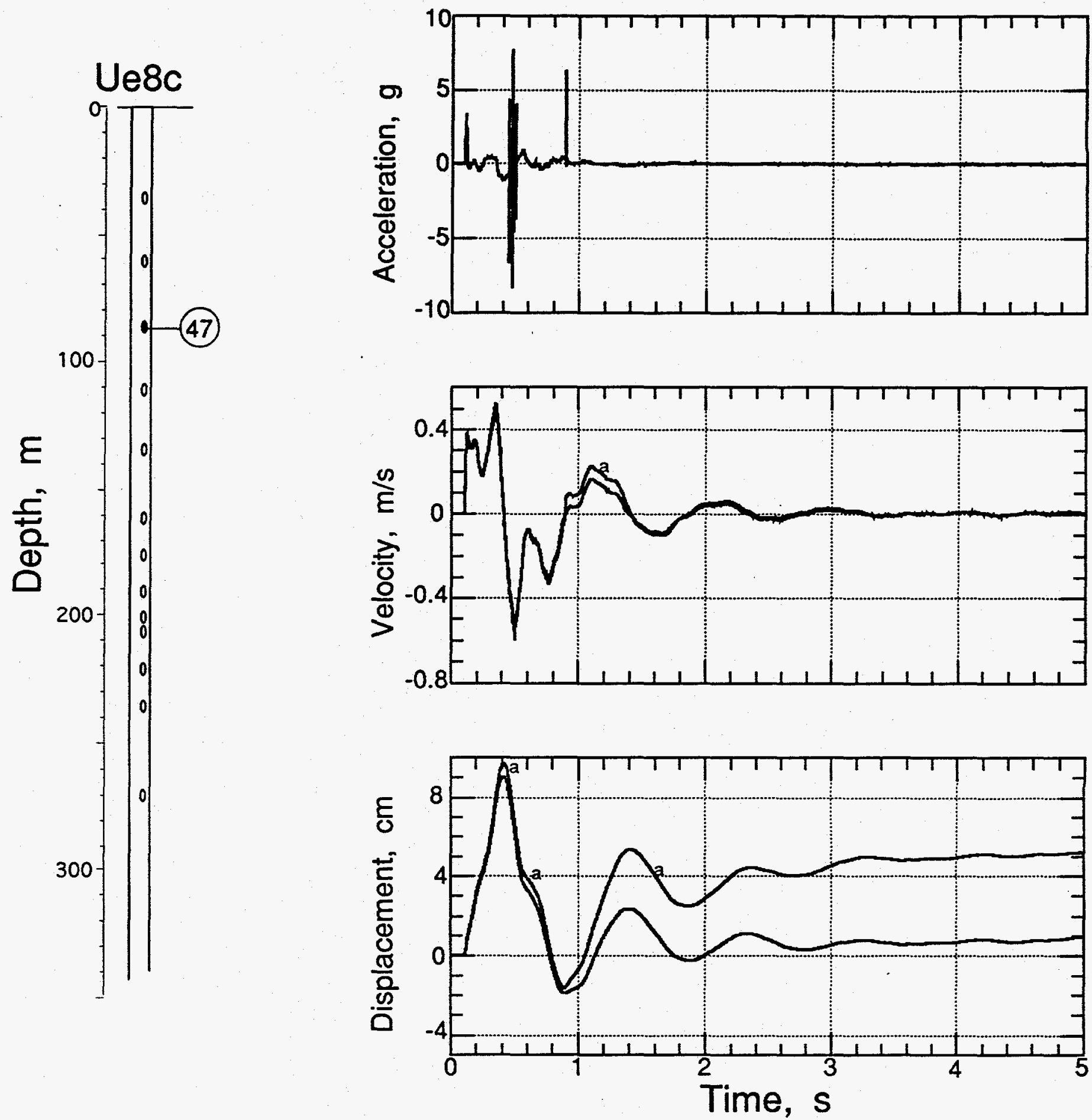

Figure 3.8 Vertical motion in the satellite hole at a slant range of $185.6 \mathrm{~m}$ (station 47 at a depth of $86.0 \mathrm{~m}$ ) 

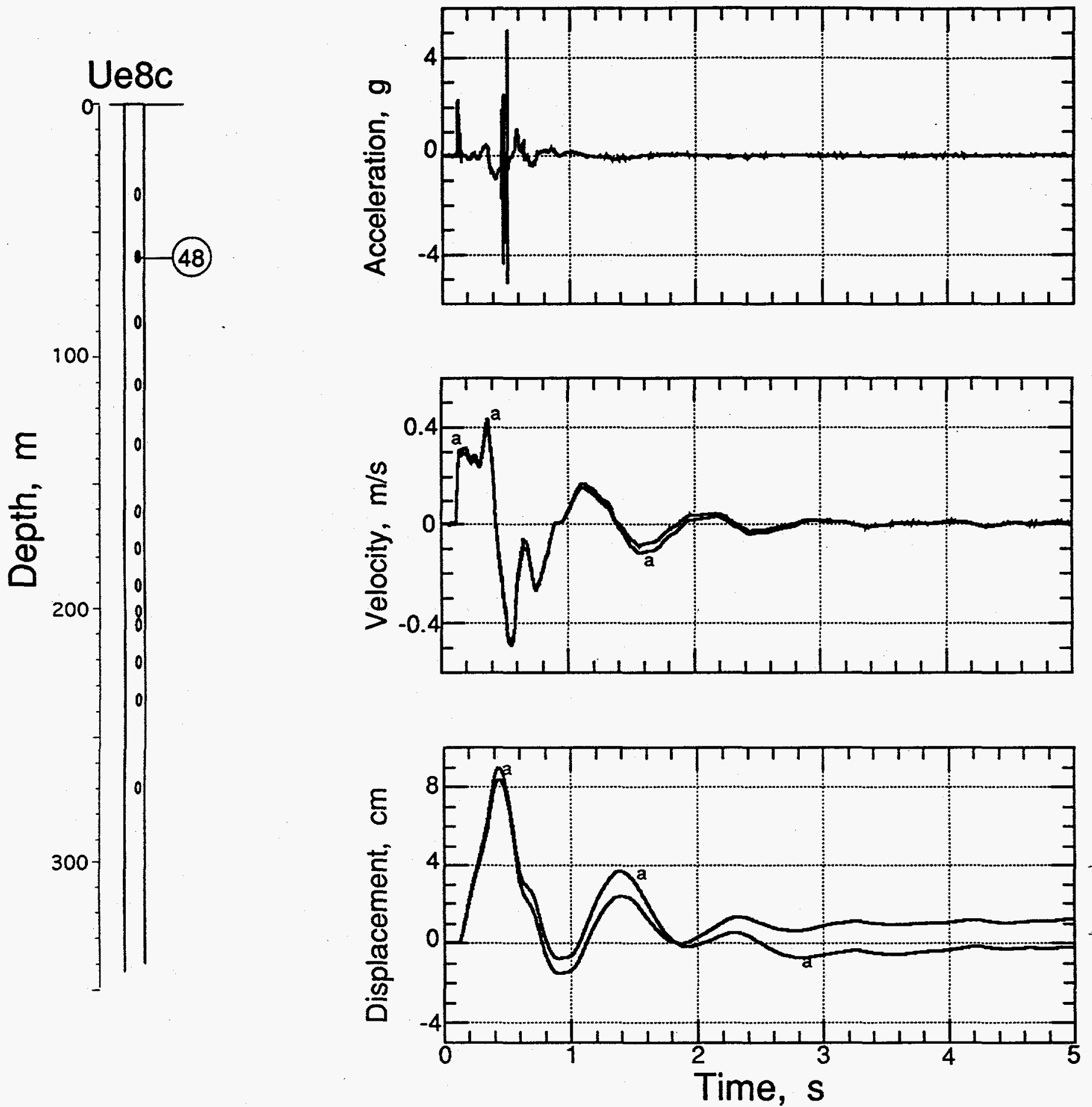

Figure 3.9 Vertical motion in the satellite hole at a slant range of $210.6 \mathrm{~m}$ (station 48 at a depth of $61.0 \mathrm{~m}$ ). 

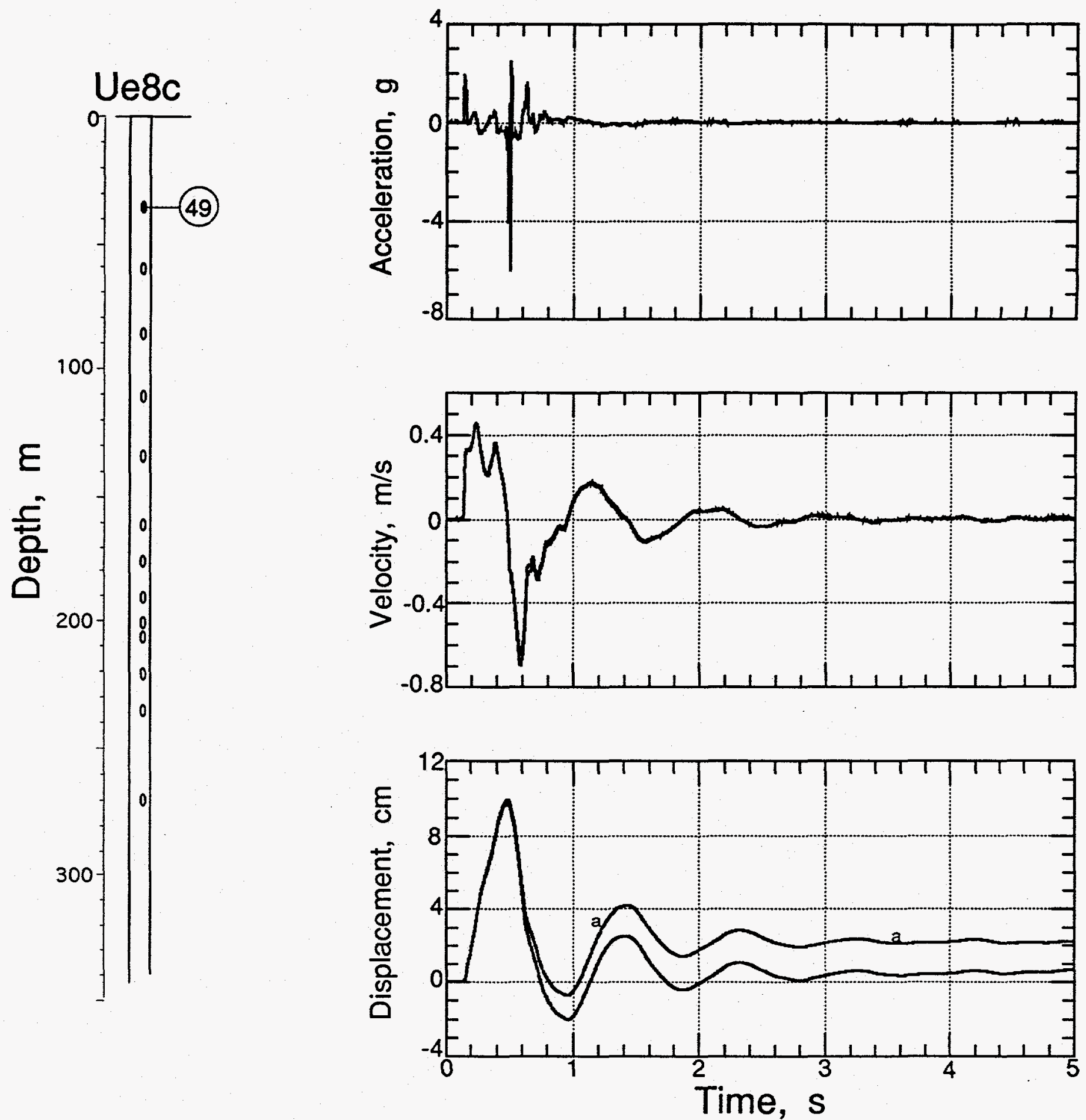

Figure 3.10 Vertical motion in the satellite hole at a slant range of $235.5 \mathrm{~m}$ (station 49 at a depth of $36.0 \mathrm{~m}$ ). 


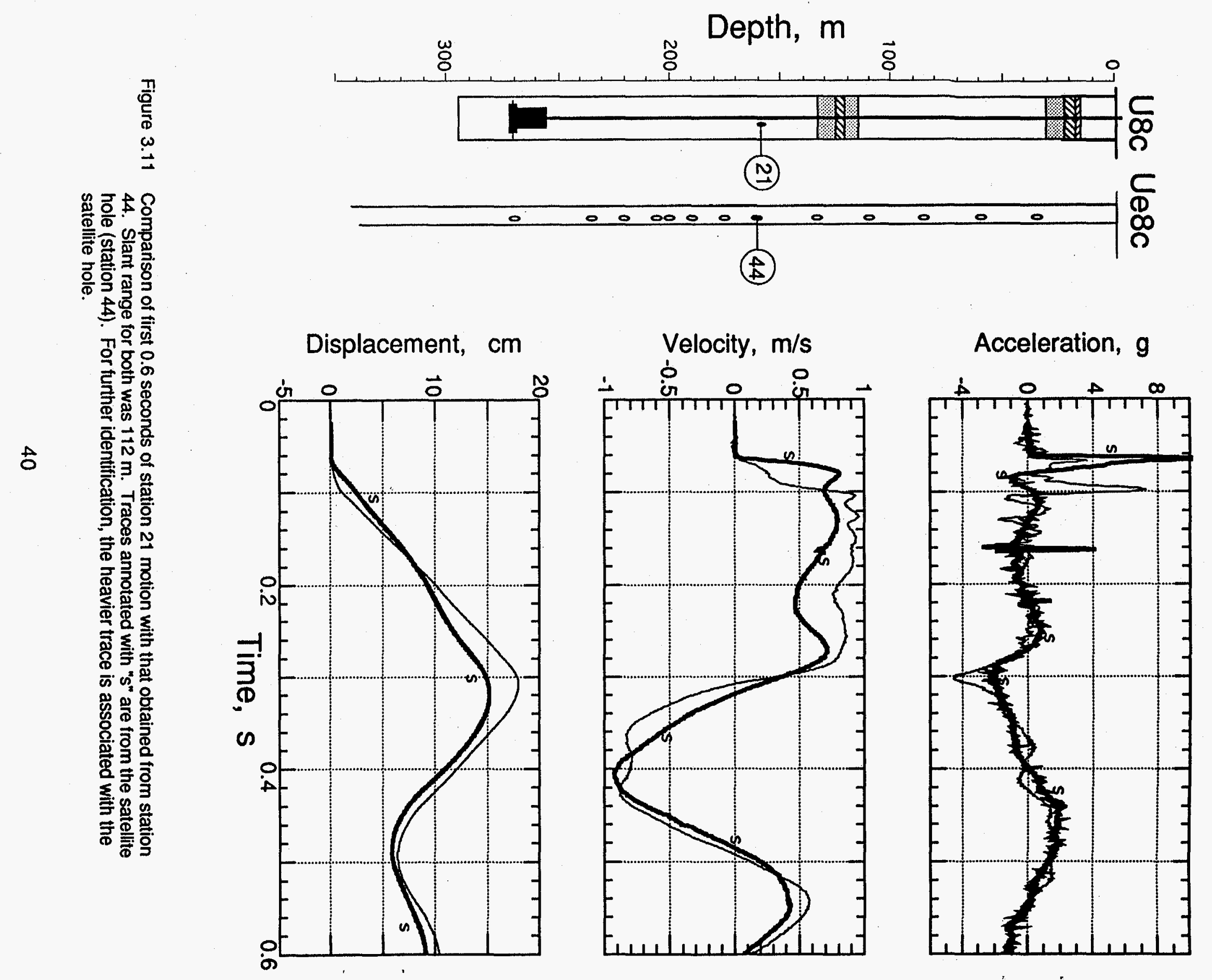




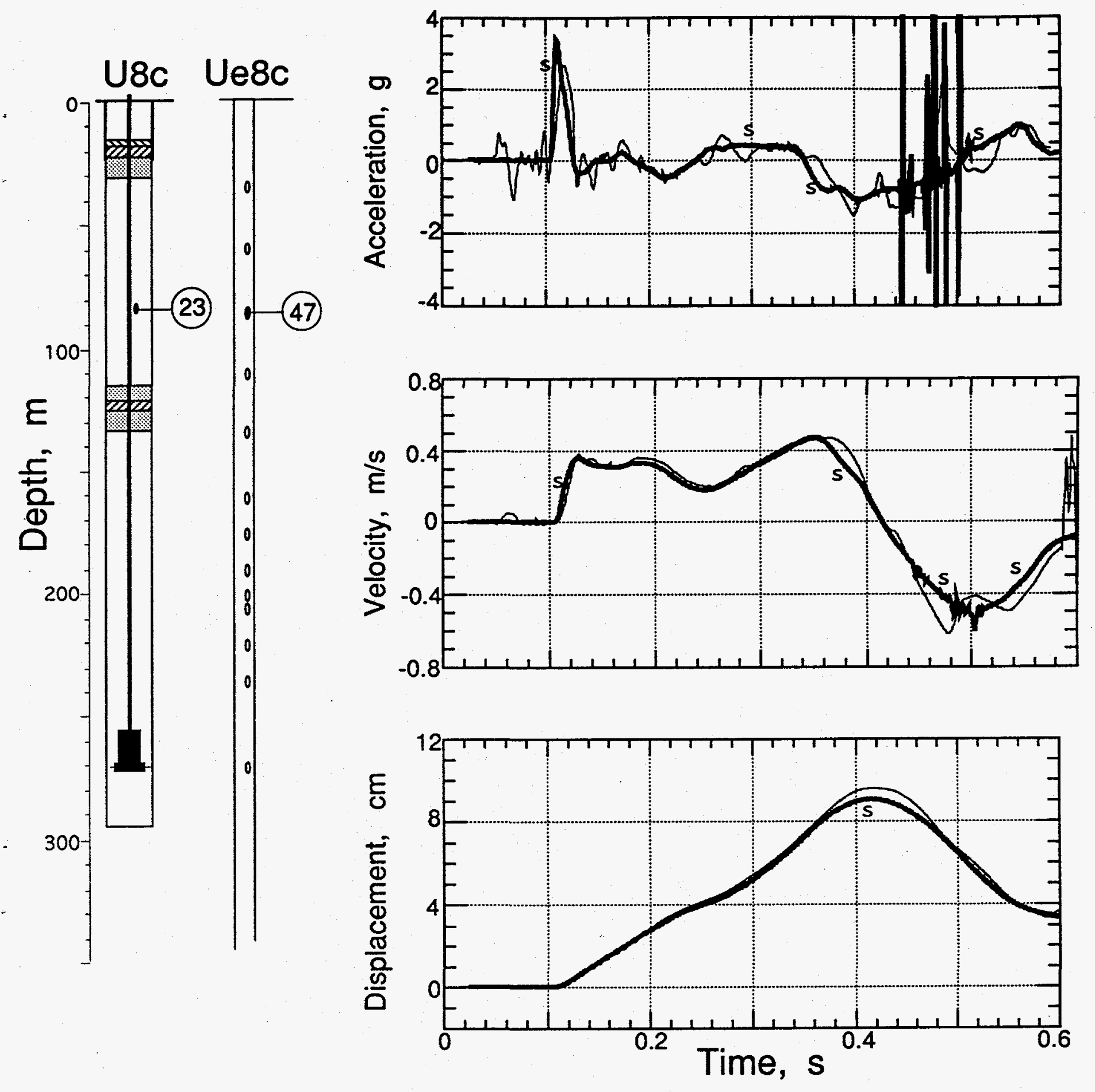

Figure 3.12 Comparison of first 0.6 seconds of station 23 motion with that obtained from station 47. Slant range for both was $186 \mathrm{~m}$. Traces annotated with " $\mathrm{s}$ " are from the satellite hole (station 47). For further identification, the heavier trace is associated with the satellite hole. 


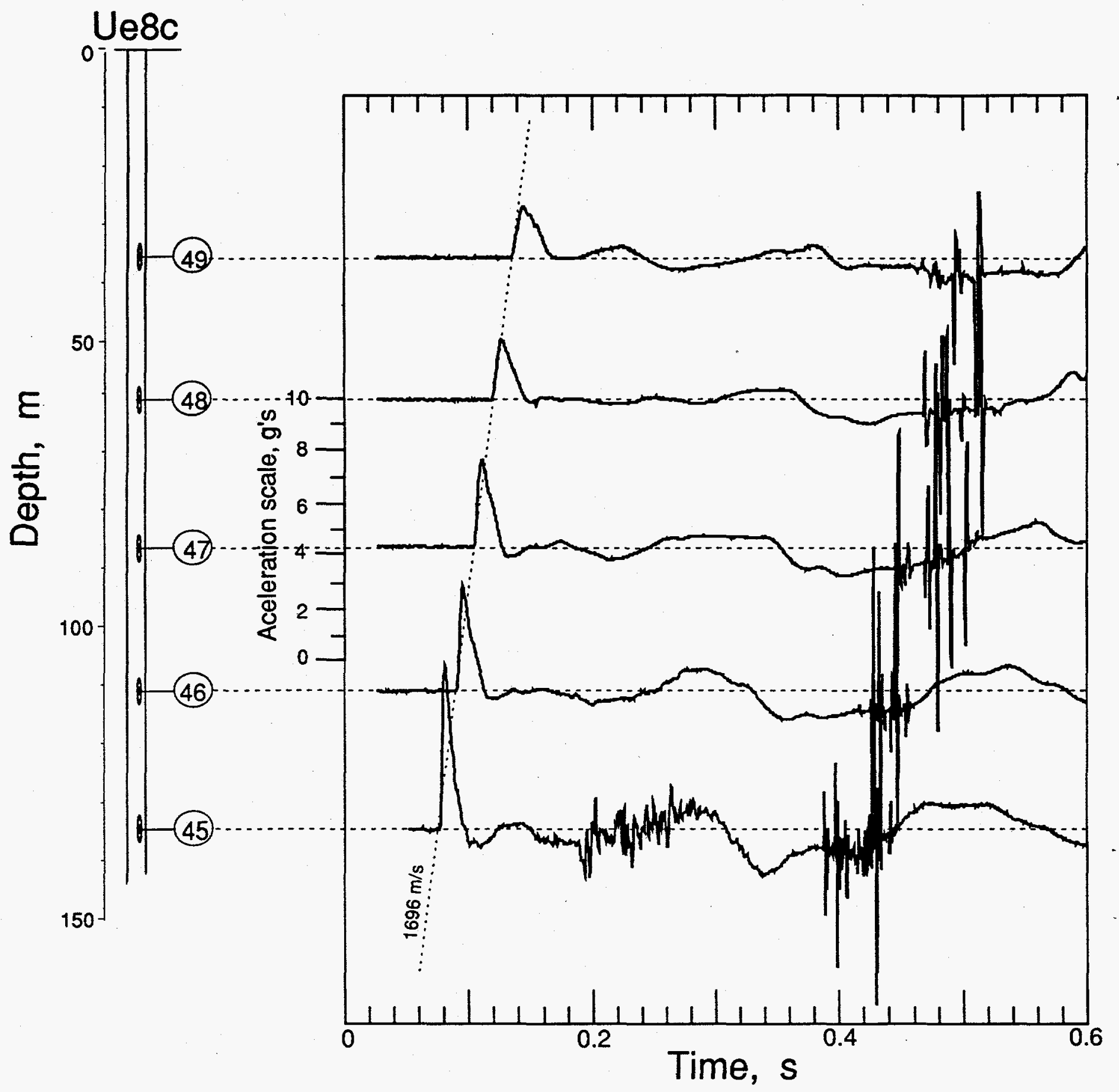

Figure 3.13 Composite of the first $0.6 \mathrm{~s}$ of acceleration from the top five stations in the satellite hole. The "noise" occurring between 0.4 and $0.5 \mathrm{~s}$ is clearly seen on each trace. 


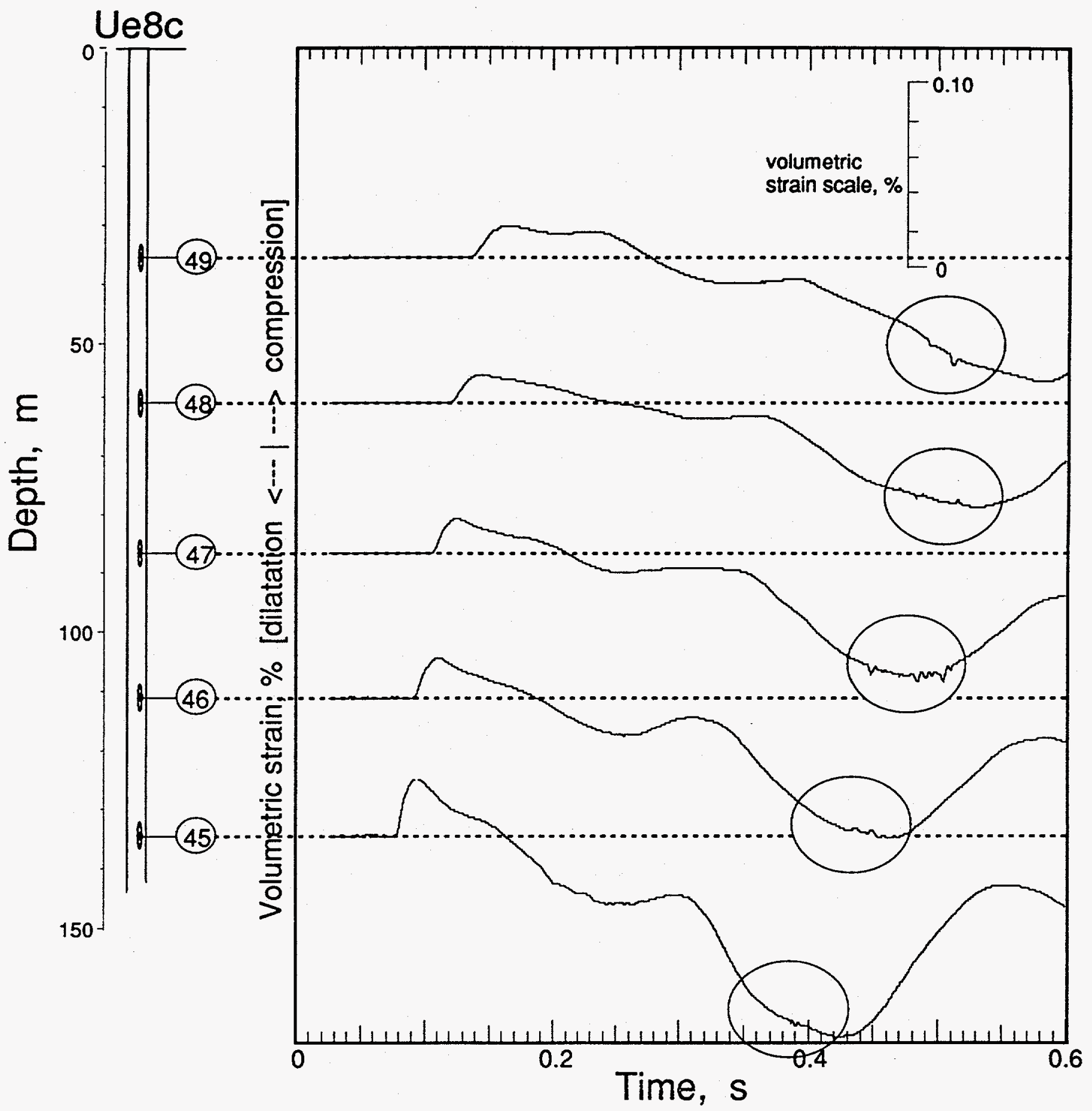

Figure 3.14 Volumetric strain computed from the motion of the top five stations in the satellite hole. The circled areas on each trace include the effects of the "noise" periods seen in the corresponding acceleration records (figure 1.13). Compression (decrease in strain) is in the upward direction relative to each base line. 
4. Collapse phenomena

Data from all stations sensing collapse motion are shown in figures 4.1 through 4.12. Station 22, in the bottom plug, did not survive beyond the first $100 \mathrm{~ms}$ and is thus not shown. Both the acceleration and velocity channels of station 23 were lost at about $0.6 \mathrm{~s}$ and the action of the calibration system (applied at about 60 s) seemed to recover the acceleration signal. However, the validity of the data for this channel are in question and should be used only for timing. No collapse motion was detected at stations 24,61 , or 71 .

The CLIPER cables in the emplacement and satellite holes (stations 92, 93 and 51, respectively) performed as expected, giving the lower positions of the cable ends as a function of time during the cavity collapse. These records are shown in figure 4.13 along with selected displacement wave forms measured both in the satellite hole and the emplacement hole. One pressure wave form from the station immediately below the top plug is also shown. Data obtained from the satellite hole are shown by heavy traces.

CLIPER data indicate that subsurface collapse terminated at a depth of about $75 \mathrm{~m}$ in the satellite hole while there were two collapse levels indicated in the emplacement hole. The deepest level was about $120 \mathrm{~m}$ (station 93), the depth of the bottom plug, and the second collapse level was just below the top plug. This was registered by station 92 and the D-cable, station 91 . There is an apparent discrepancy of 3 to 5 seconds between the cable break data (CLIPER and D-cable) and the pressure and displacement wave forms.

Pressure records and the loss of motion signal from station 23 suggest that there was an emplacement stemming fall continuing to just below the top plug, at a depth of about $25 \mathrm{~m}$. To gain further insight into the radiation detected in the emplacement hole after collapse, the pressure histories of the top four pressure stations are plotted in figure 4.14 for a period of $60 \mathrm{~s}$ covering the collapse. The signal from station 33 below the bottom plug was lost at about $4171 \mathrm{~s}$ while none of the data from stations at elevations above this were lost. The early portions of the collapse records from stations 35 and 36 are characteristic of rapid stemming fall, leaving an air gap in the vicinity of the sensors, station 36 for a longer period than station 35 . Since no collapse motion was detected in the top plug (station 24), it is reasonable to assume that the top plug acted as a stemming platform. Later, upon reentry to the site, it was discovered that the top plug had fallen out of the surface casing and was displaced downward almost $25 \mathrm{~m}$. (The interior of the surface conductor was inspected photographically and found to be coated with rust scale and mud cake with only a small area of bonding with the top plug remaining in evidence.) 
As stated in section 2, it is suspected that the source of radiation seen at stations 35 and 36 was shine from the prompt gas sample hose. Station 35 had a very high background source chip which tended to mask the induced signal. However, to test the assumption that station 35 detected nearly the same external source as did station 36 , the record from station 35 was lowpass filtered at $0.01 \mathrm{~Hz}$ and the background level of $0.5 \mathrm{R} / \mathrm{Hr}$ was subtracted. The resulting record is plotted in figure 4.15 along with that from station 36 . Correlation of the two records is good, including the activity at about $12,000 \mathrm{~s}$.

Gas sample activities halted a few minutes after the subsurface collapse and there was no further activity by the nuclear chemistry group, particularly around $12,000 \mathrm{~s}$. This late perturbation in the radiation wave forms could have been caused by another shift in the stemming (not registered on the pressure transducers), further altering the radiation shielding effect of the stemming. 

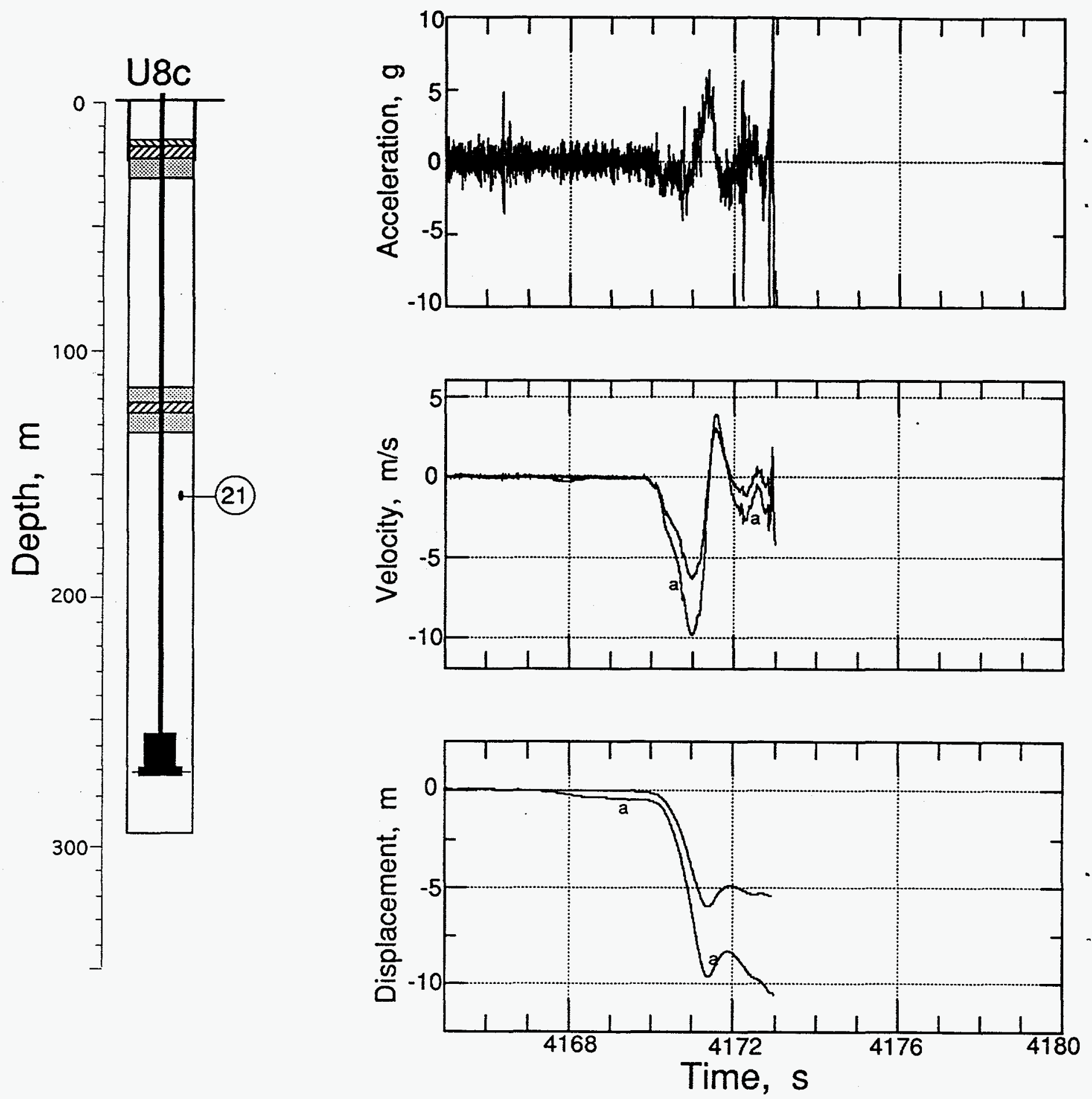

Figure 4.1 Vertical motion, during collapse, of the stemming below the bottom plug (station 21 at a depth of $159 \mathrm{~m}$ ) 

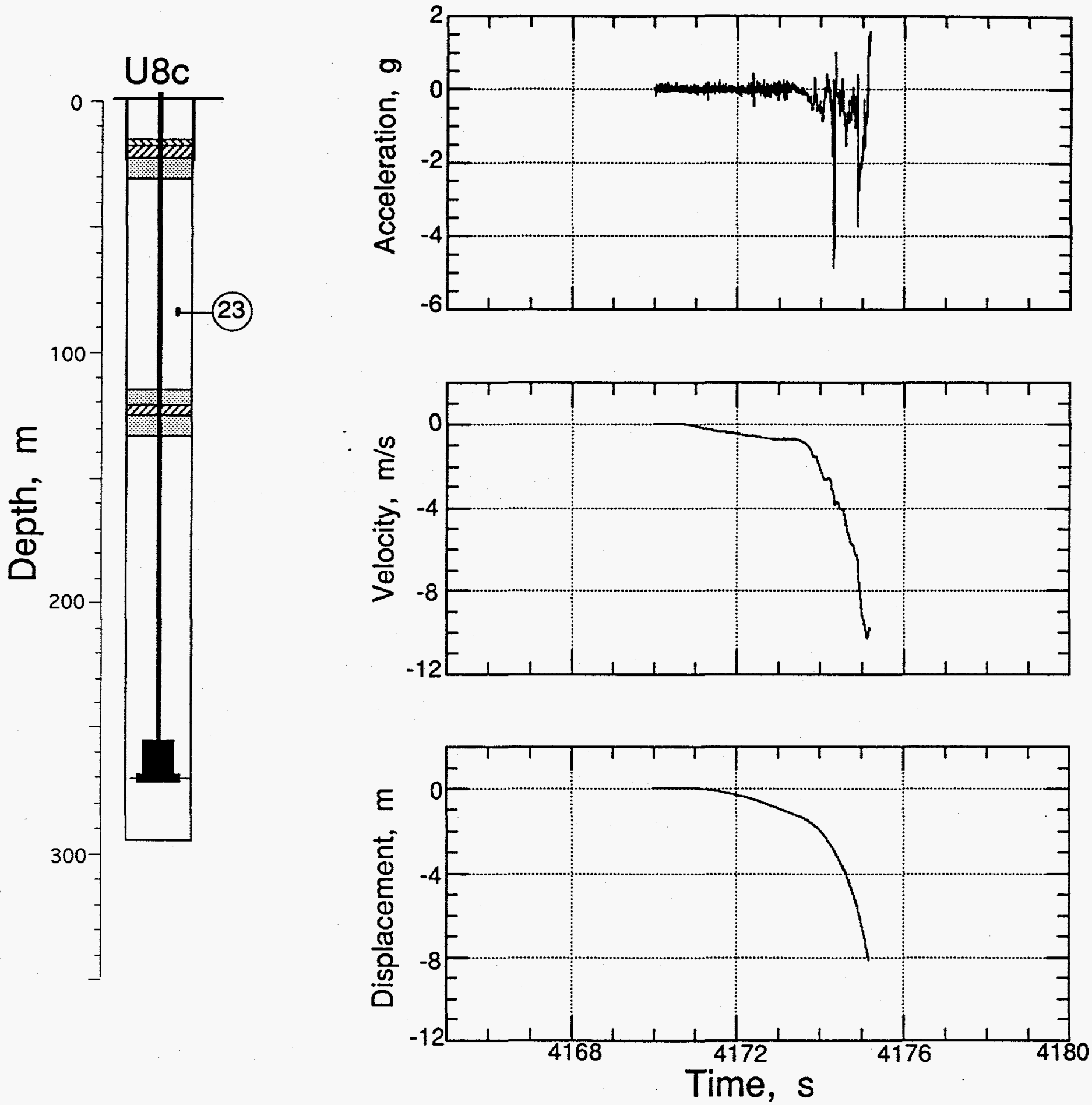

Figure 4.2 Vertical motion, during collapse, of the stemming between the bottom and top plugs (station 23 at a depth of $85 \mathrm{~m}$ ). These data are used for timing and wave form only: the calibration is in question because the acceleration channel was driven out of band shortly after detonation and the velocity channel was lost at about $0.6 \mathrm{~s}$. 

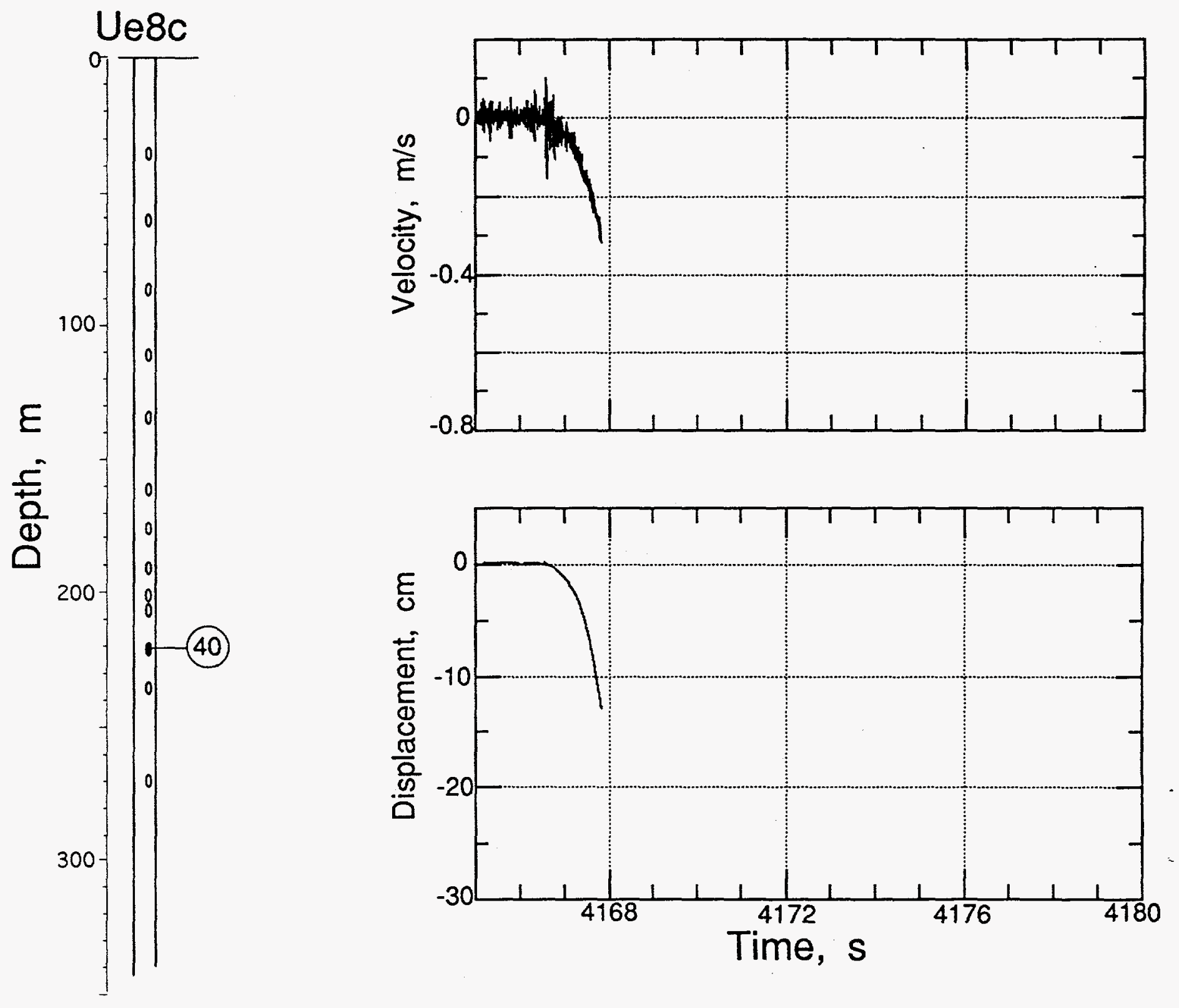

Figure 4.3 Vertical motion, during collapse, of the satellite hole at a depth of $220.5 \mathrm{~m}$ (station 40). 

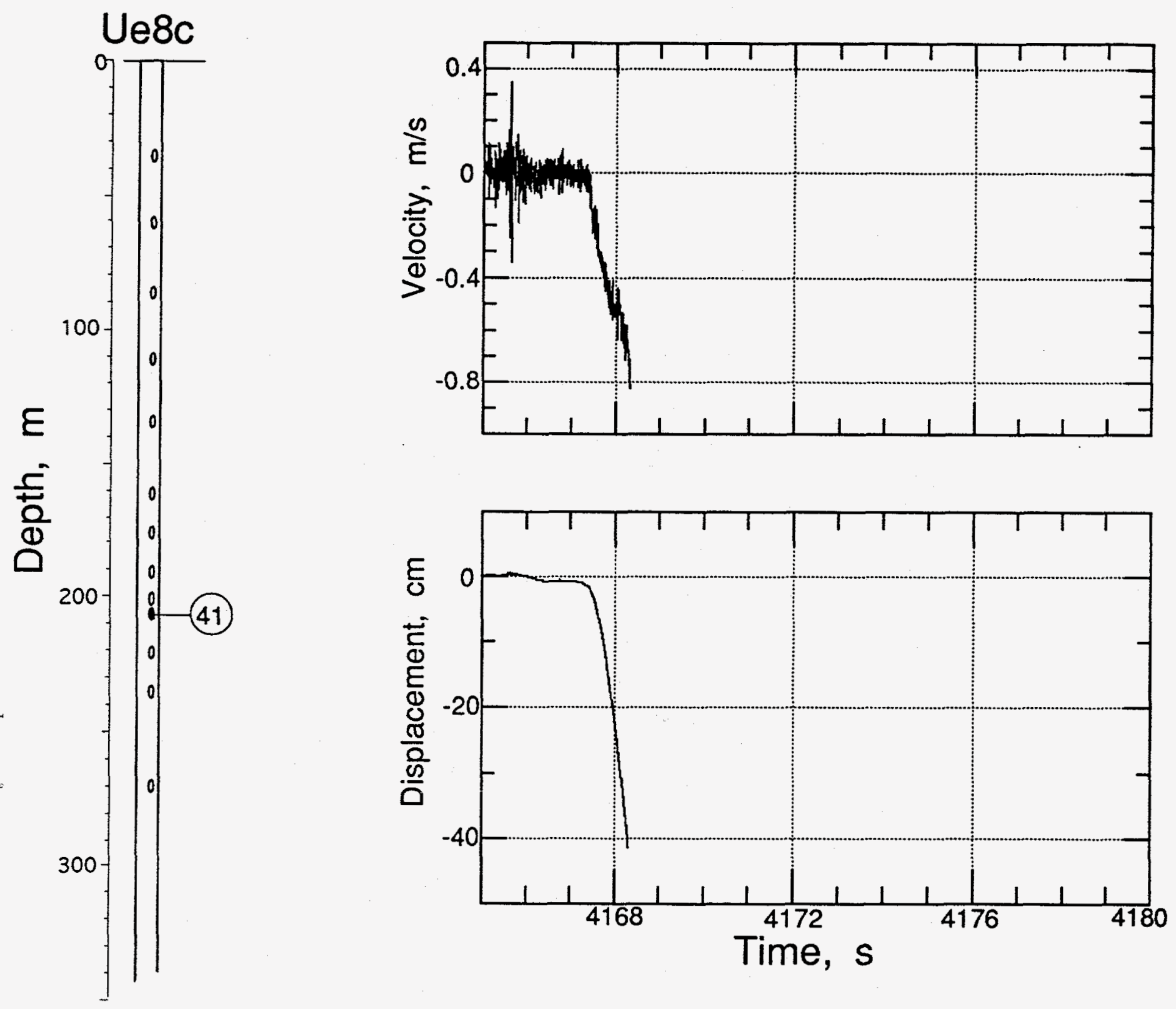

Figure 4.4 Vertical motion, during collapse, of the satellite hole at a depth of $206 \mathrm{~m}$ (station 41). 

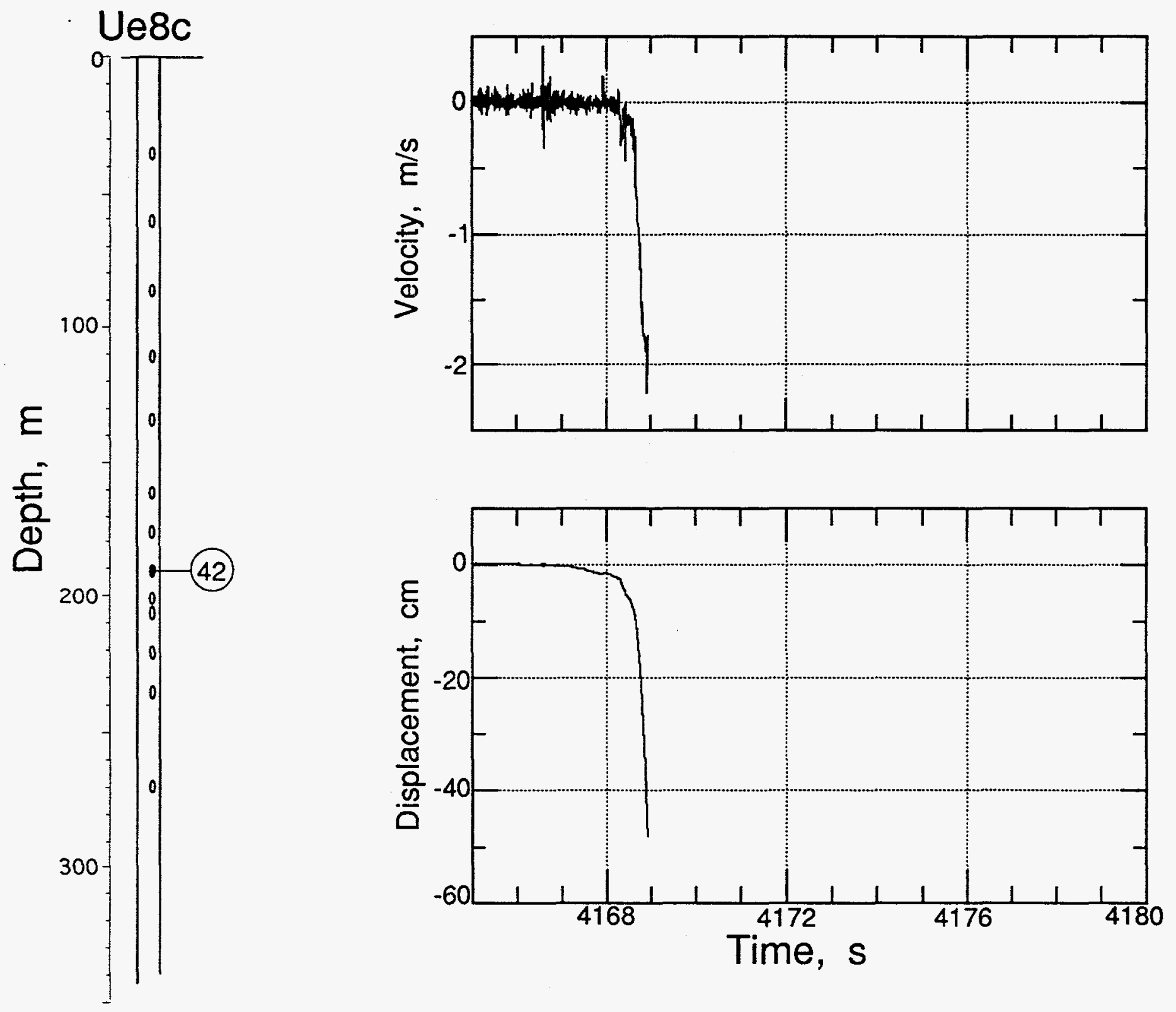

Figure 4.5 Vertical motion, during collapse, of the satellite hole at a depth of $191 \mathrm{~m}$ (station 42). 

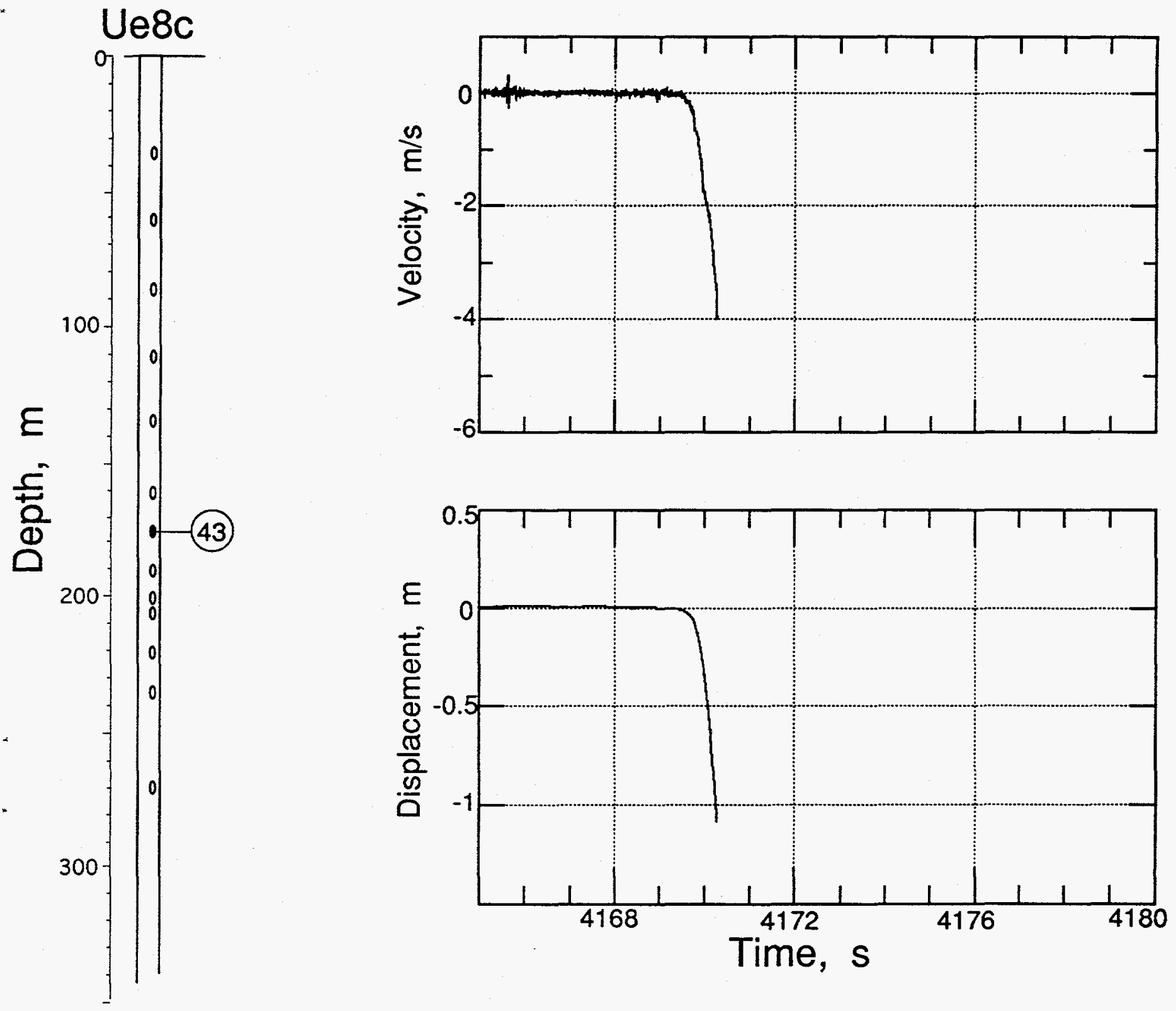

Figure 4.6 Vertical motion, during collapse, of the satellite hole at a depth of $176 \mathrm{~m}$ (station 43 ). 

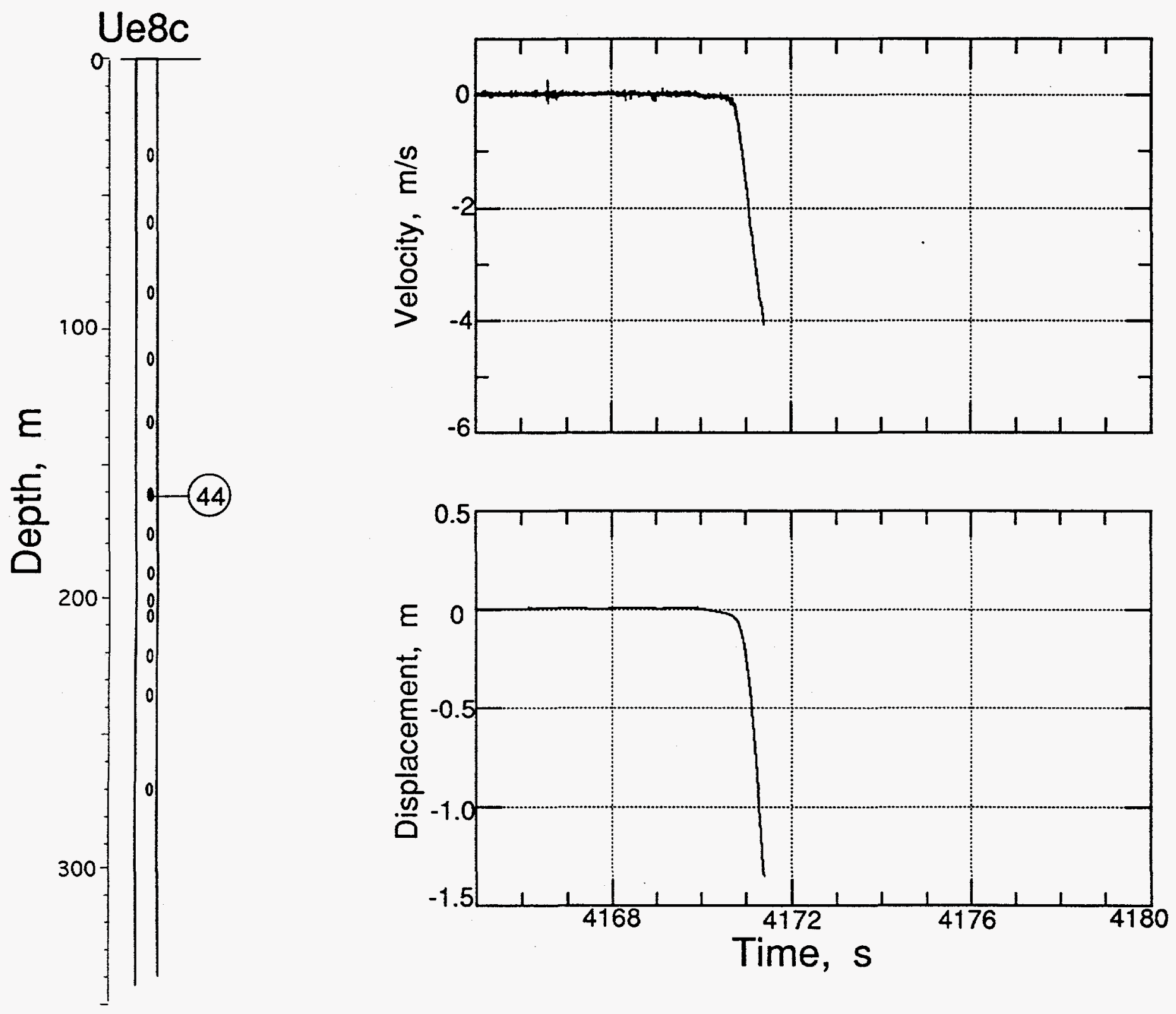

Figure 4.7 Vertical motion, during collapse, of the satellite hole at a depth of $161 \mathrm{~m}$ (station 44 ). 

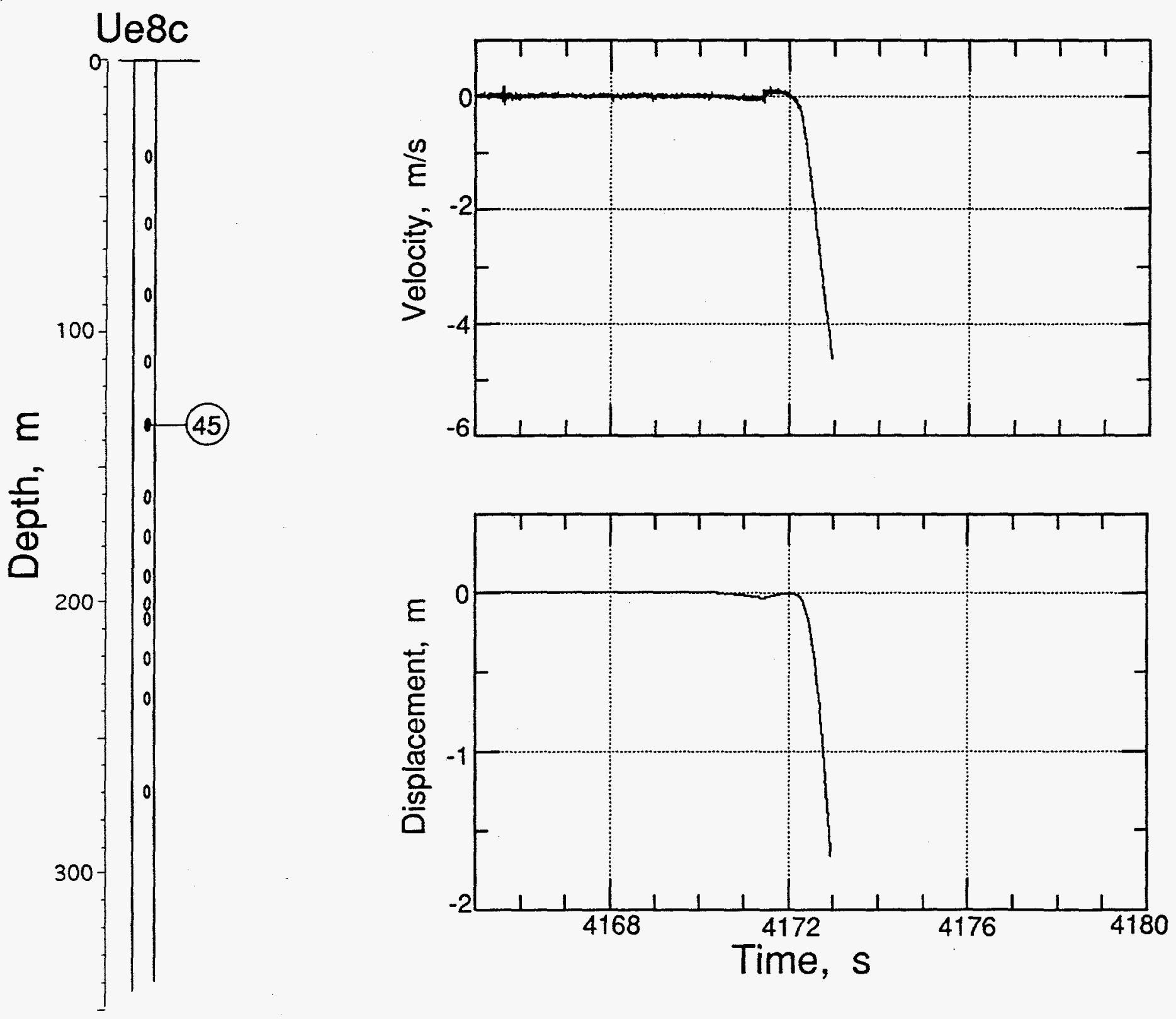

Figure 4.8 Vertical motion, during collapse, of the satellite hole at a depth of $135 \mathrm{~m}$ (station 45). 

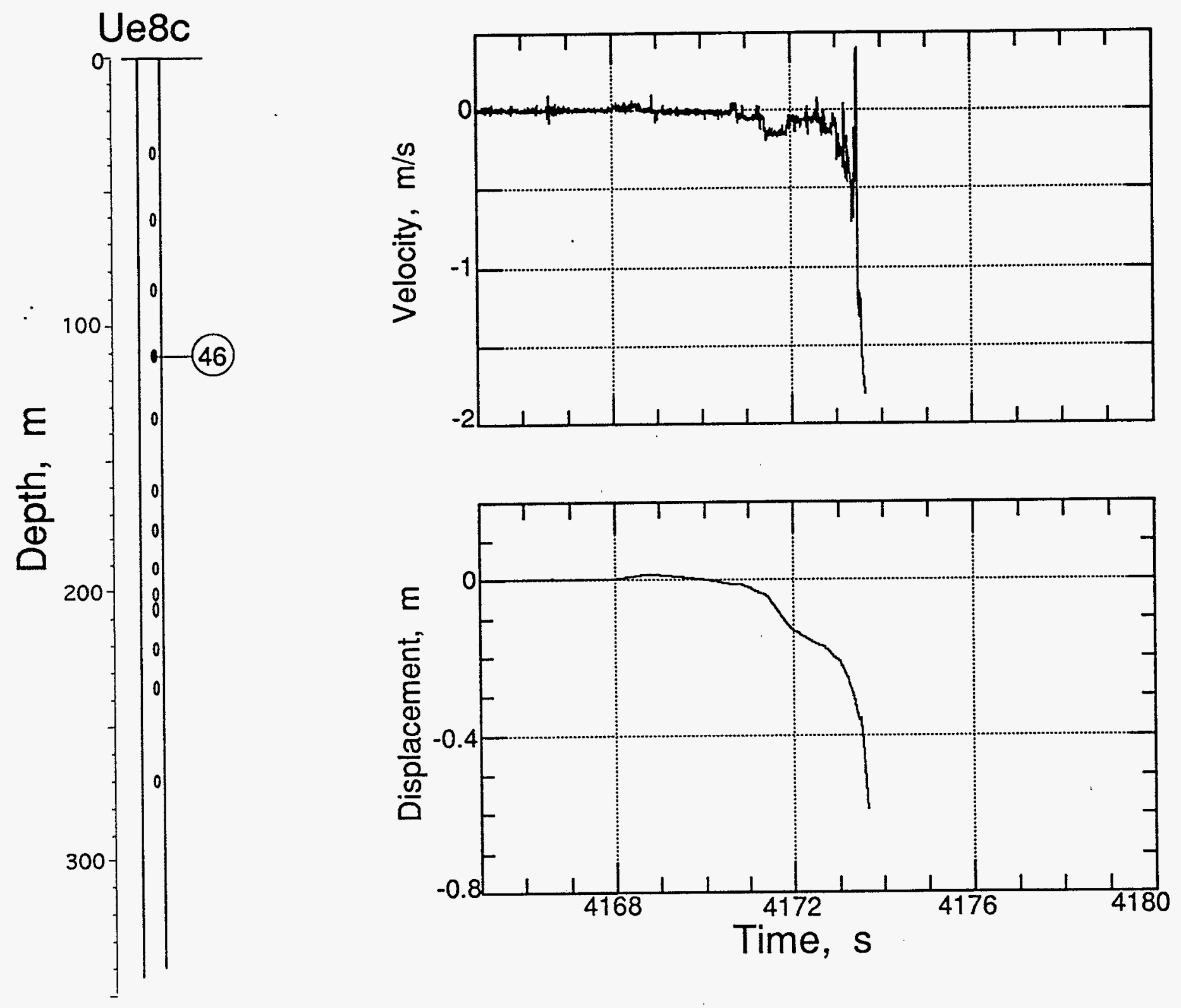

Figure 4.9 Vertical motion, during collapse, of the satelite hole at a depth of $111 \mathrm{~m}$ (station 46). 

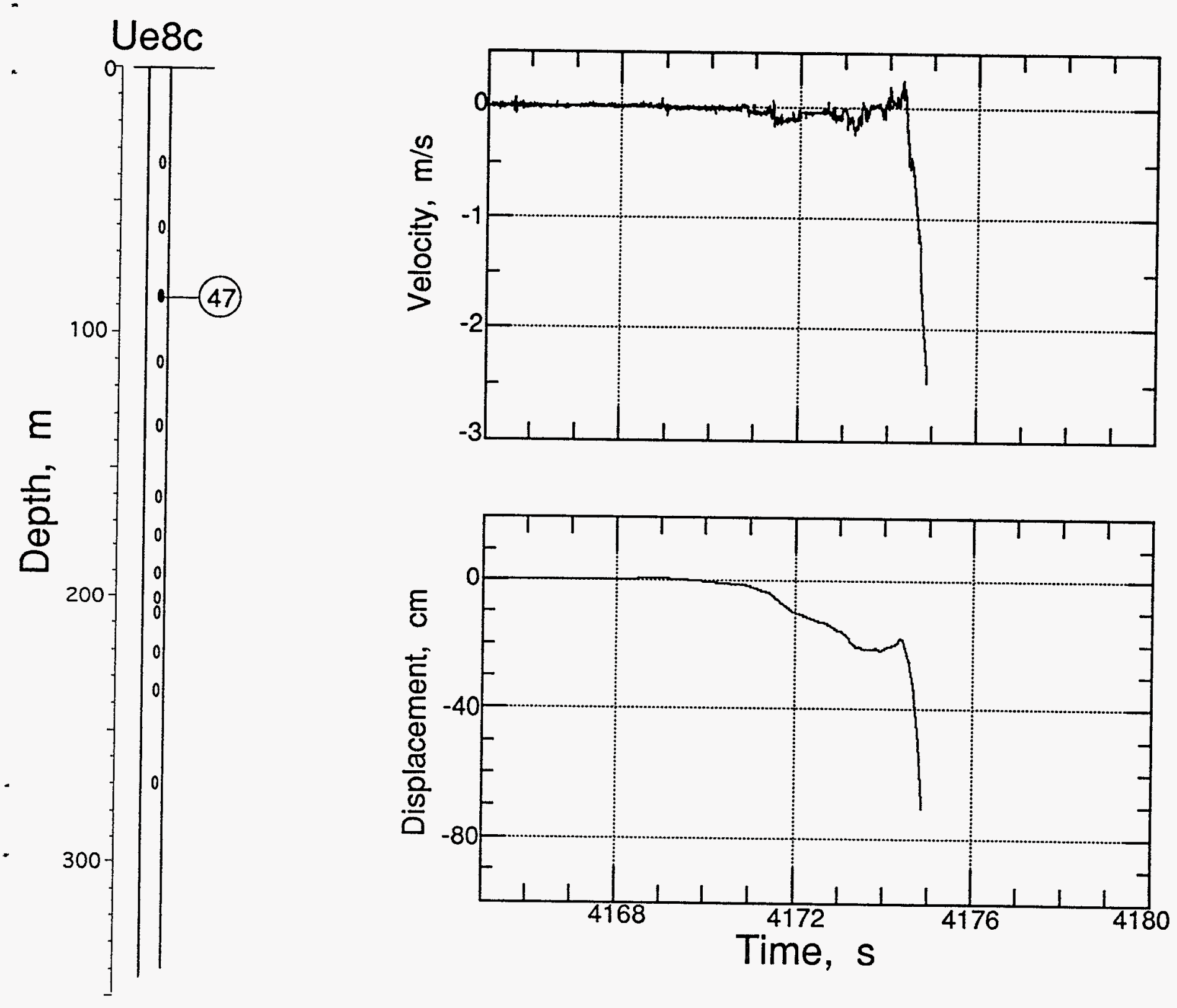

Figure 4.10 Vertical motion, during collapse, of the satellite hole at a depth of $86 \mathrm{~m}$ (station 47). 

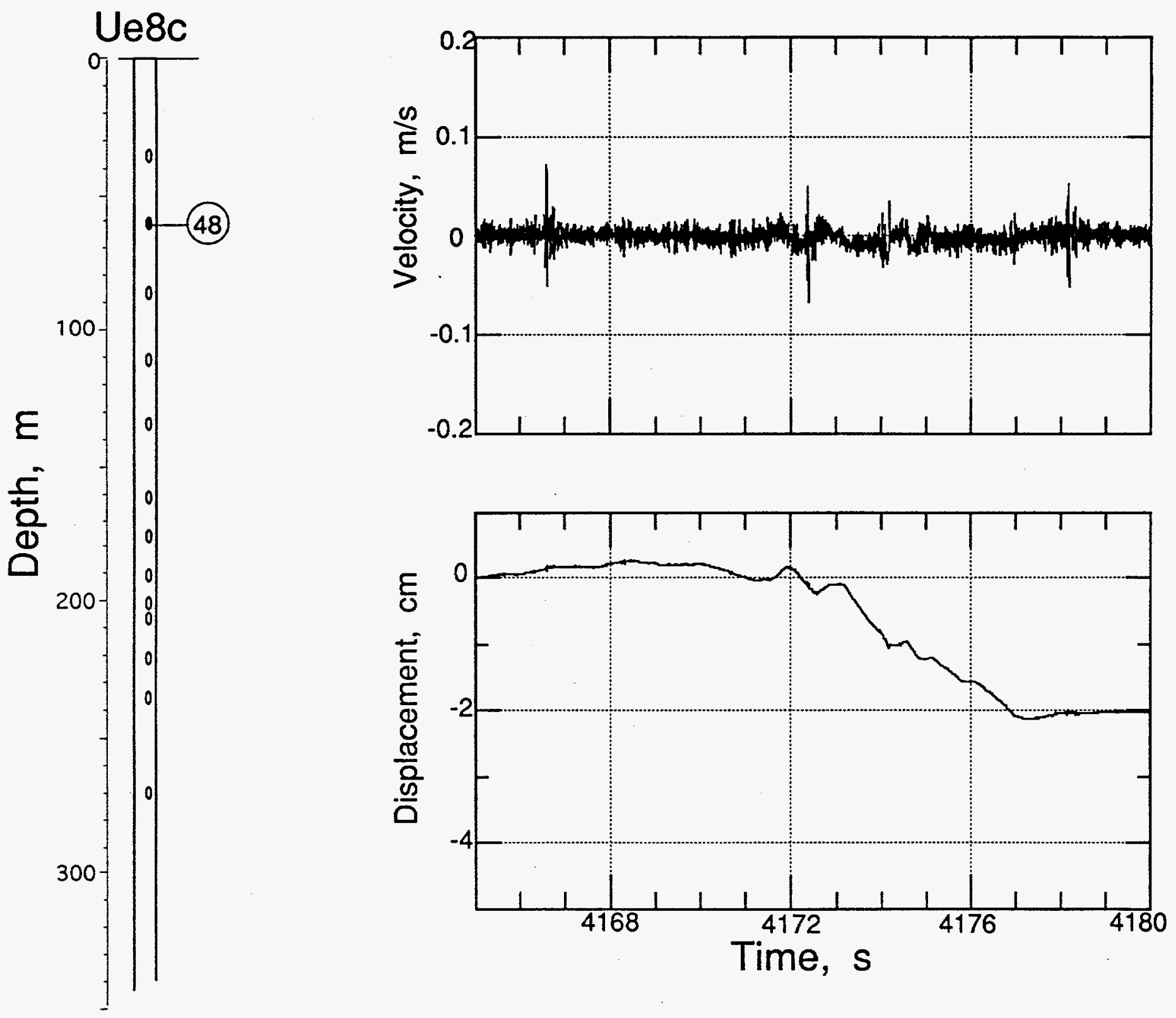

Figure 4.11 Vertical motion, during collapse, of the satellite hole at a depth of $61 \mathrm{~m}$ (station 48). 

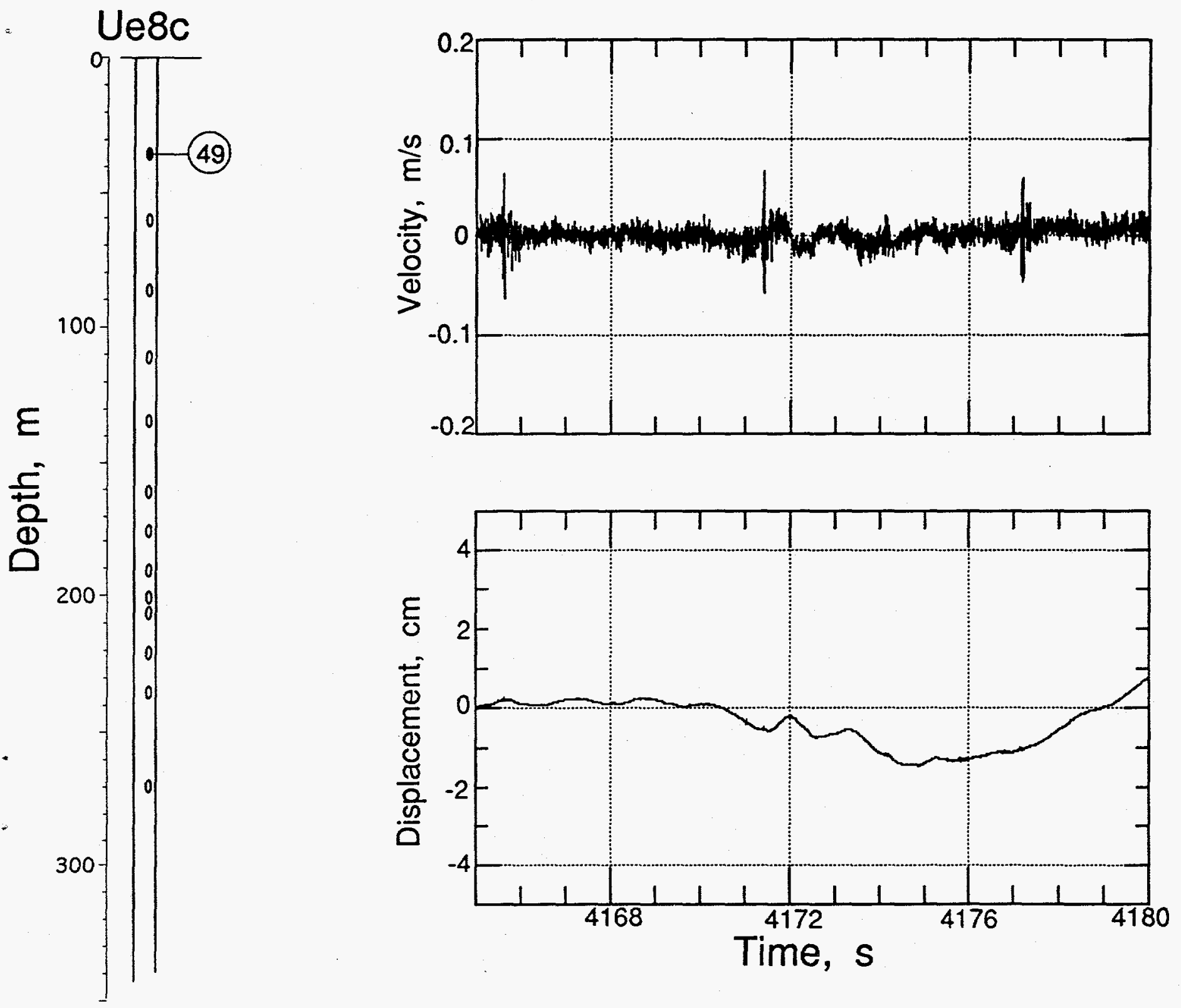

Figure 4.12 Vertical motion, during collapse, of the satellite hole at a depth of $36 \mathrm{~m}$ (station 49). 


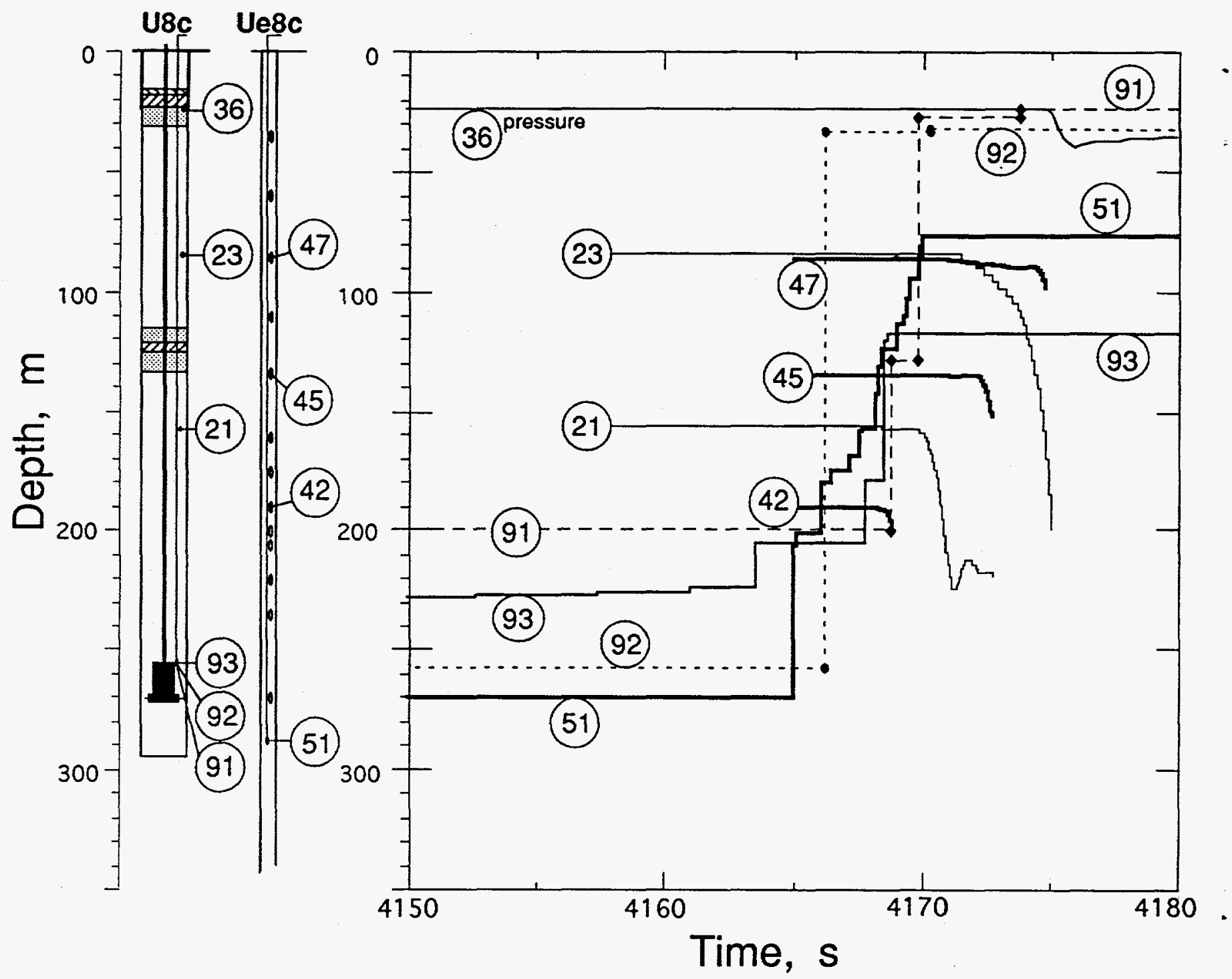

Figure 4.13 Progression of the collapse as determined from the CLIPER records (stations 51 , 92 , and 93 ) and the D-cable (station 91). The upper limit of the subsurface collapse in the emplacement hole is indicated to be at a depth of about $25 \mathrm{~m}$ while in the satellite hole the depth of subsurface collapse is indicated to be about 75 $\mathrm{m}$. The pressure record from the station just below the top the bottom plug and the displacement histories from the motion gauges in the stemming suggest that the stemming fall in the emplacement hole progressed upwards to the region of the top plug. Heavy traces are associated with the satellite hole. A discrepancy of several seconds between the CLIPER and D-cable data and the motion records is unexplained. 


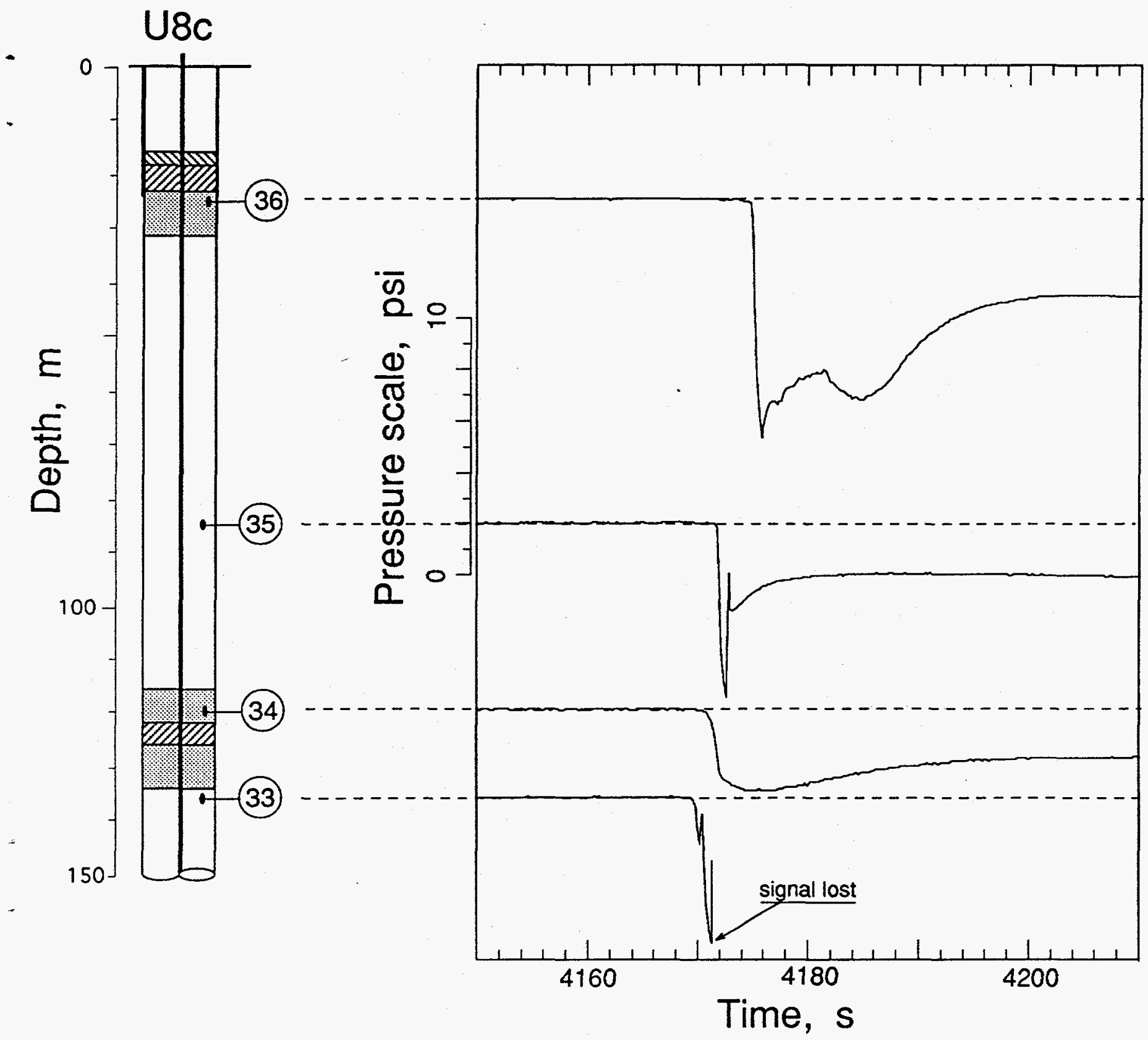

Figure 4.14 Composite plot of the pressure records from the top four stations. One minute covering the subsurface collapse is shown. 

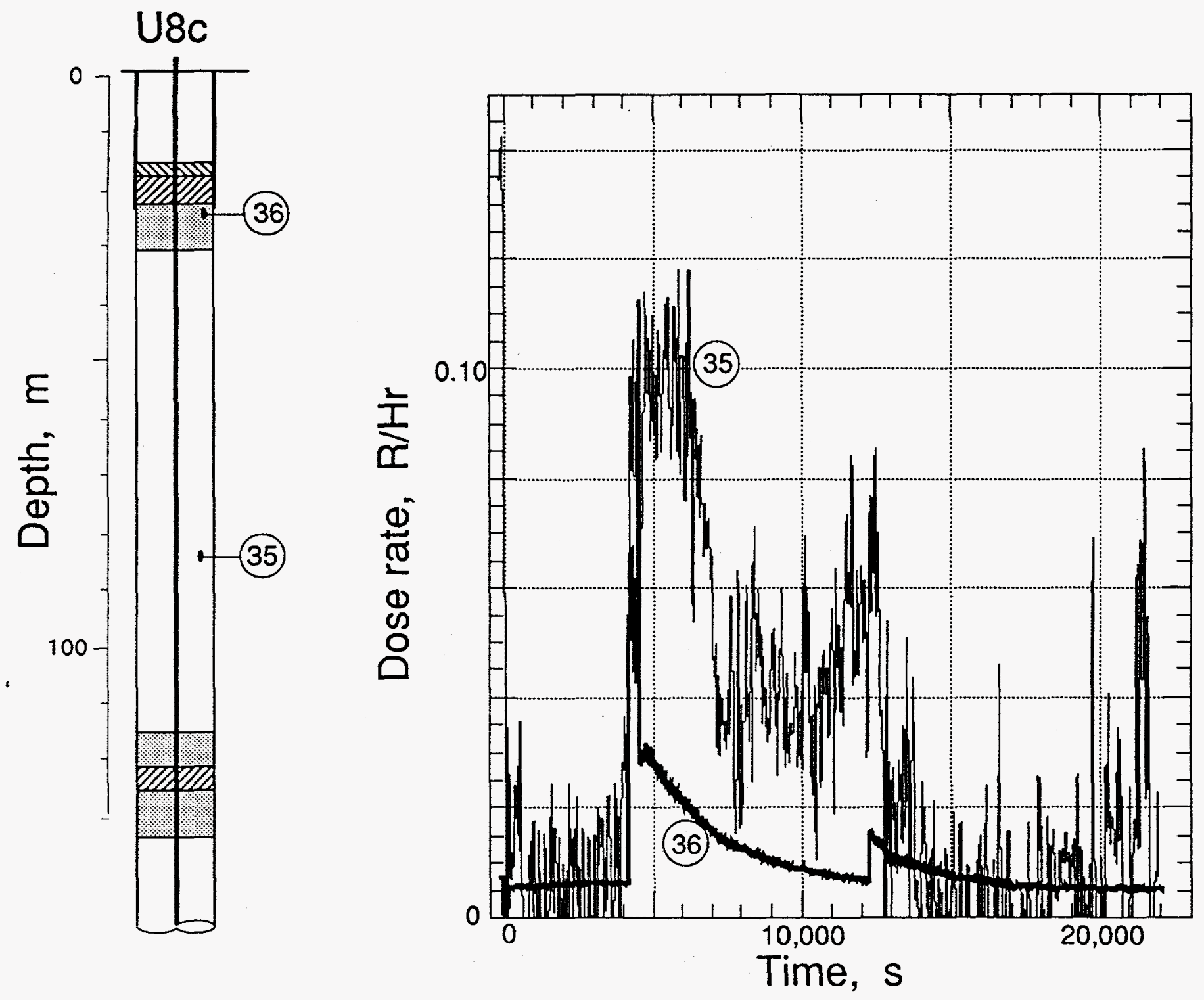

Figure 4.15 Overlay of the radiation records from stations 35 and 36 . The record from station 35 (figure 2.5) was low-pass filtered at $0.01 \mathrm{~Hz}$ and $0.5 \mathrm{R} / \mathrm{Hr}$ was subtracted. The heavy trace is the record from station 36 . 
5. Stress measurements

As part of a continuing effort to develop a transducer to measure in-situ stress, three flatpack, carbon foil element transducers were fielded in the satellite hole. Although at different elevations, each of the gauges was oriented such that the plane of the transducer was the expected plane of the wave front (to within $3^{\circ}$ ). Figures 5.1-5.3 show the output from each of transducers.

Each of the transducers was excited with a 30 ma constant-current source and the signal polarity was such that an increase in output signal indicated a decrease in resistance. The original foil resistance of each element is given in the corresponding figure caption. These data are shown only for completeness. 


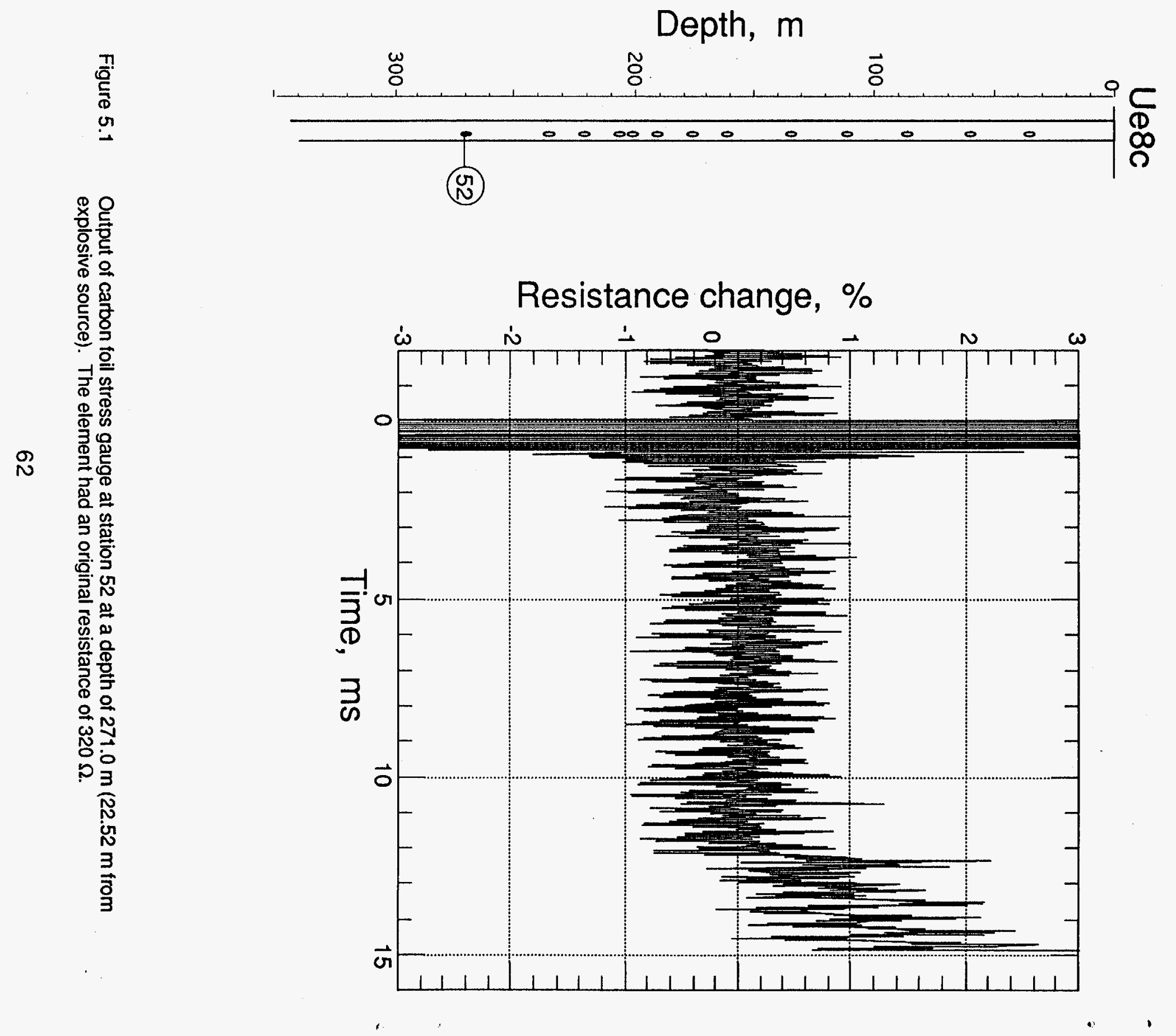



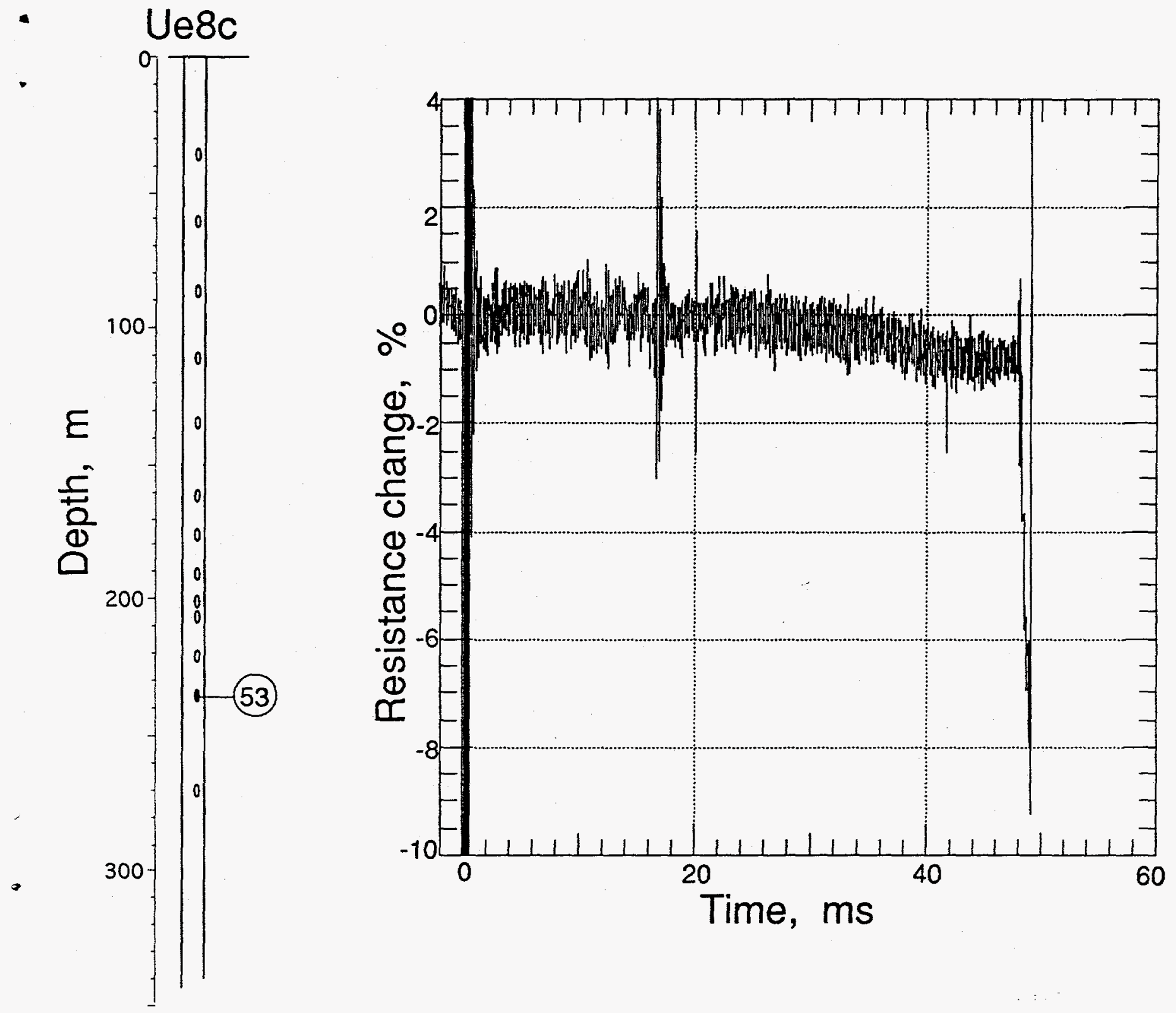

Figure 5.2 Output of carbon foil stress gauge at station 53 at a depth of $236.0 \mathrm{~m}(41.61 \mathrm{~m}$ from explosive source). The element had an original resistance of $313 \Omega$. 

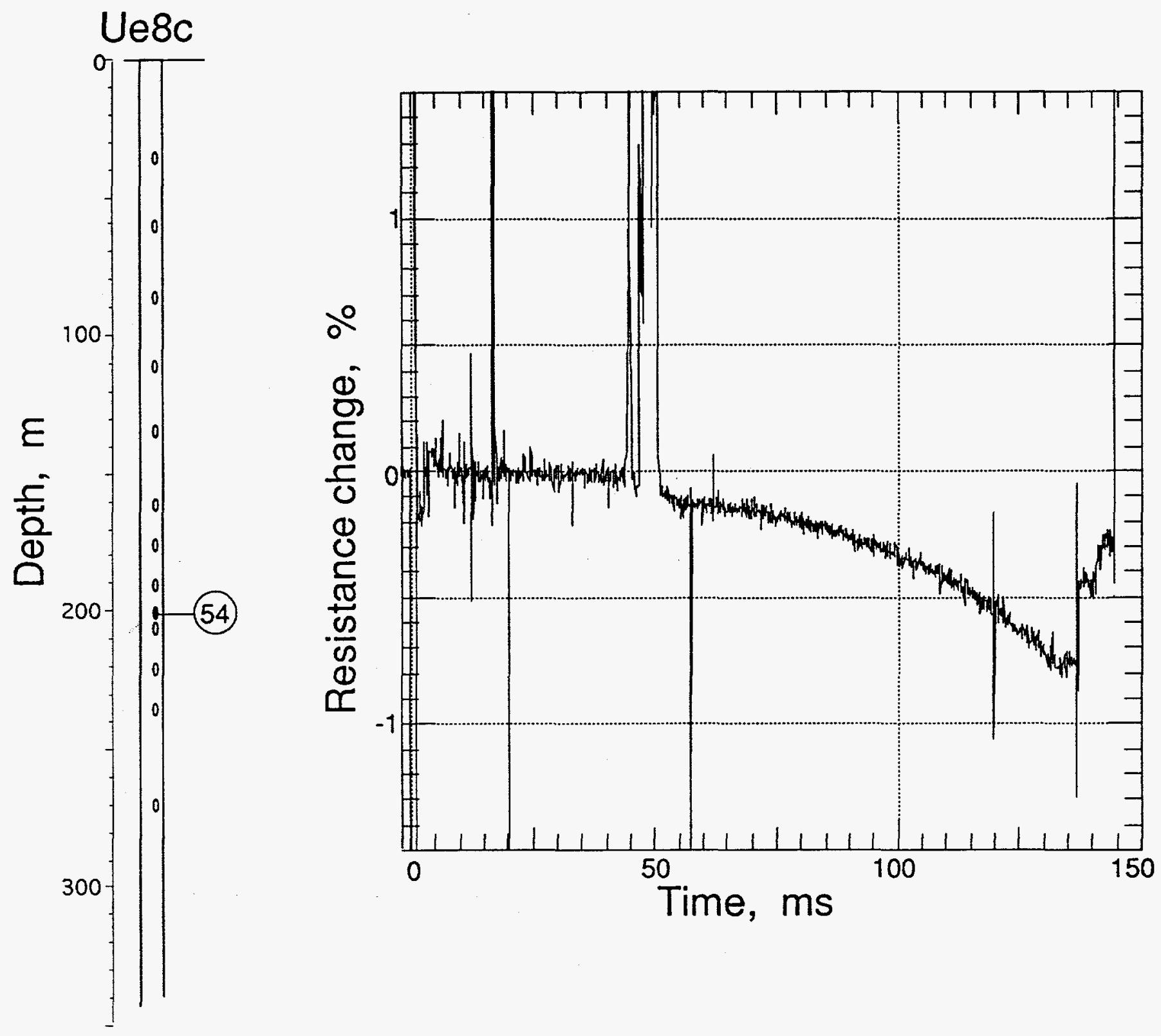

Figure 5.3 Output of carbon foil stress gauge at station 54 at a depth of $201.0 \mathrm{~m}(73.49 \mathrm{~m}$ from explosive source). The element had an original resistance of $326 \Omega$. 


\section{Beferences}

1. Nancy W. Howard, "U8c Preliminary Site Characteristics Summary", DM 79-57, Lawrence Livermore National Laboratory, Livermore, CA, October 191979.

2. George Kronsbein, "Containment Report for U8c," Holmes \& Narver, NTS:A2:80-28, March 6, 1980.

3. LLNL contacts for additional information: R. A. Heinle (CORTEX and SLIFER data)

4. William G. Webb, "Special Measurements Final Engineering Report NORBO, U8c", EG\&G, Energy Measurements, Las Vegas, NV, SM:80 E-75-34, 26 March, 1980.

5. William G. Webb, "Special Measurements Physics/Instrumentation Package for NORBO, U8c, Revision 'A' (Final)", EG\&G, Energy Measurements, Las Vegas, NV, SM:80E-75-35, 26 March, 1980. 
APPENDIX Computation of strain from motion in a spherical field.

Under the assumptions that a spherical wave is traveling at large distances in a linearly elastic, isotropic, homogeneous medium, we may approximately derive the strain history from the motion history at a point.

The wave equation of the displacement potential, $\Phi$, is given by (a):

$$
\begin{aligned}
& \frac{1}{C^{2}} \bullet \frac{\partial^{2} \Phi}{\partial t^{2}}=\nabla^{2} \Phi \quad \text { having a traveling wave solution of the form: } \\
& \Phi(r, t)=\frac{f\left(t-\frac{r}{C}\right)}{r} .
\end{aligned}
$$

The vector displacement is given by: $\quad \vec{D}=\vec{\nabla} \Phi$.

In spherical symmetry, with all angular derivatives vanishing, these equations become:

$$
\frac{1}{C^{2}} \cdot \frac{\partial^{2} \Phi}{\partial t^{2}}=\frac{1}{r^{2}} \cdot \frac{\partial}{\partial r}\left(r^{2} \frac{\partial \Phi}{\partial r}\right) \quad \text { and } \quad D=\frac{\partial \Phi}{\partial r}
$$

Strain along a transverse principal axis is given by $(a)$

$$
\varepsilon_{\theta \theta}=\frac{D}{r}
$$

and along the radial principal axis

$$
\varepsilon_{r}=\frac{\partial D}{\partial r}=\frac{\partial}{\partial r} \frac{\partial \Phi}{\partial r}=\frac{\partial}{\partial r} \frac{\partial}{\partial r}\left(\frac{f}{r}\right)=\frac{\partial}{\partial r}\left(\frac{1}{r} \frac{\partial f}{\partial r}-\frac{\Phi}{r}\right)
$$

But since we have a traveling wave, $\frac{\partial f}{\partial r}=-\frac{1}{C} \frac{\partial f}{\partial t}$, and replacing this in equation (2b) and performing the derivative we have:

$$
\varepsilon_{r}=\frac{\partial}{\partial r}\left(-\frac{\Phi}{r}-\frac{1}{r C} \frac{\partial f}{\partial t}\right)=\frac{\Phi}{r^{2}}-\frac{1}{r} \frac{\partial \Phi}{\partial r}-\frac{1}{C} \frac{\partial}{\partial r} \frac{\partial \Phi}{\partial t}
$$

which reduces to $(b)$ :

$$
\varepsilon_{r r}=\frac{\Phi}{r^{2}}-\left\{\frac{\frac{\partial D}{\partial t}}{C}+\frac{D}{r}\right\}
$$


Now, remembering that $\frac{\partial D}{\partial t}$ is the particle velocity, $U$, and neglecting the term $\frac{\Phi}{r^{2}}$, the volume strain is given by

$\bullet$

$$
\varepsilon_{v}=\varepsilon_{r}+2 \varepsilon_{\theta \theta}=\frac{D}{r}-\frac{U}{C}
$$

(a) Y. C. Fung; "Foundations of Solid Mechanics", Prentis-Hall, Inc., 1965, pp. 114 \& 186.

(b) We are indebted to R. W. Terhune for initially showing us this relationship. 
Distribution:

LLNL

TID (11)

Test Program Library

Containment Vault

Burkhard, N.

Cooper, $W$.

Denny, $M$.

Dong, $\mathbf{R}$.

Goldwire, $\mathrm{H}$.

Hannon, W. J.

Heinle, R. (5)

Mara, G.

Moran, M. T.

Moss, W.

Patton, $\mathrm{H}$,

Pawloski, G.

Rambo, J.

Roth, B.

Valk; T.

LANL

App, F.

Brunish, W.

Kunkle, $T$.

Trent, B.

\section{Sandia}

Chabai, A.

Smith, Carl W.
L-053

L-045

L-221

L-221

L-049

L-205

L-140

L-221

L-205

L-221

L-049

L-777

L-200

L-205

L-221

L-200

L-049

L-154

F-659

F-659

F-665

F-664

MS-1159

MS -1159
EG\&G/AVO

Brown, $T$.

A-5

Gilmore, L.

A-1

Hatch, $M$.

A-5

Still, G.

Stubbs, $T$.

A-5

A-5

EG\&G/NVO

Bellow, B.

N 13-20

Davies, $L$.

N 13-20

Moeller, A.

Robinson, R.

N 13-20

Webb, W.

N 13-20:

N 13-20

DNA

Ristvet, B.

S-Cubed

Peterson, E.

Eastman Cherrington Environment

1640 Old Pecos Trail, Suite H

Santa Fe, NM 87504

Keller, $\mathrm{C}$. 